\title{
Die ,literarischen Repräsentanten" der DKP - Kritik am Marxismus des Projekts Klassenanalyse
}

\author{
Manfred Scharrer, Dieter Schütte
}

\section{Vorbemerkung}

Unsere Kritik am Projekt Klassenanalyse richtet sich gegen die von dieser Gruppe vorgelegte Konstruktion eines marxschen Systems, ihrer damit vorgenommenen Operationalisierung und ihrer davon abgeleiteten politischen Position. Diese Dreieinigkeit legte das Projekt Klassenanalyse in ihrem vor einem Jahr erschienenen Buch „Leninismus - neue Stufe des wissenschaftlichen Sozialismus?" dar.

Wir meinen, daß dieses System eine willkürliche, wenn auch philologisch exakte Konstruktion ist. Dieses System ist in einem zentralen Punkt unmarxistisch: Theorie erhält gegenüber der Praxis den Primat einer exakten Handlungsanweisung.

In früheren Veröffentlichungen war das Projekt Klassenanalyse in politischen Aussagen und Kritiken ziemlich zurückhaltend und beschränkte sich meist darauf, Interpretationen des Marxschen „Kapitals“ zu liefern. Erst beim Leninismusbuch kann man davon sprechen, daß der Versuch unternommen wurde, einen längeren Zeitabschnitt aus der Geschichte der Arbeiterbewegung kritisch zu untersuchen. Zur Diskussion steht die Leninsche Theorie und Politik. Gegenüber den früheren allgemeinen Schlüssen des Projekts Klassenanalyse ist damit eine konkretere Ebene der kritischen Auseinandersetzung möglich geworden.

Die Entstehung des Projekts Klassenanalyse kann man auf seine Vorläufer, die organisierten Kapital-Arbeitskreise 1968/69, zurückführen, die entstanden waren, als die spektakulären „Osterunruhen“ bereits über ein halbes Jahr zurücklagen. Damals begann sich die linke Bewegung aus dem SDS herauszuverlagern und auf einer breiten Massenbasis neue organisatorische Formen zu suchen. An den Hochschulen bildeten sich ad-hoc-Gruppen, die die repräsentativen Studentenvertretungen und den Konvent/AStA in der politischen Willensbildung ablösten. Stadtteil-, Basis- und Betriebsgruppen sollten die politische Isolierung in den Hochschulen aufbrechen. Einerseits waren diese Organisationsformen ein Schritt nach vorn, indem sie eine größere Öffentlichkeit herstellten als die alten Verbände und repräsentativen Vertretungen. Zugleich waren es jedoch - zumindest außerhalb der Hochschule - pragmatisch-voluntaristische Ansätze, denen keine sozialistische Strategie zugrunde lag. Dazu kam eine Erwartungshaltung, die von jeder Kampagne, von jeder größeren Aktion einen Umschwung in den gesellschaftlichen Verhältnissen erwartete. Jede Schwäche erschien sogleich als Ohnmacht, jeder nicht zeitgerecht zustandegekommene Erfolg erschien als Niederlage. Verzweiflungsre aktionen, verselbständigte Militanz waren die Folge. ,Wir dürfen nicht hinter ein einmal erreichtes Niveau (der Aktion) zurückfallen", war ein häufiges charakteristisches ,Argument". Die eigenen Erfahrungen der vorangegangenen Jahre wurden theoretisch nicht aufgear- 
beitet. Vielmehr führte die Bewufitwerdung der Schranken der eigenen Möglichkeiten der revolutionären gesellschaftlichen Veränderung zu einer unvermitteiten ..Wiederentde ckung" des Proletariats als revolutionärem Subjekt. Linterstutzt wurde dieser Prozer durch den Franzosischen Mai und später durch die Septemberstreiks in der BRD.

Als einzige revolutionäre Alternative entstand ein immer fetischartiger werdendes Bild von der revolutionären Partei des Proletariats. Da diese eben als Bild nur imaginär existierte. schlüpfte ein Teil der Genossen in das abgetragene Kostum einer traditionellen Form dieser Partei. Andere erkamnten in der DKP. der wieder legalisierten KPD bzw. in der SEW. die Inkarnation dieses Bildes. Den ..Intellektuellen" traute plotzlich keiner mehr eine selbstänàge praktisch-revolutionsire Fähigkeit zu. Bestenfalls konnten sie als ..kleinbürgerliche Bündnispartner" dem . Volke dienen ${ }^{*}$. d. h. sich der Partei mit Haut und Haaren unterordnen.

Die Rehabilitierung und Wiederbelebung stalinistischer Organisationsformen brachte die notwendige Organisationsdebatte auf einen lediglich formalen Disziplin-Nenner. Der aus der bürgerlichen Familiensozialisation hervorgehende autoritäre Charakter. dessen Lnterwürfigkeit und Anpassungsfähigkeit in der Studentenbewegung aufgehoben werden sollte. konnte sich jetzt in den Parteihierarchien wieder zu Hause fühlen. Die 1969 entstandenen Roten Zellen, die radikalen sozialistischen Organisationen der Studenten losten sich meist auf in aktuelle (KSV. ADSen etc.) oder potentielle (MLH's) Lnterorganisationen von Parteien oder Parteiattrappen. In dem Mafie wie unter den Studenten die Strategiediskussion sich rückentwickelte zu formalistischen Interpretationen des ..Demokratischen Zentralismus". wuchs der Einfluf von sozialdemokratischen oder Volksfront-Gruppen wie Jusos. Spartakus. SHB usw.. die sich von sog. .,Alltagsproblemen" nicht völlig entfernt hat ten und damit in der praktischen Politik uberzeugender wirken mußten.

Gegen eine unglaubliche Versimpelung der theoretischen Arbeit und Diskussion. vor allem hervorgerufen durch die marxistisch-leninistische Linienzänkerei, behauptete sich in Arbeitskreisen eine ernsthafte theoretische Arbeit. Das Projekt Klassenanalyse ist ein Ausdruck dieser Tendenz. Der Anspruch dieser Tendenz. in .Kapital"-A rbeitskreisen die Voraussetzung einer jeden revolutionären Theorie zu erarbeiten, entsprach einem weitverbreiteten Bedurfnis linker Studenten, die sich militant betätigt hatten, für die jedoch das Abgleiten in einen von umfassenden politischen Konzeptionen losgelosten Aktionismus immer bedenklicher wurde. Allerdings trat der Anspruch, die eigene politische Erfahrung in einen theoretischbegrifflichen Rahmen zu stellen, zunehmend zurück hinter das Selbstverständnis, sozialistisches Bewufstsein lasse sich in mehreren Kursen „Kritik der Politischen Ökonomie" erlernen

Waren die ersten Veröffentlichungen des Projekts Klassenanalyse noch weitgehend bemüht, eine explizit politische Haltung zu vermeiden, so erklärte sich die Gruppe (1971) unvermittelt zur DKP bzw. SEW. Das Verblüfende an diesem Bekenntnis war, daß die Gruppe in der Einleitung zu ihrer Leninismus-Kritik behauptet, dafs dieses Bekenntnis sich als Konsequenz ihrer bisherigen Marxrezeption ergeben habe. Unsere Kritik an den Arbeiten des Projekts Klassenanalyse betrifft vor allem diesen Zusammenhang von Marx- und Leninrezeption mit der Hinwendung 


\section{zur DKP.}

In der systematischen Erarbeitung der Kritik der Politischen Ökonomie und der massenhaften Verbreiterung dieser Arbeit hegt das Verdienst des Projekts Klassenanalyse. Das Selbstrerständnis. das sie daraus entwickelten. ist unserer Meinung nach zu kritisieren. Indem das Projekt Klassenanalyse die politische Arbeit ron Studenten auf Theorieerstellung und berufliche Qualifikation beschrankt sehen will - wenn man von einer quasi-gewerkschaftlichen Interessenvertretung in den Institutsvertrerungen absieht - propagiert es einen intellektuellen. auf theoretische Expertisen beschränkten Akademiker. dessen politisches Engagement bestenfalls im Besitz eines Parteibuches besteht

Das Projekt Klassenanalyse kritisiert an linken Intellektuellen pauschal, daf sie leicht in Aktionismus verfielen. Lnserer Meinung nach neigt die Charakterstruk. tur der meisten Studenten gerade nicht einem politischen Engagement zu, das mit dem Risiko von nilitanten Aktionen behaftet ist. Die Bereitschat zu praktisch-politischer Arbeit sollte nicht diffamiert. sondern gefördert werden. Wenn das Projekt Klassenanalyse den Popanz eines sendungsbewukten Studenten aufbaut und ihm die richtigere Alternative des linken Theoretikers entgegenhalt. dann kommt uns das eher vor wie die Rationalisierung der eigenen Arbeit. die Rechtfertigung gegenuber . linken“ Kritikern. Die Diffamierung radikaler politischer Arbeit druckt wohl mehr die eigene politische Lnsicherheit aus. So falsch die populistische, mit bügerlichaufklärerischem Pathos propagierte Berriebsarbeit von zahlreichen Studentengrup. pen auch war. so ist es ein Fortschritt. daf politisches Engagement nicht bloke Gesinnung bleibt. Nur aus praktischen Erfahrungen lassen sich Fehler korrigieren und Strategien entwickeln. nicht aus theoretischen Systemen. Theoretische Fragestellungen missen mit praktischer Erfahrung vermittelt sein. Diese V'ermittlung trit noch nicht dadurch ein. dar man das Mitgliedsbuch einer ..proletarischen Partei" besitzt

Die theoretische Arbeit. die das Projekt Klassenanalyse propagiert. kommt den Neigungen und Bedüfnissen von bürgerlichen Intellektuellen weitgehend entge. gen. indem sie diesen ihre auch von der bürge rhchen Gesellschaft zugewiesene Funktion als ausschliefiliche Theorieproduzenten beläkt, zwar nun mit anderen Inhalten. aber mit dem gleichen guten Gewissen. das jetzt sogar noch das Prädikat ..revolutionar ${ }^{\prime \prime}$ trägt. Die Identifizierung von theoretischer Arbeit mit politischer Strategie trifft auf die Bedüfnisse von vielen Intellektuellen zu. die sensibel gegenüber gesellschaftlicher Unterdruckung sind. aber es nicht schaffen. ihre Passivität und ihre Sicherheitsbedürnisse zu überwinden. Das aus diesem Konflikt entstehende schlech. te Gewissen wird vom Projekt Klassenanalyse abgefangen, indem es sich und uns einredet. theoretische Arbeit sei für Studenten die revolutionärste aller möglichen. Mit der ..Autorität” Marxscher Zitate, die diese Auffassung zu belegen scheinen. betreibt das Projekt Klassenanalyse massive Entpolitisierung unter potentiellen Ge. nossen.

Das Bekenntnis zur DKP als ..proletarischer Partei” ist deshalb konsequent. Es verpflichtet zu nichts und lakt die Rolle des Theoretikers. die man sich selbst zugeschrieben hat, unangetastet. In kaum einer anderen Organisation könnten die Genossen des Projekts Klassenanalyse diesen Status weiterptlegen. Es ist deshalb 
berechitigt. bei seinem DKP-Bekenntnis von Opportunismus zu sprechen. Zumal im Zusammenhang mit der „Begründung, die die Genossen vom Projekt Klassenanalyse dafür angeben: Sie bezeichnen die DKP als den fortgeschrittensten Ausdruck der bundesdeutschen Arbeiterklasse, ohne dies auch nur an einer Stelle zu begründen. (Das wurde ein Eingehen auf die konkrete Geschichte dieser Partei und ihrer aktuellen praktischen Politik bedeuten.) Damit wird vom Projekt Klassenanalyse ein unerläßlicher Begründungszusammenhang stillschweigend umgangen. Der Opportunismus-Vorwurf vergißt hier nicht, daß DKP-Mitglieder - ebenso wie die Mitglieder anderer Fraktionen der Linken - innerhalb des staatlichen Feindbildes Repressionen ausgesetzt sind. Das DKP-Bekenntnis von Studenten bezeichnet jedoch innerhalb der radikalen Linken die bequemste Position.

Obwohl das Projekt Klassenanalyse meint, man könne aus einer Theorie praktische Politik deduzieren. hält es sich indirekt nicht an diese Maxime. Es erkennt sehr richtig, daf der Leninismus in einer Reihe von Punkten im Gegensatz zu marxistischen Positionen steht. Dennoch bleibt die Kritik inkonsequent, indem sie die DKP selbst ausspart. Theorie soll das Kriterium für richtige politische Praxis sein. Es ist daher unlogisch, daß das Projekt Klassenanalyse die Theorie der DKP kritisiert, die Politik dieser Partei aber nicht grundsätzlich in Frage stellt. Das Projekt Klassenanalyse will die DKP durch ihre Kritik auf Marx und Engels zurïckbringen. Dazu reicht seiner Meinung nach die rationale Diskussion aus. Daß de r Leninismus, diese prinzipienlose ,Zitatologie“(Lukács), seit Mitte der 20er Jahre Legitimationsrüstzeug des Sowjetmarxismus und seiner Anhänger ist, das nicht mehr abgeschafft werden kann, es sei denn, die Rechtfertigungsgrundlage für 50 Jahre sowjetischer Innen- und Außenpolitik entfiele, entgeht dem Projekt Klassenanalyse. Zudem kann der Leninismus nicht ohne weiteres mit Lenin gleichgesetzt werden. Lenin kannte keiner Leninismus, er schrieb Pamphlete zu konkreten Problemen, seine Aussagen ließen sich für ihn nicht willkürlich zu einem theoretischen .System" vermischen. Das blieb Sinowjew, Stalin und anderen vorbehalten, die nach Lenins Tod seine Schriften zum Maßstab revolutionärer Gesinnung machten. Da sich aus verschiedenen Zeiträumen zu ähnlichen Problemer unterschiedliche Meinungen Lenins heranziehen ließen, verkam die Berufung auf die Autorität Lenins zu einer willkürlichen, den jeweiligen Fraktionserfordernissen angepaßten Zitatenhuberei.

Einmal sind wir durch die immanente Kritik des Projekts Klassenanalyse gezwungen, auf der zitatenreichen philologischen Interpretationsebene zu verbleiben. Wir denken, daß diese durch die politische Polemik - die wir als eine solidarische verstehen - immer wieder in ihrer Bedeutung sichtbar wird. Zum anderen fehlt in unserer Kritik die Ausformulierung praktischer politischer Konsequenzen. Das Projekt Klassenanalyse behauptet, aus ihrer Marxlektüre die Konsequenz ziehen zu müssen, sich zur DKP/SEW zu bekennen. Wir sind der Auffassung, daß sich von Marx her, begrenzt auch von Lenin, keine ,Hinwendung“ zu diesem kommunistischen Parteitypus ergeben kann, schon gar nicht aus der Analyse der konkreten Geschichte und der aktuellen Politik der DKP.

Die Herausbildung einer revolutionären Organisation der Arbeiterklasse kann nicht aus dem ,Kapital" destilliert werden, ebenfalls nicht analogiehaft und sche- 
matisch aus der revolutionären Erfahrung der internationalen Arbeiter- und Bauern. bewegung. Wenn wir den ökonomistischen Determinismus des Projekis Klassenanalyse und ihre politische Konsequenz weitgehend nur negativ kritisieren, d. h. dafo wir nicht selbst eine positive Konsequenz gegenüberstellen, so kennzeichnet das unsere augenblickliche Situation, in der wir gerade erst versuchen, neue praktische Möglichkeiten sozialistischer Arbeit aufzubauen.

\section{Kritik am „Marxismus“ und „Leninismus" des Projekts Klassenanalyse (PKA)}

Das Projekt Klassenanalyse begreift seine. eigene Geschichte folgendermaßen: Während sich Teile der "Intellektuellen" nach dem erfahrenen .Gegensatz zum Kapital " in einen .,reformerischen und einen radikalen-linkskommunistischen und anarchistischen Flügel" spalteten, begann ein anderer Teil ..ernsthaft mit dem Studium der Schriften von Marx und Engels". um sich ,Klarheit zu verschaffen ... über den Charakter der revolutionären Theorie von Marx und Engels und (über die) Grundlagen kommunistischer Taktik". Erste Resultate dieses Studiums waren, dafs die proletarische Partei bei einer "konsequenten revolutionären Taktik" an den ..vorhandenen Bewußtseinsformen anknupfen muß, um den aus der Entwicklung der materiellen Verhältnisse selbst hervorgehenden naturwüchsigen Prozefs ihrer Auflösung" bewußt beschleunigen zu können. „Die Konsequenz aus diesen ersten Resultaten muß die Hinwendung zur wirklichen Arbeiterbewegung sein, genauer. die Unterstützung ihres fortgeschrittensten Teils, der DKP" (1).

Aus dieser Selbstdarstellung und vor allem in dem der Analyse des , Leninis. mus" vorangestellten Bekenntnis zur DKP stellt sich fur uns zunächst die Frage. aus welchen Schriften von Marx und Engels hat das Projekt Klassenanalyse die Konse. quenz gefolgert, daß man sich zur DKP hinwenden muß? Wir meinen. daß diese politische Position des PKA für das Verständnis ihrer ..Leninismus"-Kritik von Bedeutung ist und versuchen deshalb, den Begründungen für dieses Bekenntnis in den vorangegangenen Marxinterpretationen des PKA nachzugehen. Zentralen Stellenwert scheint uns dabei die Interpretation des Marxschen Verständnisses von ,wirklicher Arbeiterbewegung"zu haben, die das PKA mit der von ihm als ,distinkte Arbeiterpartei" (2) bezeichneten DKP identisch setzt.

1) Projekt Klassenanalyse: Leninismus - Neue Stufe des Wissenschaftlichen Sozialismus? Verlag für das Studium der Arbeiterbewegung GmbH.. Westberlin 1972, 1. Halbband. Einleitung, S. 24 f. (in der Folge zit. als: Leninismus).

2) Der Terminus, distinkte Arbeiter parteit stammt von Engels, der ihn 1886 in einem Brief an F. A. Sorge verwendet: ,Der erste Schritt, worauî es in jedem neu in die Bewegung eintretenden Land ankommt, ist immer die Konstituierung der Arbeiter als selbständige politische Partel, einerlei wie, solange es nur eine distinkte Arbeiterpartei ist. " hEW. Bd. 36. 
In Artikel .Zur Aktualität der Leninschen Partei" (3) versucht das PKA die Parteikonzeption von Marx und Engels darzustellen (4). Die Verfasser gestehen eingangs. dafs sie dabei ..eine bestimmte Abstraktionsebene nicht verlassen" können, ., was nämlich eine Analıse einer konkreten historischen Situation zur Voraussetzung hätte". Sie meinen jedoch. dat bei der ..Bestimmung der Partei des Proletariats unterschieden werden (mufn) zwischen Phasen. wo die Vergesellschaftung der Arbeit noch relativ unentwickelt ist und isolierte Arbeit vorherrscht, und wo bei hochentwickeltem Stand der Produktivkräfte die Mehrheit der unmittelbaren Produzenten aus Lohnarbeitern besteht" (5). In der Folge stellen sie die allgemeinen Bestimmungen dar. die Marx aus der Analvise desallgemeinen Kapitalbegriffs für die Konstitution der Klasse , für sich" "gewinnt. Zusammenfassend erhalten sie hier das Resultat. daf durch die immanenten widersprüchlichen Tendenzen des Kapitals dieses sein eigenes Geheimnis selbst lüftet. dafe es also selbst zur Auflösung der von ihm verschuldeten Mystifikationen im Bewulstsein der Produzenten treibt und diesen so ermóglicht. das Totenglöckchen der bürgerlichen Gesellschaft zu läuten. In der Allgemeinheit der zusammenfassenden Marxschen Formulierung: .... durch den Mechanismus des kapitalistischen Produktionsprozesses selbst geschulten, vereinten und organisierten Arbeiterklasse" (6) läst sich jedoch nicht ein einziger Hinweis aut die Form dieser Organisierung erkennen. Im gesamten ..Kapital" findet sich nirgends auch nur der Versuch einer systematischen Ableitung einer Form der Klassenorganisation. Lnterstellt man hier Marx keinen Lapsus - was das PKA auch nicht tut - so kann der Verzicht auf die Ableitung einer Form der Klassenorganisation nur damit erklärt werden. dafs diese überhaupt nicht aus dem allgemeinen Begrift des Kapitals entwickelt werden kann. daf dafür die im allgemeinen Begriff nicht en thaltenen spezifischen. historisch-politischen Bedingungen eines besonderen konkreten Kapitalverhältnisses. d. h. einer besonderen konkreten Ausprägung bürgerlicher Gesellschaft, wesentliches Konstituens darstellen.

Marx verweist im ..Kapital" auf eine solche spezifisch historische Form von Klassenorganisation. nämlich auf die Trade-Lnions (7). Aufserhalb des ..Kapitals" läfrt Marx dann überhaupt keinen Zweifel darüber, dafs er die Trades-Unions bzw. die Gewerksgenossenschaften als die durch den kapitalistischen Produktionsprozef erzwungene historische Form der Klassenorganisation begreift. In den ,Instruktionen ... formuliert Marx: ..Auf der anderen Seite sind die Gewerksgenossen-

3) Dieser Artikel wurde nur von einem Teil der Genossen des Projekts Klassenanalyse verfalst: Heinz Bierbaum. Joachim Bischoff. Michael Kratke, Michael Menard: Zur Aktualitat der Leninschen Partei. Sozialistische Politik. Nr. 10. S. 39 if. (in der Folge zit. als: SoPor.

4) Zur Parteikonzeption von Marx und Engels. S. $63 \mathrm{ff}$.

5) SoPo. Nr.10.S. 63

6) Karl Marx. Das Kapital. Bd. 1. S. 791, zit, nach Marx-Engels-Werke (MEW), Berlin (DDR)

7) Karl Mars, Das Kapital, MEW. Bd. 23, S. 669: ... . . sobald sie daher durch Trades Unions usw, eine planmarsige Zusammenwirkung zwischen den Beschäftigten und Unbeichaftigten zu organisieren suchen.... 
schaften, ohne daß sie sich dessen bewuß 3 t wurden, zu Organisationszentren der Årbeiterklasse geworden"(8). Er begreift hier eindeutig die Gewerksgenossenschaften als die Klassenorganisation des Proletariats, das sowohl den „ökononischen" als auch den ,politischen" Kampf zu führen hat. Er sieht allerdings (vor allem am Beispiel des ökonomisch am fortgeschrittensten Landes (England), mit der weitesten Organisierung der Arbeiterklasse), dak diese Organisationen ihren eigentlichen Kampfauftrag noch nicht begriffen haben (9), wenngleich sie beginnen, sich ihrer ,großen historischen Mission" bewußt zu werden. Marx stellt deshalb an die Gewerksgenossenschaften die Forderung, neben ihren ursprünglichen Zwecken ,bewußt als organisierende Zentren der Arbeiterklasse zu handeln, in großen Interesse ihrer vollständigen Emanzipation" (10). Als Marx diese Forderung erhob (1867), gab es in England keine besondere exklusive politische Organisation der Arbeiterklasse. Im ökonomisch zurückgebliebenen Deutschland mit noch entsprechend schwach ausgebildeter Klassenorganisation hatte sich eine solche Organisation mit dem Allgemeinen Deutschen Arbeiterverein (ADAV) 1863 bereits gebildet. Marx bekämpfte diese Organisation als Sekte: ,In Deutschland - die Lassalleclique. Ich habe selbst während zwei Jahren mit dem berüchtigten Schweitzer korrespondiert, und inm unwiderleglich nachgewiesen, daß Lassalles Organisation eine bloße Sektenorganisation ist und als solche der von der Internationalen angestrebten Organisation der wirklichen Arbeiterbewegung feindlich ist" (11) und kritisierte diese Sekte wiederholt inhaltlich und formal - jedoch nur in ,privaten" Briefen, nie öfentlich (12) - und stellte ihr die Trade-Unions als die eigentliche Klassenbewegung gegenüber (13).

Die Gründung der Internationalen Arbeiter-Association (IAA) 1864 hatte für Marx den Zweck, die verschiedenen Klassenorganisationen der verschiedenen Länder zu verbinden und zu verallgemeinern. Sie ,wurde gestiftet, um die wirkliche Organisation der Arbeiterklasse für den Kampf an die Stelle der sozialistischen oder halbsozialistischen Sekten zu setzen“ (14). Marx begreift also zu dieser Zeit wesentlich die Trade-Unions als die Klassenorganisationen des Proletariats, d. h. als die

8) Karl Marx: Instruktionen für die Delegierten des Provisorischen Zentralrats zu den einzelnen Fragen. MEW, Bd. 16, S. 197.

9) „Sie haben sich deshalb zu fern von allgemeinen sozialen und politischen Bewegungen gehalten." (Ebd.)

10) Ebd.

11) Karl Marx: Brief an Friedrich Bolte vom 23. 11. 1871. MEW, Bd. 33, S. 329

12) ,Kritisiere ich sein Zeuge, so wäre das Zeitverlust; . . Bleibt also nichts übrig, als abzuwarten,..." (Karl Marx, Brief an Engels vom 12. 6. 1863, MEW, Bd. 30, S. 357) und dazu Engels Antwort: „Deine Politik dem Itzig (d. i. Lassalle -- d. Verf.) gegenüber ist ganz recht." (Friedrich Engels, Brief an Marx vom 24. 6. 1863, MEW, Bd. 30, S. 360) Dieses politische Verhalten von Marx und Engels gegenuiber Lassalle bzw. dem ADAV soll hier nicht weiter erörtert werden. Es scheint jedoch von der Kenntnis der späteren Entwieklung der Sozialdemokratie aus wichtig, hier auf dieses problematische politische Verhalten der beiden hinzuweisen.

13) "Stattdessen haben sie in der Tat die Forderung an die Klassenbewegung gestellt, sich einer besonderen Sektenbewegung unterzuordnen." (Karl Marx, Brief an J. B. v. Sehweitzer vom 13. 10. 1868, MEW, Bd. 32, S. 570)

14) Karl Marx, Brief an Friedrich Bolte vom 23. 11. 1871, a. a. O., S. 328 
wirkliche Arbeiterbewegung. Dieser Zusammenhang von Klassenorganisation und ihrer historischen Form in Trade-Unions bzw. Gewerksgenossenschaften wird von den PKA-Genossen bewuth! oder unbewukt übergangen, indem dieser Zusammenhang uberhaupt mis: an wird und sie daruber hinaus versuchen, mit einer arranchen Bchatipiung cincu Zusammenhang von allgemeinen Bestimmungen (,.Kapital") und politischer Bewegung bzw. politischer Organisation zu konstruieren: Aus den akonomischen Kämplen heraus entwickelt die Arbeiterklasse vorläufige Organisationen, die eine Verschärfung der Klassenauseinandersetzungen bewirken und selbst Mitte! für die Schaffung hoher entwickelter organisatorischer Formen sind "(15). Diese Behauptung wird mit einem Brief-Zitat von Marx zu stützen versucht:

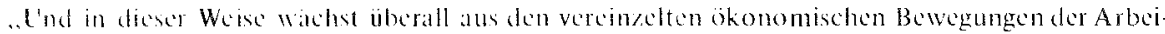

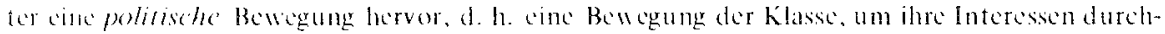
fusetzen in allgemeiner form, in ciner form, die allgemein, gesellschaftlich zwingende Kraft besild Wem diese Bewegungen dine gew isse previous organisation unterstellen, sind sie ihrerseits ebensosedr Mittel der l ntwicklung dieser Organisation" (16).

Der Zusammonhang $/$ u , lind in dieser Weise . . "lautet im Marxschen Text:

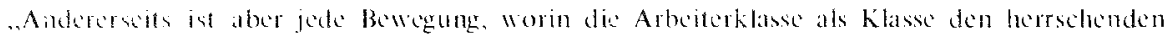
k'assen gegenubertrit und sic durch pressure from "ithout al zwingen sucht, ein political movement . . . dagegen dic Bewegung, cin Achtstunden- its. Gesetz zu arzwingen, ist cinc

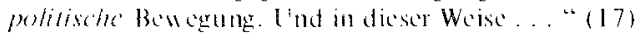

Marx meint hier also nichts weiter, als dat die ikonomischen Kämpte der Klasse, sofem sie die ganze Klasse betreffen, also nicht lokal betriebsspezifisch sind, einen politischon Kampl darstellen, diese Kampte jedoch ersi geführt werden können. wem en bestimmler Grad der Klassenorginisicung erreicht ist. Es ist hier an

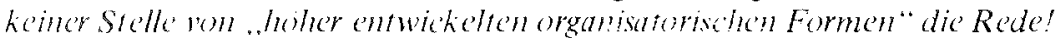

Vielmehr kamn her interpretiert werten, dats Max annimmt, dats die aus den okonomischen Kampten entstandenen Klassenorganisationen (Trade-Unions) zunehmend auch den politischen Kampf zu fuhren hab:n. Wenn dieses obige Marxzitat von den Vertassern nun verbunden wird mit einem Zitat aus dem ..Kommunistischen Manifest": "Vielmehr wird, diese Organisationder Proletarier /ur Klasse, und damit zur politischen Partei”..."(18), so wird hier zwischen der Behauptung von "höher entwickelten organisatorischen Formen" (PKA) und „politischer Partei" (Marx/Engels) von den Vertassern ein Zusammenhang suggeriert, der bei Marx nicht existicrt. Im Manifest meint der Termimus .politische Partei" nichts anderes als die verallgemeinerte Klassenorganisation, dic es 1848 erst zu schaffen galt, und nicht die "Gehemorganisation" (Engels) des Bunds der Kommunisten. Unter Klassenorganisationen verstanden Marx. und Engels zu dieser Zeit eindeutig Trade-Lnions und Gewerksgenossenschatten. Gegenuber diesen "Arbeiterparteien" (nur in diesem Sinn kann dieser Ausdruck verstanden werden) ..sind (die Kommunisten) keine 15) SoPo. Nr. 10.S. 69

16) Karl Marx, Brief an Friedrich Bolte vom 23.11.1871, a. a. O. S. $332 \mathrm{t}^{\circ}$

17) libd.

18) Karl Marx, Friedrich Engels: Manifest der Kommunistischen Partei, MEW, Bd. 4, S. 471 
besondere Partei" (19). Wenn der Terminus, politische Partei" aus dem historischen Kontext genommen wird, wie es von den Verfassern gemacht wird somul., der Leser damil die besondere historische Form von politischer Partei, wie sie sich in der 2. Internationale herausgebildet hatte, assoziieren. Diese spezifische Forin von Arbeiterpartei, die auf der grundsätzlichen Trennung von politischem und okonomischom Kampf basiert, wobei diese Partei exklusiv die politischen Interessen organisiert, während den Gewerkschaften die Vertretung der okonomischen Interessen uberlassen bleiben, diesen historisehen Typus von Partei hat Marx nic angesprochen.

Inwieweit die weitere Entfaltung der gesellschaftlichen Arbeitsteilung zu deser Trennung von okonomischer und politischer Organisationsform führte, wäre historisch zu untersuchen. Gerade das wird vom PKA immer wieder vermieden. Nimmt man seine Forderungen an die Gewerksgenossenschaften aus den "Instruktionen" (1867), dann ergibt sich, dak Marx unter politischer Bewegung brw. Organisation der Arbeiterklasse nicht eine von ihre Klassenorganisation (ökonomische) getrennte, exklusiv politische Organisation versteht. Da die Verfasser den Zusammenbang von allgemeinen Bestimmungen (, Kapital") und den historischen Bemerkungen von Marx nicht klarlegen, wird ein Zusammenhang von allgemeinem Begrili und politischer Partei konstruiert und vorgetauscht, wie er bei Marx nirgends existiert (20).

Eine Seite spater in dem Aufsatz wird diese Absicht unterstutzt durch dic Bemerkung, dak in ihren bisherigen Ausführungen ,... nur die allgemeinen Tendenzen des Kapitals skizziert werden konnten" (21), gerade aus der Skizzierung der allgemeinen Tendenzen des Kapitals ergibt sich jedoch kein Begriff von ,politischer Partei"! schon gar nicht im Sinne der Zweiten Internationale oder der Kommunistischen Internationale (Kl).

Immer noch unter ,3. Zur Parteikonzeption von Marx und Engels" kommen die Verfasser nun zum Abschnitt: „Die Partei des Proletariats“(22). Hier springen die Verfasser von cler Konstatierung der Ungleichzeitigkeit der Bewutstwerdung der Produzenten unvermittelt $z u$, ,kommunistischen Organisationen“"

"A uf Cirund der lifahrung tagtaglicher sozialer Kontlikte, ihrer Arbeits- und Lebenserfahrungen, vereinigen sich zunachst nur dic in Hinblick auf dic Entwicklung dieser Bew ufstheit fortgeschrittensten Teile des Prolctariats zu kommunistischen Organisationen" (23).

19) Karl Marx, friedrich lingelk: Manifest der Kommunistischen Partej, MIW, Bd. 4, S. 471

20) In einer anderen Schrift streitet das Projekt Klasscnanalyse übrigens cinen derartigen logischen Zusammenhang ab: ,... darf jedoch nicht zu der methodischen Verwirrung Anlats geben, auf der Abstraktionscbene des allgemeinen Begriffs des Kapitals und der Untersuchung der darin eingeschlossenen Bildung des Bewufstseins die Partei als logisch notwendiges Vermittlungsglied einzuführen." (Projekt Klassenanalyse: Klassenbewulstsein und Partei. Kritik an E. Hahn. Verlag für das Studium der Arbeiterbewcegung (VSA), Westberlin 1972, S. 126)

21) SoPo, Nr. 10, S. 70

22) Ebd., S. $71 \mathrm{ff}$.

23) Ebd., S. 73. Der ,Bund der Kommunisten“ (1848) kann in keiner Weise als allgemeines Beispicl für diese allgemeine Behauptung strapaziert werden explizit wird dies auch von Projekt Klassenanalyse nicht versucht. Eine historische Kritik hätte statt unzulässi- 
We steht bei Marx oder Engels dieses Resultat? Das Zitat, das die Verfasser als Beleg ausgraben, spricht lediglich davon, dak ..- die Kommunisten ... die letzten (sind), den Fehler zu begehen, Sektierertum zu billigen oder zu fordern“ (24). Marx. schreibt dies als Repräsentant der Internationalen Arbeiter-Association, die bekanntlich keine exklusive Kommunisten-Organisation war, sondem eine Organisation, .brcit genug, um für die englischen Trade -Unions, für die französischen, belgischen, italienischen und spanischen Anhänger Proudhons und für die Lassalleaner in Deutschland annehmbar zu sein" (25).

Noch verfälschender ist die eingeschobene Schlulsfolgerung, die das PKA unmittelbar aus den bisherigen Marxzitaten zieht: ,Selbst wenn die Avantgardeorganisation der bewuisten Minderheit notwendiges Moment im Konstitutionsprozers der Klasse fur sich ist" (26). Marx wird nicht nur unterschoben, dafh er den fortgeschrittensten Teil der Produzenten in kommunistischen Organisationen sammeln will, sondern selbst noch, daf diese Organisationen nur die Form einer Avantgardeorganisation haben können (27). Mit dieser Manipulation (die wir gar nicht als bewußte unterstellen wollen) sind die Verfasser glücklich bei der späteren offiziellen Version der Kommunistischen Internationale angelangt, die die Leninsche Partei-Konzeption als konsequente und kohärente Weiterentwicklung des Marxismus betrachtete. Sie drehen diese sogar noch logisch um: Da Lenin das "Kapital" nicht richtig verstanden hat, wird seine Partei-Konzeption in Marx hineinprojiziert, um sie theo. retisch zu legitimieren und zu retten!

Zusammenfassung: Weder aus der Analyse des allgemeinen Begriffs des Kapitals noch aus den hishorischen Bemerkungen von Marx läßt sich ihm eine. .Parrej. konzeption" "unterschieben, schon gar nicht in der Form einer A vantgardeorganisa. tion.

Aus Marx` allgemeiner Analyse ergeben sich allgemein Bestirnmungen zum Konstztutionsprozet3 von Klassenbewußstsein und Klassenorganisation, nicht jedoch auch nur ein Hinweis auf eine notwendige Form. Als Klassenorganisation des Proletariats begreift Marx in der konkreten politischen Auseinandersetzung die historische Form der Trade-Unions, Gewerksgenossenschaften usw. Das konkrete politische Verhalten von Marx und Engels gegenüber der sich herausbildenden deutschen Sozialdemokratie (ADAV und Eisenacher) wirft jedoch einige Fragen auf, die nur auf Basis der widersprüchlichen historischen Situation, mit der sich Marx und Engels auseinanderzusetzen hatten, geklärt werden konnen: Im ökonomisch und politisch zuriickgebliebenen Deutschland bildet sich 1863 eine politische Partei der Arbeiterklasse (ADAV), dic von Marx als Sekte bekämptt wird, während es im fortge-

ger Enthistorisierung konkreter Marxscher Politik dic Differenz dieser Politik die Differenz dieser Politik, der ihr zugrunde liegenden Einschätzung der verönderten historischen Situation von 1848 und der Gründung der IAA (1864) herauszuarbeiten.

24) Karl Marx. Brief an P. und L. Lafargue vom 18. 4. 1870. MEW. Bd. 32, S. 671

25) Friedrich Engels, Vorrede zur englischen Ausgabe des Kommunistischen Manifests, 1888. MEW, Bd. 4, S. 579

26) SoPo. Nr. 10, S. 72

27) Engels bezeichnet noch 1881 die englischen Trade-Unions als „Vorhut der Arbeiterklasse", obgleich diese ihre Pflicht bislang vergessen hatten (Friedrich Engels: Die Trade-Unions, MEW, Bu. 19, S. 259). 
schrittenen England mit einer ausgeprägten Klassenorganisation eine solche exklusive, vom Produktionsprozels getrennte politische Organisation nicht gibt. Von dieser fordern Marx und Engels immer wieder, dał sie neben ihren ökonomischen Aufgaben endlich ihre eigentliche Aufgabe, die vollständige Emanzipation der Arbeiterklasse angehen sollen. Der Sekte ADAV gegenüber bezeichnen Marx und Engels die Gewerksgenossenschaften überhaupt als Klassenbewegung. Beide sprechen nun andererseits von der Sozialdemokratischen Arbeiterpartei 1869) (den Eisenachern) als von , ihrer Partei“ obwohl sie wulkten, dath diese den "Lasselleschen Glaubensartikeln" ebenfalls tief verbunden war (28).

Dieses Verhalten von Marx und Engels scheint uns darauf hinzuweisen, daks ihnen die beginnende Entwicklung von exklusiv politischer und exklusiv ökonomischer Organisation noch nicht als Problem bewußst war. Marx geht in seiner Kritik zum Gothaer Programm nirgends darauf ein, dałs die eigentliche Klassenbewegung darin an keiner Stelle erwähnt wird. Engels bemerkt dieses Fehlen einer Stellungnahme zur ,eigentlichen Klassenorganisation“ zwar, kaw aber dazu nicht mehr sagen, als daßs es ,unbedingt notwendig (wäre), ihrer im Programm $z$ u gedenken und ihr womöglich einen Platz in der Organisation der Partei offenzulassen" (29). Der permanente Streit um die Bestimmung des Verhältnisses von Partei und Gewerkschaften wurde durch die weitgehende Unklarheit, die Marx und Engels hier hinterlassen haben, entscheidend gefördert. Dieses historische Resultat der Herausbildung von politischen und ökonomischen Organisationen der Arbeiterklasse und ihrer Verselbständigung gegeneinander wird vom PKA überhaupt nicht aufgegriffen. Stattdessen versuchen sie mit der Verwischung dieser Differenz Marx und Engels als Konstrukteure der leninistischen Parteikonzeption darzustellen.

In dem Artikel „Zur Aktualität der Leninschen Partei“ wird nun auf den real historischen leninistischen Parteitypus überhaupt richt eingegangen. Allgemein wird gegen die "marxistisch-leninistischen" Sekten formuliert, dak erst "die Gültigkeit sogenannter allgemeiner Prinzipien revolutionärer Taktik für gegenwärtige gesellschaftliche Verhältnisse zu zeigen (ist)" (30), bevor man ein ,Bekenntnis zu bolschewistischen Parteiprinzipien" ablegt und bedingungslos den Leninschen Parteitypus übernimmt. Das glaubt das Projekt Klassenanalyse wahrscheinlich dann mit der Konstruktion einer Marx-Engelschen Parteikonzeption geleistet zu haben. Jedenfalls folgt in der nächsten Publikation der Gruppe (Versuch zur Bestimmung der Aufgaben der kommunistischen Intellektuellen) völlig unvermittelt ihr Bekenntnis zur DKP als ,distinkter Klassenpartei“ (31). Da sie in der Einleitung zu ihrer

28) Marx begreift ihren Beitrag zum Gothaur Programm als ,ungehoucrliches Attentat auf dic in der Parteimasse verbreitete Einsicht" (Karl Marx, Kritik des Cothaer Programms, MEW, Bd. 19, S. 767). Warum er sie trotzdem als seine Partej bezeichnet, soll hier nur als Frage gestellt werden.

29) Friedrich Engels: Brief an Bebel vom 18./28. 3. 1875, MEW, Bd. 19, S. 6

30) SoPo, Nr. 10, S. 39

31) Das Bekenntnis im Wortlaut: ,In einer Situation, wo die proletarischen Massen trotz der Verschärfung der Klassenkämpte weitgehend unter dem Einfluts der hersschenden Klasse stehen, muls die Politik der Kommunisten in erster Linie auf das A ufrutteln der arbeitenden Klasse und auf die Konsolidierung der proletarischen Massenpartei gerichtei sein, auch um den Preis eines unzureichenden Programms, solange diese Partei eine distinkte 
"Leninismus-Kritik" behaupteten, die Hinwendung zur DKP sei Konsequenz der Resultate ihres Marxstudiums, haben wir versucht, den Resultaten nachzugehen, die zu dieser Konsequenz geführt haben. Selbst wenn wir noch von der gewaltsamen Konstruktion einer Marxschen Parteikonzeption, sogar Leninschen Typus, absehen. bleibt uns die zuletzt gezogene Konsequenz rätselhaft, da dazu doch wenigstens der Nachweis gchort, dak die DKP tatsachlich die ,distinkte Arbeiterpartei“ ist. Dieser Nachweis wurde vom PKA nicht einmal versucht. Die Hinwendung zur DKP kann so nur als ein opportunistisches Bekenntnis eines isolierten Intellektuellenzirkels verstanden werden.

\section{Leninsehe Klassenanalyse und leninseher Parteitypus}

Das Projekt Klassenanalyse beginnt seine Lenin-Kritik, indem es seine aus der Marxrezeption gewonnenen allgemeinen Bestimmungen, unter denen Kommunisten beschleunigend auf den Konstitutionsprozeß von Klassenbewuß tsein. Aneignung des allgemeinen Begrifts des Kapitals, Klassenanalyse, Taktik - wirken konnen, als Mathstab auch für die Moglichkeit des russischen Revolutionärs Lenin formuliert. Sie konmen dabei zu dem Resultat, dal Lenin zwar die logische Reihenfolge der Bestimmung einer konkreten kommunistischen Politik einhält, daß er aber , das von ihm selbst aufgestellte Programm nicht vollständig einlösen kann" (32). Der Sündenfall liegt dabei für die Genossen des PKA noch vor der eigentlichen Rezeption der Marxschen Analyse, nämlich in seinem Verständnis über ihr Zustandekommen.

Lenin begreift nach Auffassung des PKA die Marxsche Analyse, d. h. den wissenschaftlichen Sozialismus, ,nicht selbst noch als Produkı der wirklichen Bewegung der bürgerlichen Gesellschaft" (33), ,sondern letztlich doch als Frucht einer relativ autonomen Entwicklung des Denkens, als Konzipierung eines Kritikmafisstabs" (34). Lenin erweist sich mit dieser Auffassung von der Genesis des wissenschaftichen Sozialismus insofern als bürgerlicher Wissenschaftler, dak ,.er das Grundtheorem burgerlicher Erkenntnistheorie (akzeptiert), die Vorstellung eines ,objektiven Kriteriums", das von auken an den Gegenstand herange tragen wird, und mit den die Mannigfaltigkeit der Erscheinungen zu ordnen und auf den Begriff zu bringen ist" (35). Er sieht also nicht, daks der Gegenstand die bürgerliche Gesellschaft real strukturiert ist und nicht erst noch durch Begriffe geordnet werden muls. Wie die literarischen Vertreter der Arbeiterklasse 7 u ihrem Standpunkt zur proletarischen Anschauungsweise -.. kommen. kann Lenin aufgrund sein methodi-

Klirsenpartei ist und am Ziel der sozialen Emanzipation des Proktariats festhalt. Dals sich de konsolidierung nur in Prozets der Kritik und korrektur der unzurcichenden Teik de Programms volizichen kann, gilt atuch für die DKP und für die SEW. Ls bedeutet. den wissenschaftichen Soziatismus nicht begriffen zu haben. wonn Intelleknelle cine besondere Partei gegen die bestehende und in den Massen verankerte Arbeiserpartei

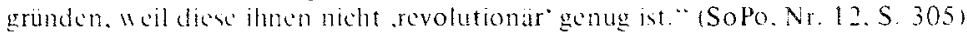

32) Leniniาmus, S. 771

3.) Ibd.S. 64

341 lod. S. 65

35) 1.bd.. S. 64 
schen Fehlers nicht erklären" (36).

Dieser Fehler im Verstandnis des Zustandekommens der Marxschen Analys: wird nun ergänzt durch sein falsches Verständnis dieser Analyse selbst. „Da Lenin die Problematik der genetischen Entwicklung der Formbestimmungen des Werts nicht verstanden hat, kann er zu der folgenschweren Auffassung gelangen, dals in „Kapital“ die verschiedenen Stadien der Entwicklung des Kapitalismus dargestellt seien" (37): Lenin mißversteht das „Kapital" als historische Darstellung der burgerlichen Gesellschaft, begreift den von Marx dargestell ten dialektischen Zusammenhang von „einfacher Warenzirkulation " und ,kapitalistischer Produktion" als historische Darstellung der „Entstehung und Entwicklung des Kapitalismus" (38) und kann sich dadurch später einbilden, die Marxsche Analyse mit der Darstellung eines weiteren Entwicklungsstadiums bürgerlicher Gesellschaft, der des ,staatsmonopolistischen Kapitalismus" ergänzt bzw. erweitert zu haben. Daß davon keine Rede sein kann, wird vom PKA schlüssig nachgewiesen. Das Dogma des sowjetischen Parteikommunismus und aller ihm verpflichteten Kommunistischen Parteien, Lenin sei der Karl Marx der imperialistischen Etappe, wird damit erheblich angekratzt.

Da Lenin „den spezifischen Status dieser (Marxschen - d. Verf.) Darstellung als allgemeiner Theorie des Kapitalismus in wesentlichen Punkten nicht begriffen hat" (39), ,ist ihm der richtige Ausgangspunkt jeder Klassenanalyse schon verwehrt" (40). Lenin versteht die Anwendung der allgemeinen Theorie nicht als die Bestimmung eines spezifischen Entwicklungsgrades der bürgerlichen Gesellschaft, „,sondern da die allgemeine Theorie direkt Darstellung der historischen Entwicklung ist, ist in ihr der Entwicklungsgrad des Kapitalverhältnisses der zu untersuchenden Länder schon enthal ten“(41). ,Trotz dieser aufgezeigten Mängel und problematischen Ansätze gibt Lenin ein ungefähres Bild der sozialökonomischen Verhältnisse Rußlands ${ }^{6}(42)$ - meinen die Genossen. Wie er dieses Kunststück fertigbringt - bei derart mangelhaften Voraussetzungen - verraten uns die Verfasser nicht. Als allgemeines Fazit des ,ungefähren Bildes" der Leninschen Klassenanalyse falst das PKA zusammen: ,daß das Kapitalverhältnis in der Industrie wie auf dem Lande dominiert, wenn auch Rußland, verglichen mit anderen kapitalistischen Ländern, in seiner Entwicklung zurückgeblieben ist" (43). Obwohl das PKA feststellt, dał Lenin keine Anstrengungen unternimmt - angeblich auf Grund seiner Marxrezeption auch gar nicht kann -, die tatsächlich bestehenden Mischformen der Produktion zu analysieren, daß ihm deshalb bei der Bestimmung der Bewußtseinsformen der Fehler unterläuft, ein nur demokratisches Potential auf dem Lande zu vermuten, das nur für bürgerliche Forderungen zu mobilisieren sei (44), und obwohl es in der Anmer-

36) Ebu., S. 66

37) Ebd., S. 75

38) Ebd., S. 76

39) Ebd., S. 81

40) Ebd., S. 83

41) Ebd., S. 88

42) Ebd., S. 94

43) Ebd., S. 108

44) ,Es gerät aus dem Blickfeld, dats hinter dem Eintreten für eine Rekonstitution der Dorfgemeinde nicht nur cine Gegnerschaft gegen Fronwirtschaft und Leibeigenschaft 
kung zu seinem Fazit der Leninschen Analyse konstatieren muß, daß auf dem Lande sich erst die „Tendenz" der zukünftigen Kapitalherrschaft abzeichnet, die Situation aktuell gekennzeichnet ist durch die Dominanz der ,isolierten Produktionsweise" (45), schlieft es sich in seiner weiteren Kritik der leninschen Behauphung pon der Deminanz des Kapinalperhälthisses rikckhattlos an (46):

In Anmerkung 45 wird versucht, die .,Tendenz" gegenüber der faktisch nicht vorhandenen .Dominanz" zu retten, ohne daß dies auch nur an einer Stelle belegt wird. Was vorher noch als "Mischsystem dorfgemeindlicher, fronwirtschaftlicher, kleinbäuerlich-isolierter" (47) Produktion auf dem Lande erschien, wird hier versucht, zu Gunsten der Dominanz. „isolierter Produktionsweise" - also einer bereits bürgerlichen Form zu lösen, ebenfalls ohne einen Nachweis zu bringen. (Diese Behauptung von der Dominanz der ",isolierten Produktionsweise" wird dem PKA weiter unten noch wertvolle Dienste leisten.) Hätte sich bei einer konkreten Untersuchung der russischen Verhältnisse - die das PKA durchweg vermeidet -. gar das Resultat ergeben, dath die vorbürgerlichen Produktionsweisen dominieren, nicht nur auf dem Lande, sondern gesamtgesellschaftlich, indem sie über Jahre eine Stagnation auch der Stadt verursachen, danm ware ihr einziger Maßstab der Kritik - der allgemeine Kapitulbegriff hinfallig geworden, ihrer ganzen Kritik der Boden entzogen (48)

Nur so wird verständlich, warum das PKA die in diesem Zusammenhang notwendige Vergewisserung über die tatsächliche Beschaffenheit der russischen Gesellschaft unterläht und sich bequem die durch nichts belegte Behauptung Lenins von der Dominanz des Kapitals die dieser später wieder zurücknimnt - zu eigen

stand, sondern sich auch cin Protest gegen die Auflosung des bisherigen gesellschaftlichen Charakters der Produktion im Rahmen der cinzelmen Dortgemeinden und Gutswirtschaften verbarg." (Kbod., S. 102)

45) „188) Wenn Lenin von der Dominanz des Kanitalverhälenisses in $R$ uthland spricht, so ist darunter zu verstehen, datia das Kapital auch hier die Grundlage der Produktionsverhältnisse ergriften hat und damit in der weiteren intwicklang tendenziell die Hersehaft des Kapitals in alle Sphären des gesellschattle-len Lebens cindringen wird. Die Dominanz kann hier keineswegs quantitativ bestimnt werden, dem obwohl sich das Kapitalverhaltnis als sich durchsetzendes etablict hat, ist dic isolierte Produktionsweise gerade aluf dem Linde noch die vorberschende" (Ebd. S. 103) Ein grobsartiger Trick: Das Kapitalverhaltnis dominiert, obwohl es noch nicht dominicrt.

46) Seine vorherige Konstatierung, dab Lenin nicht die antikapitalistisehen Potenzen der Dortgemeinde berücksichtigt, spielt tür die Systematik seiner Kritik keinc Rolk mehr. Bei der einmal angenommenen Dominanz des Kapitals spielen diese Relikte auch nur noch sinc untergeordnete Bedeutung. Das Projekt Klassenanalyse versucht so auch nicht an einer Stelle auszuführen, was ein Anknüpten an die tradierten Produktionsverhältnisse für die konkrete Politik Lenins bedeutet hätte.

47) Ebd., S. 92

48) Wenn in Rubland un die Jahrhundertwende nicht vom Kapitalverhältnis als herrsehendem gesprodhen werden kann, also auch nieht vom herrschenden Klassengegensatz zwischen Bourgeodic und Proletariat, dann ist auch dar allgemeine Kapitalbegriff - der die voll entfaltete bürgerliche Gesellschaft voraussetzt . als Grundlage ciner revolutionären Taktik nicht verwendbar. Dann kann auch Lenins Politik nicht am Matsstab des allgemeinen Begriffs gemessen werden. Abgesehen noch davon, daf cine historisch-materialistische Kritik nicht einzig und allein von der kenntnis des ,Kapitals" aus geteistet werden kann. 
macht. Weiter erklärt dies auch, warum das PKA die ihm bekannte Marxsche Ein. schätzung der russischen Verhältnisse und ihrer Entwicklungsmöglichkeiten hier unterschlagt. Marx sieht noch 1882 weder eine herrschende Tendenz noch eine Dominanz von kapitalistischen bzw. bürgerlichen Eigentums(Produktions)formen. Er sieht eindeutig die Dominanz von „Gemeineigentum an Grund und Boden ${ }^{56}$ (49). also die Dominanz von vorbürgerlicher Produktionsweise, und zwar einer spezifisch russischen Abart der asiatischen Produktionsweise (50). Im Zusammenhang dieser russischen Ungleichzeitigkeit mit den weit entwickelten Produktivkräften (wenn auch in kapitalistischer Form) Westeuropas sieht Marx, ,die schönste Chance, die die Geschichte jemals einem Volk dargeboten hat" (51). Nämlich den Sprung von vorbürgerlicher Produktionsweise in die Entwicklung einer kommunistischen Produktionsweise (52). Da die Dorfgemeinde jedoch ,schon bis an den Rand des Untergangs gebracht (ist)" (53), kann für Marx nur eine, ,russische Revolution" die ,russische Gemeinde" retten (54). Das Aufnehmen dieser Fragestellung von Marx - was weder von Lenin noch vom PKA geschah, das jedoch im Unterschied zu Lenin diese Marxschen Überlegungen kannte - hätte bedeutet, daß der Nachweis geführt werden müßte, daß die russische Gemeinde bereits $20 \mathrm{~J}$ ahre nach der MarX. schen Einschätzung den endgültigen „Todessto $3^{66}$ erhalten hatte, sich unwiderruflich auf dem Weg ins ,Kaudinische Joch" befand. Die Leninsche Bemerkuig, daß „,das Jahr 1905 der Anfang vom Ende der ,östlichen" Unbeweglichkeit" war (55), weist eher auf das Gegenteil hin (56). Ebenso die Selbstkritik von 1907:

,Wir nahmen an, die Elemente der kapitalistischen Landwirtschaft seien in Rufoland bereits vollkommen ausgebildet - sowoh in der Gutswirtschaft...., als auch in der bäuerlichen Wirtschaft ... Nicht der ,Furcht ${ }^{\star}$ vor der bäuerlichen Agrarrevolution entsprang das fehlerhafte Programm, sondern der Überschätzung des Grades der kapitalistischen Entwicklung in der

49) Karl Marx: Brief an V. I. Sassulitsch, dritter Entuurf, MEW, Bd. 19, S. 403

50) „Das ,kommunistische Manifest" hatte zur Aufgabe, die unvermeidlich bevorstehende Auflösung des modernen bürgerlichen Eigentums zu proklamieren. In Rufiland aber finden wir, gegenüber rasch aufblühendem kapitalistischen Schwindel (Hervorh. v. Verf.) und sich eben erst entwickelndem bürgerlichen Grundeigentum, die größere Hälfte des Bodens im Gemeinbesitz der Bauern." (Karl Marx, Friedrich Engels: Vorrede zur russ. A usgabe des Kommunistischen Manifests, 1882, MEW. Bd. 4, S. 576)

51) Karl Marx: Brief an die Redaktion der "Otetschestwennyje Sapiski". 1877, MEW, Bd. 19, S. 108

52) „Wenn sie im Gemeineigentum am Boden die Grundlage für die kollektive Aneignung besitzt, so bictet ihr das historische Milieu, die Gleichzeitigkeit mit der kapitalistischen Produktion, alle fertigen Bedingungen der gemeinsamen Arbeit im grofsen Mafsstab. Sic ist daher imstande, sich die positiven Errungenschaften des kapitalistischen Systems anzueignen, ohne durch dessen Kaudinisches Joch gehen zu müssen." (Karl Marx: Brief an V. I. Sassulitsch, erster Entwurf, MEW, Bd. 19. S. 391) Bedingung ist dabei für Marx und Engels (1882), daß , die russische Revolution das Signal einer proletarischen Revolution im Westen (wird), so daß beide einander ergänzen," (Karl Marx, Friedrich Engels: Vorrede zur russ. Ausgabe des Kommunistischen Manifests, a. a. O.)

53) Karl Marx: Brief an V. I. Sassulitsch, erster Entwurf, a. a. O.. S. 394

54) ..Um die russische Gemeinde zu retten, ist eine russische Revolution nötig." (Ebd., S. 395)

55) W. 1. Lenin: Tolstoi und seine Epoche. Lenin Werke (LW), Berlin (DDR), Bd. 17, S. 36

56) Der Marxist Lenin sprach dabei im Original von ,orientalischer Stagnation“, während die Revisionisten mil ,östlicher Unbew eglichke it" ubersetzten. 
rusischen Landwirtschaft. Die Uberteste der Leibeigenschaft erschienen uns damals als unwesentiche: Detail. die kapitalistische Wirtschaft ... als vollig ausgereift und gefestigt" (57).

Diese Selbstkritik ändert jedoch nichts an Lenins grundsätzlicher Einschätzung der Entwicklung Rufslands. Nach wie vor hält er die zivilisatorische Wirkung des Kapitals notwendig für die Überwindung der vorbürgerlichen Produktionsweise, des niedrigen Kulturniveaus etc. Da Lenin die revolutionären sozialistischen Potenzen der russischen Dorfgemeinde nicht sieht. versucht er auch gar nicht erst eine Konzeption für die revolutionäre Organisierung dieser Potenzen zu entwickeln (58). Lenin erweist sich mit seiner theoretischen Einschätzung der russischen Entwicklung als ein Marxist in dem Sinne. wie Marx sie charakterisiert: nämlich als Leute, die seine ..historische Skizze von der Entstehung des Kapitalismus in Westeuropa (gemeint ist sein Kapitel uber die sog. ursprüngliche Akkumulation - d. Verf.) in eine geschichtsphilosophische Theorie des allgemeinen Entwicklungsganges verwandeln. der allen Volkern schicksalsmäfig vorgeschrieben ist" (59).

Das PKA kritisiert Lenin. daf er in seiner Klassenanalyse die tradierten Bewufitseinsformen vernachlässigt. in seiner praktischen Politik gerade aber dort anknüpft (60). . so dak Klassenanalyse und Taktik jetzt in einem unvermittelien Widerspruch stehen" (61). Als Lenin dann 1907 seine Klassenanalyse in Übereinstimmung zu seiner Taktik bringt (62), begreift das PKA dies nur als .,Akzentverlagerung in der Klassenanalyse" (63). Den Widerspruch, an den Lenin hätte anknupfen sollen. sieht das PKA im Gegensatz der Dorfgemeinde zum feudalen Großgrundbesitz (auch kapitalistischen) und des Landproletariats zur kapitalistischen Agrarproduktion. Ohne sich der tatsächlichen Verhältnisse auf dem Lande vergewissert zu haben. und zwar auch auf Basis der heutigen wissenschaftlichen Resultate, ohne sich die Frage zu stellen, ob Lenin vielleicht mit der Revision seiner Klassenanalyse der russischen Wirklichkeit naher gekommen ist. obwohl er dabei in Widerspruch zum orthodoxen Marxisten der II. Internationale gerät. machen sie die Vernachlässigung der kapitalistischen Agrarproduktion zum zentralen Kritikpunkt an Lenins

57) W. I. Lenin: Das Agrarptogramm der Sozialdemokratie, LW. Bd. 13. S. 289 f.

58) Die chinesische Revolution gab ein konkretes historisches Beispiel fïr eine revolutionäre Organisierung von Bauern. Abgesehen von der anderen politischen Situation werden u. a. die russischen Fehler und Erfahrungen erst cine andere Politik ermoglicht haben. Mao Tsetung geht erst nach der von der Kommunistischen Interenationale (KI) mit verbrochenen Viederlage der Schanghai-kommune (1927) aufs Land.

59) Karl Varx: Briet an die Redaktion der ,Otetschestwennyje Sapiski". a. a. O.. S. 111. Die Genossen des Projekts Klassenanalyse gehören ebenfalls zu dieser Sorte von Marxisten, wenngleich sie dieses Kapitel nicht in c'ieser Weise mitsverstehen. In der Methode ihrer Kritik verfahren sie aber praktisch entsprechend. denn die Marxsche Einschätzung einer alternativen Entwicklungsmöglichkejt für Ruisland wird von ihnen nicht aufgenommen.

60) ..In seiner Konzeption der Bündnispolitik dagegen virnachlässigt er die kapitalistischen Antagonismen auf dem Lande fast vollständig und rückt den Widerspruch zwischen der Bauernschatt in ihrer Gesamtheit und den Grologtundbesitzern in den Mittelpunkt." (Leninismus. S. 126)

61) Ebd.

62) ..Allerdings gelingt es ihm dadurch. dafs nun auch in der Klassenanalyse der Widerspruch zWischen Bauernschaft und Kapital völlig in den Hintergrund tritt, die eingangs cruähnte Inkongruenz zwischen Klassenanalyse und Taktik zu be seitigen." (Leninismus. S. 212 f.) Ebd. S. 2 I 3 
Agrarpolitik und sehen in der Leninschen Revision nur den ..schlagenden Beleg" für ihre These: ..daf Lenin aufgrund seiner Mifverständnisse der Marxschen Theorie. insbesonderes des Kapitals. die beiden Seiten des gesellschaftlichen Antagonismus auf dem Lande nicht zu vermittehn vermag"(64). Ihre Alternativorstellungen gehen dabei nie über die abstrakte Formulierung ...anknüpen müssen" hinaus. Welche organisatorischen Konsequenzen ein solches antikapitalistisches Anknüpen bedeute thätte. wird an keiner Stelle auszuführen versucht.

Obwohl Lenir seine Einschatzung der russischen Situation andert klammert sich das PKA noch weiterhin an seine ursprungliche Einschatzung von der Dominanz des Kapitals. wenn auch nur als Tendenz. Konsequent lafint es auch die Marxsche Alternative der Entwicklung unerwähnt. Zu erklären ist dieses Vorgehen nur als Rettungsversuch der Methode inrer Kritik (Vergleich des Ubereinstimmungsgrades der Leninschen Aufserungen und dem allgemeinen Kapitalbegriff).

An der ersten Einschätzung Lenins und deren Widerspruch zu seiner praktischen Politik wird jedoch eine zentrale Schwierigkeit Lenins sichtbar: Mit dem theoretischen Instrumentarium fuir entwickelte bürgerliche Gesellschaften versucht er. die Besonderheiten Ruflands zu fassen. Er schafft dies aber nur. indem er diesen Begriffsapparat der besonderen Realität Rufslands mehr oder weniger willkürlich überstülpt. Er kann so nur ungenügend die russische Wirklichkeit theoretisch tassen und baut Widerspriche zwischen theoretischen Aussagen und praktischer Politik. die zwischen Wirklichkeit und Politik in dieser Form nicht bestehen. Eine Kritik an Lenin. die die Analyse der russischen Wirklichkeit vollständig ausklammert oder sie nur in der literarischen Fassung Leninscher Schriften aufnimmt. führt letztlich nur Scheingefechte.

Für die Konzeption des Leninschen Parteitypus sind sowohl die Klassenanalyse als auch die politische Herrschaftsform der russischen Gesellschaft entscheidende Bestimmungsgründe. Als Marxist der II. Internationale kommt Lenm erst einmal zum Ergebnis, dafi das nächste Etappenziel der russischen Gresellschaft die bürgerliche Revolution ist. We der die soziale Emanzipation der Arbeiterklasse noch die soziale Emanzipation der Bauern im sozialistischen Sinne stehen für ihn auf der Tagesordnung. Trifft sein Parteikonzept der Organisation der Berufsrevolutionäre ungefahr die Situation der Arbeiterklasse. soweit ihre soziale Emanzipation nicht auf der Tagesordnung steht. so deckt es jedoch in keiner Weise die sozialen Interessen und Aufgaben der Bauen ab. Der Widerspruch zwischen dem Überwiegen des Landes und einer quantitativ wenig entwickelten Arbeirerklasse wird auch nicht dadurch gelöst. dafi Lenin für seine Berufsrevolutionäre als Vorbild nicht den ..Sekretär einer Trade-Lnion" hinstellt, sondern den ..Volkstribun" (65). Sowohl für die Arbeiter als auch für die Bauern hat Lenins Parteitypus nicht die Aufgabe. die Interessen ihrer sozialen Emanzipation auszudrücken. sondem primär die Aufgabe der Zerschlagung der Selbstherrschaft. also eine exklusiv politische Aufgabe. Das Programm der russischen Sozialdemokratie hat nur den Charakter einer äuferlichen Bindung der unter der Selbstherrschaft geknechteten Klassen. In dieser Bezlehung aber nur in dieser - unterscheidet sich die russische Sozialdemokratie 6+) Ebd.

65) W. I. Lenin: Wantun? LW. Bd. S. S. +37 
- ebenso wie die westeuropäische - nicht von bürgerlichen Parteien. Der entscheidende Unterschied liegt darin. dafi die Bolschewiki den westeuropäischen Sozialdemokratischen Parteien gegenüber eine wirklich praktisch revolutionäre Partei in bezug auf die politische Veränderung der Verhältnisse waren.

Sowohl die Räte als auch die Bauernaufstände drücken jedoch aus, daß die Organisation der ,Volkstribune" nicht eine Klassenorganisation war, die den Emanzipationskampf der Klasse als Klasse ausdrückte, sondern primär eine Spezialistenorganisation für den politischen Aufstand. Genau in dieser Funktion konnte sie in einer einmaligen historischen Situation - der spezifischen Form der Doppelherrschaft von 1917 - ihren historischen Auftrag erfullen. Als Lenin mit diesem Organisationstypus versuchte, die soziale Emanzipation der Klassen anzugehen, ist er gescheitert.

Das PKA formuliert bei seiner Betrachtung des bolschewistischen Parteitypus, dafs Lenin zwei Bestimmungsgründe für die Form (und Aufgaben) der Organisation benennt: einmal solche, .,die den spezifisch russischen Verhälinissen geschuldet sind, und solchen. die aus der Bestimmung von Klassenbewußstein erwach.

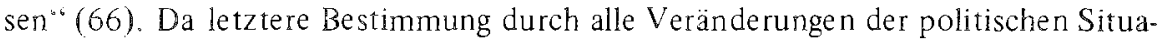
tion erhalten bleibt. muß auf diesen Zusammenhang besonders eingegangen werden.

Das PKA kann nachweisen, das Lenin aufgrund seines falschen Verständnisses von der Entstehung der Marxschen Theorie dazu kommt, der spontanen Arbeiterbewegung als höchstes Niveau nur ein tradeunionistisches Bewußtsein und entsprechende Kampfformen zuzugestehen und die Intelligenz auf der anderen Seite allein zur Einsicht in das Wesen der burgerlichen Gesellschaft für fähig zu halten. Daraus ergibt sich für Lenin als Aufgabenstellung der Intelligenz das Hinein tragen des wissenschaftlichen Sozialismus in die tradeunionistische Arbeiterbewegung, die auf diese Weise zur sozialdemokratischen Bewegung verschmilzt. Obwohl das PKA das Verständnis des Konstitutionsprozesses von Klassenbewußtse in als entscheidende Bestimmung für die Organisationsform (und ihre Aufgaben) begreift, und das falsche Verständnis Lenins davon aufzeigt, führt es seine Kritik nicht auf die Leninsche Organisationskonzeption selbst weiter. Die spezifische Form des Leninschen Parteitypus wird in der Folge nur apologetisch aus den besonderen politischen Verhältnissen erklärt (67). Das Herumdrücken des PKA um die Kritik am Organisationstypus läßt für uns folgende Interpretationen zu:

1. Das a-priori-Bekenntnis zur DKP als traditionalistischer Partei Leninschen Typus läßt diese Kritik nicht opportun erscheinen.

2. Ihre Konstruktion einer Marx-Engelschen Parteikonzeption, nach der sich der bewußteste Teil der Produzenten als „Avantgardeorganisation" exklusiv neben oder über den eigentlichen Klassenorganisationen als politische Partei etabliert, entspricht weitgehend dem Leninschen Parteitypus, wenngleich nur als Resultat und nicht in der Begründung. Es blieb tatsächlich Lenin vorbehalten - in inhaltlicher Übereinstimmung mit Kautsky - der historischen Spaltung von exklusiv politischen und ökonomischen Organisationen der Arbeiter-

66) Leninismus, S. 110

67) Vgl. ebd., S. $117 \mathrm{ff}$. 
bewegung einen prinzipiellen Begrindungszusammenhang zu verpasser.

3. Die Methode ihrer Kritik - die literarische Monade Lenin befindet sich nur immer wieder mit seiner eigenen mangelhaften Marxrezeption in permanenter Auseinanderserzung und nicht mit der russischen Wirklichkeit - spielt ihnen hier einen Streich. Die Frage. Warum Kautsky und Lenin Marx ungenügend rezipiert haben. stellt sich für sie nicht. Der Widerspruch zwischen Lenin als Marxist der Il. Internationale und Schuler Kautskys und der besonderen russi. schen Wirklichkeit rückt ebenfalls nicht in den Gesichtskreis.

Gegenuber der Marxschen These, daf die Arbeiterklasse durch den ...Mechanismus des kapitalistischen Produktionsprozesses selbst" geschult und vereint wird und der Konsequenz, „daf die Emanzipation der Arbeiterklasse durch die Arbeiterklasse selbst erobert werden mus " $(68)$. steht die These Lenins dar die .spontane Arbei. terbewegung an und für sich nur fähig (ist). Trade-Lnionismus hervorzubringen". und der Konsequenz. dak Intelligenz und ..Arbeiterintelligenz" (69) als .Fuhre"." die Klasse zum Ziel geleiten. Für die .Führer"-Organisation ist die zentralisrische Form der einzig adäquate Ausdruck. Es ist bezeichnend. daf die klarsten Stellen über diesen Zusammenhang im. Brief an einen Genossen . . " (70) vom PKA wberhaupt nicht erwähnt werden. Lenin berihrt hier u. a. die Frage, was geschieht. .wenn der Zentralstelle zufälig ein mit sehr grofen Machtbefugnissen ausgestatte ter Mensch angehört". Lenin meint, daf dagegen keine Statuten, also keine instutio. nelle Form etwas hilft, sondern nur kameradschaftliche Einwirkung (71). Während er die Fühung organisatorisch absichert. uberträgt er die Kontrolle dieser Fürung der moralischen Kategorie der kameradschaftlichen Einwirkung:. sowohl innerhalb der Organisation wie im Verhältnis der Avantgardeorganisation zu den Massen bleibt letztlich als Kontrolle der Fuhrung deren Selbstkontrolle.

Die grundsätzliche Einschätzung von der beschränkten Erkenntnis- und Handlungsfähigkeit der Massen bildet die Grundlage seines Zentralisationsbegriffs, dessen Umsetzung dann nur noch eine technisch organisatorische Frage ist, die entspie. chend der Situation flexibel gehandhabt wird (72). Diese grundlegenden Bestim. mungen für einen zentralistischen Organisationstypus sind weitgehend unabhängig von dern durch die spezifischen russischen Verhältnisse erzwungenen Notwendigkeiten einer zentralistischen Organisation. Erweist sich Lenins Parteitypus noch als adäquat zur Durchfürung des erfolgreichen Aufstandes. so als zunehmend inadäquat zum Aufbau einer sozialistischen Produktion, d. h. zur Realisierung der sozia-

68) Karl Marx: Provisorische Statuten der Internationalen Arbejter-Association. MEW. Bd. 16, S. 14

69) .Jede lebensfähige Arbeiterbewegung hat solche Führer aus der Arbeiterklasse hervorgebracht, ihre Proudhon und Vaillant, ihre Weitling und Bebel." W. I. Lenir: Eine rücklau* fige Richtung in der russischen Sozialdemokratie, IW. Bd, 4, S. 275) Von den vier Beispielen von Arbeiterintelligenz ist kein einziger der Klasse der modernen Lohnarbeiter angehörig. Bebel z. B betrieb Zeit seines Lebens einen selbständigen Handwerksbetrieb.

70) W. L. Lenin: Brief an einen Genossen uber unsere organisatorischen Aufgaben. 1904. LW. Bd. 6.S. 227 if.

71) Ebd.. S. 234

72) „Die Zahl der Komiteemitglieder soll möglichst nicht sehr grob sein (damit diese Mitglieder ein hohes Niveau haben und sich besser auf den revolutionaren Beruf spezialisieren können)."(Ebd., S. 230) 
len Emanzipation der Produzenten. Die historischen Schranken dieses Organisationstypus werden hier schlagend sichthar. Die Kritik daran kann aber nun nicht sein. dafi man nach dem Sieg der Oktobertevolution abstrakt die Verschmelzung von Gewerkschaften. Räten und Partei fordert - wie es das PKA tut -. und sich idealtypisch am allgemeinen Begriff orientiert. sondern die Frage, warum diese vom Primat der Pohtik bestimmte Organisation. de Vermittlung von Stadt und Land nicht in den Griff bekam?

Zentral scheint uns dabei. dats die Bolschewlkı nie eine revolutionäre Organisierung der Bauem versuchten, sich inmer nur am Industrieproletariat orientierten. auf die soziale Bewegung der Bauem überhaupt kemen Einflufi nahmen. mit deren Dynamik nur äuferlich konfrontiert wurden. Nicht, wie das PKA vernutet. die mangelnde marxistische Orthodoxie Lenins verhinderte eine angemessene Bauenpolitik. sondern genau umgekehrt, sein unerschutterfiches orthodoxes Festhalten an der Theorie des entwickelten Kapialismus. Erst 1918 spurt Lenin dieses Problem. indem er eine eigene Organisation der Bauern als Notwendigkeit begreift (73). Hier war es jedoch dann bereits zu spät.

Ebenso war die Orientierung der Bolschewiki am Industrieproletariat eine rornehmlich theoretische: der soziale Inhalt der Emanzipation der Arbeiterklasse stand für sie ohnehin nicht auf der Tagesordnung. die nächsten politischen Interessen (Sturz der Selbstherrschaft) hatten sie mit der überwiegenden Mehrheit des Volkes gemein. Nach dem Sturz der Selbstherrschaft und der Machtibernahne der Bolschewiki konnte die soziale Bewegung der Arbeiter mit sozialistischem Inhalt von den Bolschewiki auch nur äufierlich vermittelt werden. Den entsprach die Ubernahme des Staatsapparats als Vermittlungsinstitution durch die Bolschewiki und konsequent die Funktionalisierung der Räte und Gewerkschaften als Exekutivorgane dieses obersten Leitungsapparates. Die Forderung des PKA nach Verschmel. zung von Partei. Gewerkschaften und Räten ist ausgehend von der russischen Wirklichkeit nach dem Oktober 1917 absurd.

Da die ganze Kritik des PKA von der Dominanz des Kapitalverhältnisses ausging, griff ihre Kritik vor 1917 zu kurz und nach 1917 daneben. Nur wenn man davon ausgeht. dar im Zeitalter des Imperialismus nach dem Sieg der Oktoberrevolution die sozialistische Emanzipation auf der Tagesordnung gestanden hat - und die Bolschewiki haben spätestens seit 1918 nichts unterlassen, diese Einschätzung zu stärken - fafit die Kritik des PKA in einigen Punkten historische Realität. Entscheidend für die weitere Einschätzung der Kritik des PKA ist ihr Verständnis von der ,Commune" als dem .,rationellen Zwischenstadium".

73) .Dic Eroberung des Grund und Bodens ist. Wie jede Errungenschaft der Werktatigen, nur dann von Dauer. Wenn sie sich auf die Aktivität der Werktätigen. auf deren eigene Organisation. auf deren Beharrlichkejt und revolutionäre Standhaftigkeit stutzt. Hatten die werktätigen Bauern eine solche Organisation? Leider nicht, und das ist der Grund, die Lrsache dafür. dath der Kampf so schwer ist."W. I. Lenin: Recie an die Delegierten der Komitees der Dorfarmut, 8. Nov. 1818. LW, Bd. 2, S. 167 


\section{Einschäzung der Commune}

Die Erfahrungen der Revolution von 1905 bringen für Lenin nach Darstellung des PKA die Einsicht. daß die bürgerliche Revolution ohne. ja sogar gegen die Bourgeoisie erkämpft werden muß. Die dann zu etablierende Staatsform bezeichnet er als ..revolutionär demokratische Diktatur der Arbeiter- und Bauernschaft". Wobei ihm die ,.Dimension des Absterbens des burgerlichen Staates nach der Revolution nicht zum Problem (wird). Vielmehr handelt es sich für ihn noch immer um die Erobe. rung der Staatsmaschinerie, ohne deren allgemeinen, verselbstandigten Charakter zu

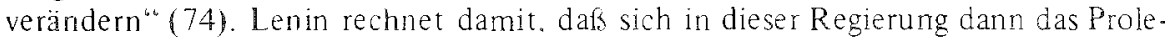
tariat in der Minderheit befinden wird (75). Ökonomisch hält Lenin nach wie vor nur die bürgerliche. d. h. kapitalistische Form der Entwicklung der Produktivkräfte für möglich. Das PKA konstatiert hier den Widerspruch, ..daf die politische Herrschaft der Bourgeoisie gebrochen werden soll. ohne bereits die ersten Schritte zu unternehmen. um auch auch deren ökonomische Macht zu untergraben und die bürgerliche Staatsmaschinerie zu zerschlagen" (76).

Das PKA glaubt nun. die Leninsche Einschätzung der nächsten Etappe und seine konkrete Taktik mit der Gegeniberstellung der Marxschen Einschätzung der Commune kritisleren zu konnen (77). Dabei offerieren sie uns nun wieder eine recht eigenwillige Interpretation der Marxschen Schriften: Sie schliefen sich zunächst der Leninschen Einschätzung an, daß ...der Grad der ökonomischen Entwicklung Ruß3lands ... und der Grad des Klassenbewußtseins und der Organisiertheit der breiten Massen des Proletariats ... eine sofortige vollständige Befreiung der Arbeiterklasse unmöglich" macht (78). Wesentlicher Inhalt der Leninschen Taktik ist die Zerschlagung der politischen und ökonomischen Schranken der Entfaltung der Produktivkräfte - Lenin meint hier die asiatischen"Schranken fur bürgerliche Fornen der Entfaltung als Voraussetzung des Übergangs in den Sozialismus. .Notwendiger-

74) Leninismus, S. 185

75) .Das russische Proletariat aber bildet jetzt die Minderhejt der Bevölkerung Rul lands.... sie wird die Beteiligung der buntscheckigsten Vertreter der revolutionären Demokratie an diescr Regierung oder sogar ihr Ĺbergewicht in dieser Regierung unvermeidlich machen. " (W. I. Lenin. Sozialdemokratie und provisorische revolutionare Regierung. 1805. L.W. Bd. 8, S. 284)

76) Ebd.. S. 185. Es ist hier einmal angebracht, auf dic Lereinstimmung des Projekts Klansenanalys: mit Trotzki hinzuweisen: ..Die politische Herrschaft des Proletariats ist unvereinbar mit seiner ökonomischen Versklavung." (I.co Trotzki: Frgebnisue und Perspekiiven, 1806. archiv sozialistischer literatur. S. 106. Verlag Neue Kritik. 1967) Auch in seiner Kritik am Agrarprogramm übernimnt es die Position Trotzkis: ..Man kann ir: keiner Weise voraussetzen, dułs eine proletarische Regierung die privaten Güter, auf denen die Grobproduktion eingeführt ist. nach ihrer Enteignung in cinzelne Parzellen aufteilen und zur Nutzung an dic Kleinproduzenten verkauten wird: hicr besteht der einzige Weg in der Organisation genossenschaftlicher Produktion unter kommunistischer Kontrolk oder direkt unter staatlicher Rechnungsführung. Das aber ist der Weg zum Sozialismus." (Ebd., S. 82); vgl. Leninismus. S. 189.

77) Wir brauchen nicht inmer wieder darauf hinzuweisen, dalo das Projekt Klassenanalyse an keiner Stelle die russische Wirklichkeit und die Antwort Lenins darauf als Grundlage seiner Kritik nimmt.

78) W. I. Lenin: Zwei Taktiken der Sozialdemokratie ... 1905. LW. Bd. 9. S. 14 
weise liegt also zwischen dem Sturz der Selbstherrschaft und dem Sozialismus eine Ưbergangsperiode, deren politische Form jetzt näher zu bestimmen ist "(79). Eine solche politische Form ist historisch erstmals während der Communeherrschaft in Frankreich entstanden und von Marx als notwendige Form des Übergangs zum Sozialismus in unentwickelten Ländern bestimmt worden" (80). Wo bezeichnet Marx die Commune pauschal als die ..notwendige Form" des Übergangs für ,unentwickelte Länder ${ }^{\circ}$ ?

Das PKA greift zu folgendem Trick, um Marx als Revolutionstheoretiker für unentwickelte Länder überhaupt und speziell für Rußland zurechtzustutzen:

..Der entscheidende Punkt ist der. dats die Kommune unter besonders günstigen historischen Bedingungen bereits errichtet werden kann. auch wenn die isolierte Arbeit noch die herrschende Form der Arbeir. wenn also das Kapitalverhälnis noch unent wickelt ist" $(81)$

Der ..entscheidende Punkt" ist nun in der Tat der. daß die isolierte Form der Arbeit tatsächlich die herrschende Form in Frankreich darstellte, d. h. also bereits einer bürgerlichen Form von A rbeit auf Basis einer bürgerlichen Form von Eigentum, und daßs diese Eigentumsform in eine entscheidende Krise durch die andere Form bürgerlichen Eigeniums, die kapitalistische, getrieben wurde (82). Das ist die reale historische Basis der Marxschen Einschätzung der Commune. Die Krise des isolierten Eigentums wurde durch Louis Bonaparte nicht gelöst, sondern verschärft. Marx kann jetzt formulieren. dafs das Parzelleneigentum, aus der Phase, in der es eine Realität war, eine Produktionsweise und eine Eigentumsform, die den ökonomischen Bedürfnissen der Gesellschaft entsprach und die ländlichen Produzenten selbst in normale Lebensbedingungen versetzte" seit langem herausgewachsen ist (83). ..Es ist in eine Verfallsperiode eingetreten. Auf der einen Seite ist daraus ein breites prolétariat foncier (ländliches Proletariat) entstanden, dessen Interessen mit denen der städtischen Lohnarbeiter identisch sind" (84). Erst wenn ein breites Landproletariat existiert, das identische Interessen mit dem Stadtproletariat hat, kann Marx formulieren, daßs ,das, was den Bauern vom Proletarier trennt, nicht mehr sein wirkliches Interesse. sondern sein illusionäres Vorurteil (ist) "(85) und daß unter diesen spezifischen Bedingungen die Bauern das Proletariat als Befreier begrußen. Der entscheidende Unterschied zu Rußland besteht nun gerade darin, daß diese erste Form bürgerlichen Eigentums noch nicht als herrschende existiert - Lenin diese erst herstellen will -, daß eben die „Überreste der mittelaiterlichen, halb-

79) Das Projekt Klassenanalyse schränkt seinen Versuch dieser Bestimmung nun wie folgt ein: .65) Diese Frage kann hier nur auf einer theoretischen Ebene diskutiert werden, die etwa dem Allgemeinheitsgrad in der Bestimmung der zwei allgemeinen Taktiken entspricht. Keinesfalls soll dargestellt werden, welche tatsächlichen historischen Bedingungen in Rußland die politische Form nach der Revolution bestimmt hätten. "(Leninismus, S. 180 )

80) Leninismus. S. 180 (Hervorh. d. Verf.)

81) Ebd.. S. 181

82) Die eklatante Krise des Parzelleneigentums findet für Marx mit Louis Bonaparte noch einmal eine reaktionäre Scheinlösung.

83) Karl Mars: Bürgerkrieg in Frankreich, erster Entwurf, MEW, Bd. 17, S. 551

84) Ebd.

85) Ebd..S. 552 
feudalen Einrichtungen noch so unendlich" (86) sind (87). Dieser wesentliche Unterschied wird vom PKA nun mit einer einfachen Behauptung unter den Tisch gewischt:

„Die Lrrichtung der Kommune ist auch in Landern noglich, in denen die vorburgerliche Produktionsweise noch eine gewisse Ausdehnung hat und die Bourgeoisie ilme Klassenhersehati noch nicht errichte that" $(88)$.

Nur durch diese Verdrehungen können sie Marx unterschieben, allgemein die ,,notwendige Form“ des Übergangs für ,unentwickelte Länder" überhaupt „,bestimmt“" zu haben (89).

Die zweite grundlegende Verkürzung des Problems, die das PKA sich in der Commune-Interpretation leistet, ist, dak sie im Rahmen Marxscher Zitate dic eigene Formulierung einschieben:

„Wenn auch die Klassenkampte keinesuegs aufgehoben sind, so stellt doch dic Kommune als Diktatur des Proletariats die rationellste form dar, unter der sie sich abspieken konnen" $(90)$.

Danit wird der Eindruck suggeriert, als ob Marx jemals die Commune als ,Diktatur des Proletariats‘ bezeichnet hätte. Dal, dies Engels 1891 vorbehalten war, wird nicht erwähnt (91). Ebenso wird die Frage, warum Marx diesen Ausdruck nicht verwendet hat, obwohl er ihn längst kannte, nicht gestellt (92). Eine Antwort auf die Differenz von Marx und Engels in der Einschätzung der Commune könnte die Verwendung dieses Ausdrucks in der Marxschen Kritik des Gothaer Programms geben:

„Zwischen der kapitalistischen und der kommunistischen Gesellschaft liegt die Periode der revolutionären Umwandlung der cinen in die andre. Der entspricht auch eine politische Übergangsperiode, deren Staat nichts andres sein kann als die revolutionäe Diktatur des Proletariats" 193 ).

86) W. I. Lenin: Was sind dic ,Volksfreunde?, 1894, LW, Bd. 1, S. 293

87) Hier wird dic Bedeutung der vom Projekt Klassenanalyse in Leninismus, Anm. 188) bchaupteten Dominanz der ,isolierter Produktionsweise gerade auf dem Lande" deutlich (Leninismus, S. 108), vgl. oben S. 11.

88) Leninismus, S. 182, vgl. Lenins, ,noch so unendlich" mit „,noch eine gewisse Ausdehnung "des Projekts Klassenanalyse.

89) Der Grad der Enthistorisierung der Marxschen Communc-Einschätzung entspricht ctwa dem Enthistorisierungsgrad der Marxschen Analysen für dic Konstruktion von „Zwei allgemeinen Taktiken“. (Leninismus, S. 180, Anm. 65); vgl. oben S. 22

90) Leninismus, S. 181

91) „Der deutsche Philister ist neuerdings wieder in heilsamen Schrecken geraten bej dem Wort: Diktatur des Proletariats. Nun gut, ihr Herren, wollt ihr wissen, wie diese Dik tatur aussieht? Seht euch die Pariser Kommune an. Das war die Diktatur des Proletariats." (Friedrich Engels, Einleitung zu: Der Bürgcrkrieg in Frankreich, (Ausgabe 1891), MEW, Bd. 17, S. 625)

92) ,2. da1s der Klassenkampf notwendig zur Diktatur des Proletariats führt;" (Karl Marx, Brief an Weydemeyer, 1852, MEW, Bd. 28, S. 508)

93) Karl Marx: Kritik des Gothaer Programms, a. a. O., S. 28 
Der Übergang vom Kapitatismus zum Kommunisnus stand für das Pariser Prole tariat nicht auf der Tagesordnung. Marx gebraucht diesen Ausdruck jedoch explizit nur für diesen Übergang (94).

\section{Russische lassung der Commune}

Nimmt man die strenge Fassung des Begriffs der Diktatur des Proletariats bei Marx. so trifft diese als konkrete Aufgabenstellung in Ru(3land (1917) noch viel weniger zu als für Frankreich (1871). Lenin trägt in seiner Schrift "Staat und Revolution“ zur Verwischung des Marxschen ,Begriffs" der „Diktatur des Proletariats" bei, indem er zwischen den Bestimmungen des Übergangs vom Kapitalismus zum Kommunismus und den besonderen Bestimmungen der Commune schwankt und dadurch falsche Identitaten herstellt. Daruber hinaus liefert er uns noch seine spezifisch russische Version der ,Diktatur des Proletariats": ,die Diktatur des Proletariats aber, d. h. die Organisierung der Avantgarde der Unterdruckten zur herrschenden K'lasse" (95). Diese unzulässige Erweiterung des Marxschen Begriffs, der das Prole ta riat erst einmal auf einen Teil dieser Klasse und zwar im Leninschen Sinne auf die Minderheit reduziert, wird von Lenin sogar noch bis zu der Möglichkeit nur einer einzigen Person ausgedehnt: „Dath in der Geschichte der revolutionären Bewegungen durch die Diktatur einzelner Personen sehr oft die Diktatur der revolutionären Klassen zum Ausdruck gebracht, getragen, vermittelt wurde, das bezeugen die unwiderleglichen Erfahrungen der Geschichte "(96) und „Deshalb gibt es entschieden kemerlei prizipiellen Widerspruch zwischen dem sowjetischen (d. h. dem sozialistischen) Demokratismus und der Anwendung der diktatorischen Gewalt einzelner Personen" (97).

94) Das Problem der Übergangsperiode bei Marx soll hier nicht diskuticrt werden. Wir wollen jedoch darauf hinweisen, dats bei Marx an keiner Stelle der Begriff der ,Diktatur des Proktariats" auther als in dieser abstrakten Algemeinheit verwendet worden ist. In dieser historisch unvermittelten form drückt die allgemeinste Bezeichnung für die Negation der bürgerlichen Gesellschaft inhaltich wenig aus. Marx kann mit diesem Begriff keinerlei allgemeines Programm für den Übergang unterschoben werden. Wie weit seine Verallgemeinerungen der Erfahrungen der Commune selbst noch verallgemeinert werden können. mübte erst kritisch nachgewiesen werden. Nachdem mit diesem Begriff .. seit der russischen Revolution beliebiges Schindtuder getricben worden ist - wozu Lenin einen "wesentlichen Beitrag geleistet hat mula auf die Unbestimmtheit dieses Marxschen Begriffes deutlich hingewiesen werden.

95) W. I. Lenin: Staat und Revolution. 1917. LW. Bd. 25. S. 475

$96)$ W. I. Lenin: Die nächsten Aufgaben der Sowjetmacht, 1918, LW, Bd. 27. S. 258

97) Hbat. S. 259. Doch! Freie bewleßste Assoziation der Produzenten und Diktatur einzelner Personen schlielst sich gegenseitig aus. Lenin nimmt mit diesen Formulierungen die idcologische Rechtfertigung der Diktutur der Einzelperson Stalin vorweg, indem er dise Form als noch subsumierbar unter dic Bezeichnung Diktatur des Proletariats erlaubt. Mit der Marxschen oder auch der Engelsschen Verwendung dicses Begrifts hat die Leninscho Interpretation wenig mehr zu tun. Ebensowenig wie die konkrete Stalinsche Diktatur noch etwas gemeinsam hat mit ., revolutionärer Diktatur des Proletariats" in Marxschen Sinne! Die Vielfalt der Verwendungsmöglichkeiten, die Lenin dem Marxschen Begrift zumutet, raubt diesem Begriff seinen ursprünglichen Sinn, fadit ihn letztlich zu cinem bloben rhetorischen Instrument verkonmen. 
Diese wesentliche Differenz der russischen Version Lenins von der Diktatur des Proletariats zur westeuropäischen Version von Marx und Engels wird vom PKA unterschlagen (98)! Sie gehen in der Folge ungerührt selbst noch über die widersprüchlichen Äuf̉erungen Lenins hinweg: "Dik tatur des Prolctariat". .Dik tatur des Proletariats und der armen Bauern " bzw. "Der Staat ist das Organ der Herrschaft einer Klasse.... Herrscht das Proletariat, handelt es sich um den proletarischen Staat, das heißt um die Diktatur des Proletariats", "Diese neue Staatsmaschineric wurde von der Pariser Kommune geschaffen, und einen "Staatsapparat vom gleichen Typus stellen die russischen Sowjets der Arbeiter. Soldaten-und Bauerndeputierten dar"(100) und "die Übernahme der gesamten Macht durch die Bolschewiki" (101).

Für das PKA stellen sich hier keine Probleme. In der Folge verläuft für sie die russische Entwicklung unter dem für Rußland inhaltslosen Allgemeinbegriff der "Diktatur des Proletariats". Dadurch sichern sie sich neben der für DKP-Linke unerläßlichen Dogmentreue die Anwendungsnöglichkeit der Methode ihrer Kritik: Die enthistorisierten Bestimmungen von Marx über die Commune in der Form der Engelschen Bezeichnung als „Diktatur des Proletariats“ können jetzt als Maßstab gegen die konkrete Taktik Lenins (in ihrer literarischen Formulierung) gewendet werden. Die Frage, wieweit Lenins widersprüchliche Außserungen den Versuch darstellen, die widersprüchliche russische Realität zu fassen und wieweit ihm das trotz unklarer theoretischer Formulierung gelingt, wird nicht gestellt bzw. nur verkürzt auf der Grundlage der einma! behaupteten Dominanz des Kapitals. Statt Lenin zu retten, wo er revolutionäre Erbschaft ist, wird er hier vom PKA auf den Hund gebracht. Lenin war wesentlich praktischer Revolutionär und nicht Marxphilologe! Damit gerät den ,DKP-Literaten" aus dem Blickfeld, dałs durch den imperialistischen Krieg für Lenin die Frage nach dem Brechen des schwächsten Gliedes verbunden ist init der Hoffnung der unmittelbar bevorstehenden westeuropäischen Revo-

98) Das Projekt Klassenanalyse weicht gerade an der für dic Neue Linke spannenden Frage aus: Inwieweit stellt die UdSSR in Kontinuität seit 1917 ,reaten Sozialismus“ dar? Obwohl es das Dogma der Dreicinigkeit (Marx, Engels, Lenin) aller moskautreuen kommunistischen Parteien in Frage stellt -.. wenngleich selbst dogmatisch - und dadurch der "distinkten Klassenpartei" DKP keine grobe Freude bereitet, so lälst es doch deren Allerheiligstes ungeschoren: ,,Wenn es irgend ein Dogma gibt, das als das Grundprinzip der bolschewistischen Politik bis zum heutigen Tag angesprochen werden kann, so ist es das von Lenin aufgestellte, wonach seine Partei als Regierungsmacht die „Diktatur des Prolctariats" organisatorisch und gleichsam organisch verkörpere." (Maximilian Rubel, Marx/Engels: Die russische Kommune - Kritik eines Mythos, München 1972, S.323). Es zeigt sich an dieser Stelle, wie den selbsternannten literarischen Repräsentanten der DKP Schraiken gesetzt sind, die sie beim besten Willen nicht überspringen können, wic ihr politisches Bekenntnis den Rahmen ihrer theoretischen Analyse begrenzt.

99) W. I. Lenin: Werden die Bolschewiki die Staatsmacht behaupten? LW, Bd. 26, S. 88

100) Ebd., S. 85

101) Dic Unklarheit Lenins verweist hier schr klar auf seine Schwierigkeit, mit dem Begriffsinstrumentarium entwickelter Länder dic unentwickelte russische Wirklichkeit in Griff zu kriegen. Dabei greift er zu willkürlicher Inhaltsveränderung der Marxschen Begriffe, die dann im unterschiedlichen Maße die Funktion erhalten, die russische Wirklichkeit zu mystifizieren. 
lution (102). besonders der deutschon (103). (Nur aulermold dieser Situation wird eine nochmalige Auseinandersetzung der russischen Marxisten mit der Marxschen Staats- und Revolutionstheorie verstandlich, und nicht aus der Auseinandersetzung mit theoretischen Positionen des Opportunismus.)

Das PKA begreift daher auch nicht den Zusammenhang der Schriften ,.Staat und Revolution" und "Werden die Bolschewiki die Stadsmacht behaupten? " bzw. deren spezifischen Inhalt. Sieht Lenin vor 1914 nur eine ,demokratische Diktatur der Arbeiter und Bauernschaft", so hält er 1917 die ..Diktatur des Proletariats" bzw. einen proletarischen Staat fur moglich, dessen Verhäitnis zur Bauernschaft das einer, wohlfeilen Regierung " (104) ist. Nur wenn Lenin auf die Unterstützung der europäischen Revolution rechnet, kann er versuchen, die ,Diktatur des Prole tariats" anzugehen. Diese Einschätzung vom Verlauf der europäischen Entwicklung ist somit entscheidend für die Politik der Bolschewiki. Das PKA versucht nichtein einziges Mal diesen Zusammenhang zu reflek tieren ( 105 ).

In ..Werden die Bolschewiki die Staatsmacht behaupten? "konkretisiert Lenin die Aufgaben für die ,Diktatur des Proletariats", d. h. fü die Stadt (,Arbeiterkontrolle" und "Rechnungstührung"). Fur das Land fehlt diese Konkretisierung weitgehend. Das PKA führt seine folgende Kritik mit dem Matsstab der Pariser Comnune, als hätte die Verwirklichung der Commune tatsächlich auf der Tagesord. nung gestanden. Dals die Besonderheiten Rulslands Modifikationen notwendig machen, gestehen sie zwar abstrakt zu (106), ohne jedoch zu versuchen, auf die Beson. derheiten einzugehen. Da die Kritik nicht versucht, die konkreten historischen Möglichkeiten herauszuarbeiten und von da aus die praktisch konkrete Politik der Bolschewiki einzuschätzen, bekommt sie trotz scheinbar radikaler Resultate einen Legitimationscharakter.

Das PKA kritisiert an Lemins Verstiadnis von der so/ialen Emanzipation des Proletariats bzw. seinem Commune-Verständnis, dats er den Inhalt der sozialen Emanzipation - die bewulkte Herstellung der Gesellschaftlichkeit der Arbeit durch die frei assoziierten Produzenten gegenüber der politischen Form (als Mittel) vernachlässigt. Als Folge davon begreift er die organisatorische Konkretion der sozialen Emanzipation des Proletariats nicht. Für das PKA wäre dies die .,Verschmelzung der verschiedenen Organisationen der Arbeiterklasse, von Parteı. Sowjets und Gewerkschaften zu einer Einheit" (107). Wie das konkret auszusehen hätte, wird in dieser einzigen Organisationskritik des PKA nicht ausgeführt. Ohne auch nur einmal versucht zu haben, den Leninschen Parteitypus organisatorisch-po-

102) ,Wenn wir, die bolschew istische Partei, das ganze Werk allein in unsere Hande genommen haben, so haben wir das in der éberzeugung getan, dals die Revolution in allen Ländern heranreift ... Unsere Rettung aus all dicsen Schw lerigkeiten ist, wie gesagt die Revolution in Europa." (W. I. Lenin. Aullerordentlicher 7. Parteitag der KPR (B). LW. Bd. 27. S. 811

103) .Das ist eine Lehre, denn es ist eine absolute Wahrheit. dato wir ohne de deutsche Revolution verloren sind -" (E bd., S. 85)

104) Leninismus, S. 480

105) Dats er eine wesentliche Rolle spielt, wird sinmal indirekt angedeutet: ,.Aut der andren Seite verzogert sich die Revolution in Westeuropa ... " (F.bd.. S. 520)

106) Vgl. Leninismus, S. $474 \mathrm{f}$.

107) Ebd., S. 550 
litisch einzuschätzen, ohne den Charakter der Räte und der Gewerkschaften em/uschätzen im Zusammenhang mit der konkreten Situation, kann dies auch gar nichı geleiste t werden. Die Frage der Vermittlung von Stadt und Land ble ibt vollständig ausgeschlossen. Die Kritik der Industriepolitik und der Agrarpolitik stehen unvermittelt nebeneinander.

Ausgangspunkt der Kritik des PKA nach dem Sieg der Ok1oberrevolution ist die allgemeine Aufgabenstellung der sozialistischen Revolution: Etablierung der bewukten freien Assoziation der Produzenten (108). Für den Aufbau des Suzialismus in unentwickelten Ländern stellen sich dabei jedoch zwei allgemeine Aufgaben:

1. Freie Assoziation der Produzenten im Bereich der ,organisierten Arbeit", d. h. freie Entfaltung der gesellschaftlichen Potenzen der Arbeit und Beseitigung der Verschwendung gesellschaftlicher Arbeit (Arbeitszeilverkürzung).

2. „Den Antagonismus zwischen stältischen und ländlichen Produzenten, zwischen isolierter und organisierter Arbeit zu beseitigen" (109). Das soll geschehen durch den Aufbau kollektiver Produktion auf dem Lande.

Aus dem Widerspruch zwischen organisierter und isolierter Produktion folgt für die erste Zeit, dak die Gesellschaftlichkeit der Arbeil noch gegen die Produrenten entwickelt werden muk, ,die gesellschaftlichen Funktionen müssen also ihnen gegenüber eine relative Selbständigkeit erhalten“. Wobei den „assoziierten Producenten der großsen Industrie, konzentriert in ihren Exekutivorganen, die allgemein geselischaftliche Leitung zu(kommt)" (110).

Bei der Frage nach der Möglichkeil, kollek tive Produktion auf dem Lande zu entwickeln, stotien die Genossen nun plotzlich auf Hinweise von Marx (111) und Engels (112) über die russische Dorfgenreinde. Dabei geht es ihnen aber nur noch um den „Assoziationstrieb", den sie ,allerdings (als) einen günstigen Ausgangspunk 1 für die Bauernpolitik" begreifen. Die entscheidende Fragestellung von Marx für dic russische Dorfgemeinde die wiroben ausfuhrlich erörtert haben hlebther eben falls undiskutiert. Nach 1917 wäre es allerdings auch zu spät gewesen, Lenin aul diese Alternative aufmerksam zu machen. Das hätte am Gegensland der Klassenanalyse getan werden müssen. Dort wird vom PKA jedoch nur lapidar festgestellt, daks Lenin ,die Tatsache ... zum Anlars (nimmt), von den Überbleibseln der Vor-Reformzeil zu abstrahieren"(114). An keiner Stelle wird jedoch ausgeführı, wie er an die „Überbleibsel“ hätte anknüpfen sollen. Die Kritik des PKA nach 1917, die Lenin seine Zustimmung zur Aufteilung des Grolsgrundbesitzes ankreidet, trifft

108) „An Stelle des durch Sachen vermittelten Zusammenhangs der Individuen tritt die bewurste gesellschaftliche Assoziation der Produzenten, an Stelle der naturwüchisen I ntstehung der gescllschaftlichen Formen der Produktion trit1 die bewutste Organisation, der geplante Aufbau der neuen Gescllschaft." Ebd., S. 522)

109) Ebu., S. 530

110) Ebd., S.531. Also muls dic Gesellschaftlichkeit nur gegen die isolierten Produzenten durchgesetzt werden und nicht gegen alle ,unmittelbaren Produzenten"?

111) Leninismus, S. 532, Fufsnote 7)

112) „Das Vorhandensein eines starken Assoziationstriebes im russischen Volk, "1 riedrich Engcls: Soziales aus Ruksland, MEW, Bd. 18, S. 561, zit. nach Leninismus, S. 532)

113) Ebd., S.532

114) Leninismus, S. 92 
Lenin nicht, da dieser durch die falsche Bauernpolitik vor der Revolution 1917 dann gar keine andere politisch-organisatorische Möglichkeit mehr hatte, als das Programm der Sozialrevolutionäre zu übernehmen.

Dic Resultate der bolschewistischen Bauempolitik werden vom PKA richtig alsammengefalst: .Nivellierung des Dorles angunsten der Mittelbauemschatt" (115). Dicse lntwichlung führte dann aur ,Nenen Okonomischen Politik', die ,in ihrem Ken nur cinc Politik der maximalen Zugestandnisse an die kleinbürgerliche Bauemschafl" war (116). Im Bereich der organisierten Arbeit läuft die Entwicklung ähnlich verhängnisvoll: Gegenüber dem Vorschlag des PKA Verschmelzung von Partei, Gewerkschaften und Räten ,hält Lenin aber unbedingt an dem Führungsanspruch der Partei fest und fordert die Unterordnung der Gewerkschaften und Betricbskomitees unter die allgemeine Leitung der Sowjetmacht"(117). Das PKA kann hier konstatieren, dafs Lenin die eigentlichen Klassenorganisationen von der Leitung ausschlietst. .Damit erscheinen die gesellschaftlichen Aufgaben aber nicht als Resultat bewulkter Vermittlungsprozesse zwischen den assoziierten Produzenten selbst, sondern als vorausgesetzte Erkemntnis der Avantgarde, die es lediglich auszuführen gilt" (118). Als (Is sache datür erkennt das PKA die schon für so viele Fehler Lenins verantwortliche Unterschätzung der Massen. „Ein-Mann-Leitung" und ,Militarisicrung der Arbeit" verstärken weiter die Tendenz der Verselbständigung der Leitungstunktionen. (Die Subbotniks erweisen sich gegen diese Tenden als hilflos) (119). Da ihre Kritik widerum nicht nach den historischen Moglichkeiten sucht, triff sie Lenin nur sehr cingeschänkt. Als düsteres Fazit ihrer Analyse fart das PKA cusammen:

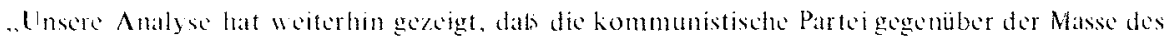
Proktatials und der Batuernschaft weitgehend verselbstindigt ist. Auf (irund dieser Situation ist es fraglich, ob uberhapt noch ane Bewegungstorm gefunden werden kann, die eine gewaltsane Losung der Widerspruche verhindert kann" (120).

Wird mit diesr Formulierung ein richtiger Hinweis gegeben, dah der Stalinismus seine Wurzeln in der falschen Politik Lenins bzw. der dadurch beeinflutsten sozialen Entwicklung hat, so wird andererseits die durch den geschichtlichen ..Zufall der Person" Stalins entscheidend geprägte Form der ..gewaltsamen Lösung" und die Person selbst historisch-deterministisch freigesprochen:

.Das Problem, dath die Transfomationsperiode in der Sowgetunion nach dem Tode Lenins micht das rationclle Zw ischenstadium darstellte calso nicht Sozialisnus bzw. Diktatur des Proletariats im Sinne der Commune? d. Vert.), in dem der Klassenkampt seine verschiedenen Phasen aut rationellste and humanste Weise durchlation komnte, kamn deshalb keineswegs subjektiv aus

$115)$ libd.. S. 648

116) libd.. S. 651

117) Ebd.. S. 550. Apologetische Ubernahme der ldentitatsbelauptung der Bolschewiki: Bolschewiki $=$ Sowjetmacht.

118) Leninismus, S. 550

119) Es ist unserer Meinung nach Humbug, Lenins Konzeption der ,Ein-Mamn-Leitung" ausschlietilich aus seiner fihlerhatten Marvezeption zu erklären. wenngleich das Projekt Klassenanalyse das Resultat dieser angeblichen Konsequenz richtig formulient.

120) Leninismus, S. 684 
dem ,Abueidhen" einzelner Personen oder (iruppen vom, richtigen Weg" erklart werden" 121 )

Die Marxsche allgemeine Einschät/ung der Wirkung auf Personen auf den allgemeinen historischen Verlauf, dak nämlich, der ,Zufall' des Charakters der Leute, dic zuerst an der Spitze der Bewegung stehen" (122) beschleunigend oder hemmend wirken können, verweist am Beispiel Stalin darauf, welch grauenhafte Dimension so ein ,Zufall ${ }^{6}$ einer Person annehmen kann. Die Kritik an Stalin und seiner Politik mit einem kruden okonomistischen Determinismus unter den Tisch fallen zu lassen, kann unserer Meinung nach nur aus dem politischen Opportunismus des PKA erklärt werden zumal die Methode ihrer Kritik an der Person Lenin das gerade Gegenteil darstellt. Das PKA fallt mit der Apologie des Stalinismus hinter das bereits erreichte fast offizielle Niveau der Stalinismus-Kritik in der Sowjetunion zurick, die konstatierte:

.Durch scine Verbrechen hat Stalin die Volksbewegung zum Sorialiomus und zum Kommunisnus aut der ganzen Welt und in der Sowjetunion nicht be schleunigt, sondern behindert, er hat sie nicht gefordert, sondern verlangsamt. In mancher Hinsicht hat er diese Bewegung gerade nach rückwarts geführt" (123).

Wenn das PKA Lenins Schriften zu Ende gelesen hätte und nicht mit der Bemerkung, dali diese wegen, ,seiner schweren Krankheit" keinen, ,systematischen und umfassenden Charakter (mehr) haben" (124), beiseite gelegt hätte, wäre es zum weiteren Resultat gekommen, dak der alte Staatsapparat, entgegen den Weisungen von Marx und Lenins ,Staat und Revolution" nicht zerschlagen, sondern ubernommen worden ist (125), dats sich nich1 nur die Räte verknöchert haben, sondern auch die Partei, und daß also sich innerhalb der Partei auch die Führung gegen die Masse verselbständigt hat (126). Dieser Prozets innerhalb der Partei im Zusammenhang mit ihrem Funktions- und Aufgabenwandel nach dem Sieg der Oktoberrevolution wird vom PKA auch nicht nur an einer Stelle erwähnt bzw. versucht zu analysieren. Wie überhaupt jede, auch die leiseste Kritik am Organisationstypus unterbleibt. Das „Testament", in dem Lenin Stalins Abberufung fordert, hat damit natürlich auch keinen ,systematischen Charakter".

121) Leninismus, S. 684

122) Karl Marx: Bricf an Kugelmann, 1871, MEW, Bd. 33, S. 209

123) Roy A. Meduedew: Dic Wahrheit ist unsere Starke Geschichte und folgen des Stalinismus, I"rankfurt a. M. 1973, S. 8

124) Leninismus. S. 673

125) "Wir haben den alten Staatsapparat abernommen, und das war unser Unglück." (W. I. Lenin, Referat auf dem IV. Kongreds der Komintern, 1922, LW, Bd. 33, S. 414), vgl. W. I. Lenin: Wie wir die Arbeiter- und Bauerninspektion reorganisieren sollen (a. a O., S. 468): ,Lnser Staatsapparat ist, mit Ausnahmo des Volkskommisæariats für auswärtige Angelegenheiten, zum grösten Teil ein Überbleibsel des Alten, an dem nur zum geringeren Teil einigermatsen crnsthafte Veränderungen vorgenommen worden sind. Er ist nur äuberlich leicht übertïncht worden, im übrigen aber stellt er etwas ganz typisch Altes aus unserem alten Staatsapparat dar."

126) "... und unscrer ganzen Bürokratic, der Sowjet- wic der Parteibürokratie, im höchsten Grade zupats kommt. Nebenbei bemerkt, Bürokraten gibt es bei uns nicht nur in den Sowjets, sondern auch in den Parteiinstitutionen." (W. I. Lenin: Lieber weniger, aber besser; a. a. O., S. 482) 
Das Resultat seiner Analyse wird von ihm an Ende nicht auf den Begriff gebracht. Verselbständigung der Partei gegenüber den Massen ist nur die Erscheinungsweisc datür. dak dic Commune nicht etabliert werden konnte, weder als ,organisiertes Mittil der Aktion" noch als "rationelles Zwischenstadium", daß also weder Form noch Inhalt der sozialistischen Revolution, der Diktatur des Proletariats, realisiert werden konnten. Obwohl das PKA dieses Resultat der „Politik der russischen Kommunisten" (127) mehr oder weniger explizit erfakt, hält es an der Bezeichmung ,Diktatur des Proletariats" für die russische Gesellschaft von 1923 fest. Lis drïkt sich damit um dic Frage: Wenn weder Form noch Inhalt der Diktatur des Proletariats (Commune) eingelost ist, die Tendenz sogar weiter in die entgegengesetzte Richtung verläuft, kann diese Gesellschaft dann noch als Diktatur des Proletariats verstanden werden, bzw. was stellt die russische Gesellschaft sozial und politisch dar?

Obwohl das PKA konstaticren muß, datì als Resultat bolschewistischer Politik eine Verselbstandigung von gesellschaftlicher Leitung und Produzenten eingetreten ist, die an der Oberflache als Verselbständigung von Partei und Massen erscheint, wagt es nicht ıu formulieren, dati dieses Resultat ein neues, spezifisch russisches Herrschafts- und Knechtschaftsverhaltmis bezeichnet, in dem die Gesellschaftlichkeit der Arbeit nach wie vor nicht durch dic bewukte Aktion der frei assoziierten Produzenten, sondern immer noch hinter deren Ricken wenn auch ganz anders als in Kapitalismus und damit auch mehr oder weniger gewaltsam gegen sie hergestellt wird. Obwohl also weder Form noch Inhalt der Commune realisiert ist, bencmut das PKA in der Einleitung die Sowjetunion als das Land, in der ,das Proletariat $/$ um erstemmal dauerhaft gesiegt hat " (1 28).

Dic gewaltsame äufierst irrational und inhumane Herstellung der Gesellschaftlichkeit der Arbeit in der Form des Stalinismus wird von ihm hier als ,Auswiichse und dogmatische Verzerrungen während zwanzig Jahren sowjetischer Politik"(129) apologetisch unschricben (130). Die Methode, Widerspriiche in der abstrakt theoretischen Analyse nicht auf den politischen Begriff zu bringen, sondem sie noch im Gegenteil mit der Subsumtion unter einem abstrakten Allgemeinbegriff za vertuschen, zeigt in diesem Zusammenhang wie der politische Opportumismus des PKA in theorctischen Opportunismus tumschlagt.

In der gleichen opportunistischen Weise versucht das PKA .. nachdem es abstakt den rationalen Kem des Antikommunismus im Nachkriegsdeutschland als "das in der Arbeiterklasse vorhandene Bewuthtsein von der dogmatischen Verzerrung eimzehner Seiten der Politik der Sowjetunion"(1.31) umschrichen, danit also den Zusammenhang der Entwicklung der Sowjetunion und der internationalen Arbeiterbewegung konstatiert hat der DKP zu versicheni, dak sie ..ebenso wie die

127) Leninismus, S. 669

128) libd.. S. 17. Viclleicht erfolgte der Sieg erst nach 1923?

129) Leninismus, S 17. Wer dic historische form und den historischen Inhalt des Stalinismus der fü die soziale Emanzipation der russischen Produzenten, wie für die internationate sozialistische Arbeiterbewegurg cine gramenvolle Niederlage bedeutet als ..dogmatische Verzerrung" verniedicht, verliert jede politische und theoretisch-wissenschaftliche Claubwürdigksit.

131) Lenintsmus, S. 23 
andern kommunistischen Parteien ein Bewußs tse in davon hat, dafs es in ihrer zuruckliegenden Entwicklung nicht nur Fehler. sondern auch dogmatische Verzerrungen gegeben hat, deren Auswirkungen mit Erfolg bekämpft wurden und werden" (132) und dak sie trotz ,kleinburgerlichem Haß" von .,intellektuellen Weltbeglickem" (133) die ,wirkliche Arbeiterbewegung" (134), genauer deren .ffortgeschrittenster Teil" ist.

Nach diesem Bekenntnis verwundert es nicht, wenn es im Abschnitt über die Kommunistische Internationale zu dem Resultat kommt. dafs trotz deren unterschiedlicher Aufgabenstellung gegenüber der I. Internationale Lenin die angebliche Marxsche Unterscheidung in .Zwei allgemeine Taktiken" beibehält. dar. jedoch ..trotz der Appelle an die Flexibilität ... eine so verfafite Kommunistische Internationale zunächst sektiererische Tendenzen unter den Kommunisten in den Metropolen bestärken (muR) ${ }^{*}(135)$. Es wird nicht erwähnt. daß die Kommunistische Internationale einen Prozeß einleitet, der einen um den revolutionären Gehalt beraubten Sektionstypus Leninscher Partei hervorbrachte. der, vermittelt durch organisatorische Unterordnung unter die russisch dominierte Zentrale (Exekutivkomitee der Kommunistischen Intemationale $=$ EKKI) das Ziel der sozialen Emanzipation der eigenen Arbeiterklasse zugunsten der Interessen des ..Vaterlan des aller Werktatigen“ erst einmal aufgab.

Die Niederlage der europäischen Arbeiterbewegung, besonders der italient. schen, deutschen und spanischen im Faschismus. ist von der verhängnisvollen Politik der Kommunistischen Internationale bzw. deren jeweiligen Sektionen nicht zu tremnen. Wer diese (jeschichte einfach ausklammert, versucht die Erfahrungen und damit auch die Erbschaft dieser Geschichte vergessen zu machen. die u. a. noch darin besteht, daß die moskautreuen kommunistischen Parteien noch immer keine „,selbständige Klassenpolitik des Proletariats“ (136) betreiben, und dar speziell für die BRD die ,zunächst sektiererischen Tendenzen“ der Kommunistischen Internationale die KPD (jetzt DKP) zu einer einflußlosen Sekte haben verkommen lassen: zu einer Sekte, deren ...point d' honneur" die Glorifizierung des .,realen Sozialismus" in der Sowjetunion und in den Volksdemokratien ist und deren ,Schibboleth" im Stamokap besteht.

Diese Geschichte und ihre Erbschaft auszuklammern, bedeutet den Verzicht auf ,ehrlich-revolutionäre“ (137) Politik, bedeutet das opportunistische Anhängen an eine kommunistische Tradition, die ihre Unfähigkeit und Unmöglichkeit, die Emanzipationsinteressen der Arbeiterklasse ,distinkt "zu vertreten, deutlich unter Beweis gestellt hat.

Aus dem Verhältnis von ..Hinwendung zur DKP" und theoretischer Arbeit des PKA wird ein Zusammenhang deutlich, der darauf hinweist, daß eine abstrakte Kapitalrezeption - mag sie auch noch so gründlich sein - wenn sie ohne Vermittlung zu historisch konkreten Klassenkämpfen bleibt, nur selbst als dogmatischer 132) Ebd.. S. 29

133) Ebd.. S. 27

134) Ebd.. S. 25

135) Ebd.. S. 763

136) Ebd... S. 24

137) Karl Marx: Brief an L. Kugelmann vom 23. 2. 1865, MEW, Bd. 31, S. 452 
Mafistab funktionalisiert wird - notwendig zum Verlust der politisch-revolutionären Dimension in der sozialistischen Theorie führt - im schlimmsten Falle zu politi. schem Opportunismus auf Basis von Bekenntnissen. Hat die Hinwendung zum politischen Opportunismus stattgefunden, schlägt dieser selbst noch in theoretischen Opportunismus um.

Was Marx als das ..allemotigste" fuir enne revolutionäre deutsche Arbeiterbe. wegung begreift, daf die Arbeiter ..selbständig gehn" lernen, wird durch dieses theoretische und politische Vernalten verhindert (138).

\section{Die Zusammenbruchstheorie des Projekts Klassenanalı'se}

Im theoretischen System des Projekts Klassenanalyse nimmt die Betonung des unvermeidlichen Zusammenbruchs der kapitalistischen Produktionsweise einen zentralen Stellenwert ein. Danach erzeugt ..die kapitalistische Produktionsweise ... mit der Notwendigkeit eines Naturprozesses ihre eigene Negation... Die wachsende Unangemessenheit der entwickelten Produktivkräfte zu den kapitalistischen Formen der Produktion drückt sich in zunehmenden Konflikten und Krisen aus" (139). Dieser Auflösungsprozef ist als solcher bereits identisch mit der Vorbereitung einer sozialistischen Gesellschaft. ..Das .strategische Ziel", auf das die Entwicklung der bürgerlichen Cresellschaft notwendig hintreibt, ist die Assoziation freier und gleichgestellter, nach einem gemeinsamen und rationellen Plan bewußt tätiger Produzenten" (140). Zwar unterliegt vorläufig das Bewufitsein der Arbeiter dem sachlichen Schein der gesellschaftlichen Verhältnisse, es akzeptiert die Formen der kapitalistischen Gesellschaft als Naturformen, aber mit den aus den Widersprüchen des Produktionsprozesses resultierenden Konflikten schärft sich das Klassenbewulstsein der Arbeiter. .Im zeitlichen Ablauf ergibt sich demnach eine mehr oder weniger vollständige Herausbildung von Klassenbewufstsein. Da der Entwicklungsprozefs der Arbeiterklasse dadurch charakterisiert ist. dafs bestimmte Teile der Klasse sich schon zur Einsicht in ihre Lage emporgearbeitet haben, wenn andere noch die Herrschaft des Kapitals als natumotwendig hinnehmen, folgt nun auch, dak gerade die bewußtesten Teile des Proletariats in den Klassenorganisationen vereint sind. Die Avantgarde der Klasse muß sich darüber hinaus eine Form geben, in der sie z.u einheitlichem Handeln fähig ist - die proletarische Partei. Diese Organisationsform ist also Resultat der Entwicklung des Klassenhewuktseins" (141).

138) V'gl. Karl Marx: Brief an J. B. Schweitzer vom 13.10. 1868. MFW. Bd. 32. S. 570

139) J. Bischoff: Zu einigen Grundfragen revolutionärer Taktik. in: SoPo 14/15, S. $104 \mathrm{f}$. - Wir beziehen die Texte von J. Bischoff, einem der Initiatoren des Projekts Klassenanalyse. in unsere Kritik ein.

140) Ebd.

141) Projekt Klassenanalyse: Klassenbew usstsein und Partei. Berlin 1972, S. 125 f. Dic Ausführungen an diesem Punkt sind widersprüchlich. Wird der Konstitutionsprozers von Klassenbewufitsein einerseits logisch au der allgemeinen Lntersuchung deduziert, das "Resultat" ist die Form der proletarischen Partei, so betont man wenige Zeilen später: Es sei methodische Verwirrung, ..auf der Abstraktionsebene de's allgemeinen Begriff's des Kapitals und der Lntersuchung der darin eingeschlossenen Bildung des Bewulstseins die Partei als logisch notwendiges Vermittlungsglied einzuführen". Ebd., S. 126 
In der Theorie des Projekts Klassenanalyse gibt es also einen engen Zusammenhang zwischen einem notwendig, unvermeidlich seiner Auflosung zustrebenden gesellschaftlichen Prozers und dem proletarischen Bewufstsein. Revolutionäres Bewußtsein ist dabei gebunden an die okonomische Krise (142).

"Eine konsistente Konzeption revolutionärer Taktik ist . . an de wissenschaftliche Lntersuchung eines Stücks Zeitgeschehen gebunden." Dabei ist ..die gründliche Aneignung diescr Darstellung des allgemeinen Begrift's des Kapitals... die erste Stufe jedweder Ausarbeitung einer Konzeption revolutionärer Taktik"(143).

Das Projekt Klassenanalyse unterscheidet dabei zwischen Ländern mit unentwickelten und Ländern mit entwickelten kapitalistischen Verhältnissen. Bedingt durch die Ungleichzeitigkeit der kapitalistischen Entwicklung auf dem Weltmarkt. ..müssen zwei prinzipiell verschiedene Stadien der kapitalistischen Entwicklung und damit auch der Klassenstruktur unterschieden werden. Da diesen zwei verschiedenen gesellschaftlichen Zuständen eine prinzipielle Differenz der Konzeption revolutionärer Taktik entspricht, kann von zwei ,allgemeinen Taktiken" gesprochen werden“(144). Das Schwergewicht der Ausfüirungen liegt fur beide Taktiken auf dem

142) ..Sind die periodisch auftretenden Krisen wesentliches Moment in Konstitutionsprozet. proletarischen Bewubtseins und damit revolutionärer Situationen in einem Land. so die unterschicdlichen Auswirkungen dieser Krisen für das L̈bergreifen des revolutionaren Funkens auf anderc Nationen." Projekt Klassenanalyse: Zur Taktik der proletarischen Partei, Berlin 1972. S. 168

143) Bischoff, a. a. O., S. 107

144) Ebd., S. 109. Bischoff geriat hier mit seinem eigenen methodisch strengen Anspruch in Konflikt. Folgt man Bischoffs Argumentation immanent, so muls aus dem ..Kapital" revolutionare Taktik deduzierbar sein. Diesen Nachweis bleibt or schuldig. Vielmehr beruft or sich auf das Kommunistische Manifest: ..Beide Konzeptionen revolutionärer Taktik lassen sich also aus dem Manifest der Kommunistischen Partei ableiten. " (Ebd., S. 125). vgl. auch: Zur Taktik...".a.a. O., S. 170. Schlägt man jedoch die von Bischoff angegebene Textstelle im Manifest auf, sucht man vergeblich den theoretischen Ansatz für die angebliche Marx/Engelssche Unterscheidung von zwei allgemeinen Taktiken. Autierdem mübte Bischoff gemäls obigem Anspruch erklären, inwiefern das Kommunistische Manifest von 1848 eine Ableitung vom allgemeinen Begriff des Kapitals ist, von dessen systematischer Darstelllung man bei Marx wohl frühestens in den Grundrissen von 1857 reden kann.

Hinzu kommt, dałs Bischoff unterstellt, dals in Ländern mit unentwickeltem Kapitalverhältnis sich notwendig einc kapitalistische Entwicklung bis zur proletarischen Revolution vollziehen muß. Gerade gegen eine solche Midinterpretation seiner Theorie hat sich Marx jedoch ausgesprochen: .,Strebt Rubland dahin, eine kapitalistische Nation nach westeuropäischem Vorbild zu werden . . so wird es dies nicht fertig bringen, ohne vorher einen guten Teil seiner Batern in Proletarier verwandelt zu haben: und dann, einmal hineingerissen in den Wirbel der kapitalistischen Wirtschaft, wird es die unerbittlichen Gesetze dieses Systems zu ertragen haben... Das ist alles. Aber das ist meinem Kritiker zu wenig. Er muts durchaus meine historische Skizze von der Entstehung des Kapitalismus in Westeuropa in eine geschichtsphilosophische Theorie des allgemeinen Entwicklungsganges verwandeln, der allen Völkern schicksalsmäłig vorgeschrieben ist. . . Wenn mann jede dieser Entwicklungen für sich studiert und sie dann miteinander vergleicht, wird man leicht den Schlüssel zu dieser Erscheinung finden, aber man wird niemals dahin gelangen, mit dem Universalschlüssel einer allgemeinen geschichtsphilosophischen Theorie, deren gröbter Vorzug darin besteht, übergeschichtlich zu sein." Karl Marx: Brief an 
Ablaufen eines unvermeidlichen Prozesses, in den die Kommunisten ..Einsicht" gewinnen und damit beschleunigen konnen.

Bischoff bemerkt den daraus zwingend folgenden evolutionistischen Charakter seiner Theorie und glaubt allen Einwänden die Spitze abbrechen zu konnen:

.So wehr dav Beharen auf den notuendigen okonomiveten Bedingungen Bextandteil der Erarbeitung der Konzeption revolutionarer Taktik auf Basis des wissenschattlichen Soztalismus ist. io weng folgt darau cine ökonomistiche Auffassung, d. h. die The von cinem Automatisnus in der revolutionaren Entwicklung. der ich au den unverneidlichen Zusanmenbruch der kapitabstisehen Produktionsweise ergeben soll . . Von cinem blinden fertrauen auf den ökonomischen Prozete kann hier keine Rede sein, wo der Akzent auf der Beschleungung und der Abküzung des revolutionaren Prozénes licot" $(1+5)$.

Dieser Einwand Bischoffs überzeugt nicht: man kann keinen ..Akzent auf bloke Beschleunigung und Abküzung" legen, wenn der Prozer nicht ohnehin abläuft. Mit seiner Zusammenbruchstheorie reiht sich das Projekt Klassenanalyse ein in die Galerie des traditionalistischen, um das subjektive Moment der .,umwälzenden Praxis“" verarmen Marxismus. In diese Tradition gehören sowohl Kautsky und Hilferding wie auch die Bolschewiki Lenin und Bucharin (146). Von diesen bedeutenden

die Redaktion der .Otetchestwennyjke Sapiski". in: Marx Engels Worke (ALW) 19. S. $111 \mathrm{f}$

Das Konzept einer allgemeinen Taktik für unentwickelte Lander (Bundnispolitik unter der Fuhrung der Arbejterklassel. Wie es das Projekt Klassonanalyse vertritt ist auterdem historisch njeht haltbar. Die chinesischen und die vietnamesischen Revolutionäre setzten sich nicht aus Bauern unter der Fuhrung der Arbeiterklasse zusammen. In beiden Fälen waren in überwiegendem Malse Batern revolutionäres Subjekt.

145) Bischotì. a. a. O.. S. 117

146) Einige Zitate aus deren wichtigen Schritten zeigen die theoretische Verwandschatt.

. Wenn wir die Aufhebung des Privateigenthums an den Produktionsmitteln iür unvermeidlich halten, so meinen wir damit nicht, dals den Ausgebeuteten sines schönen Tages ohne ihr Zuthun die gebratenen Tauben der sozialen Revolution in den Mund flicgen wirden. Wir halten den Zusammenbruch der heutigen Gesellschaft für unvermeidlich. weil wir wissen. dats die ökonomische Entwicklung mit Naturnothwendigkeit Zustinde erzeugt. "welche die Ausgebeuteten zw ingen. gegen dies Privateigenthum anzukamplen." (K. Kautsky: Das Erfurter Programm, 13. Aut7. Stuttgart 1919. S. 106)

„Etwas anderes ist es, eine Notwendigkeit zu erkennen, etwas anderes, sich in den Dienst dieser Notwendigkeit zu stellen. Es ist ganz gut möglich, dat jemand, von dem schlichlichen Sieg des Sozialismus überzeugt, sich dennoch in den Dienst seiner Bekampfung stellt. Die Einsicht in die Bewegungsgesetze der Gesellschaft, die der Marxismus gibt, gew ährt aber stets cine Überlegenlejt dem, der sie sich zu cigen macht." (R. Hilferding: Das Finanzkapital. Frankfurt 1968. S. 201

..Aus dem Vorhergehenden ist ersichtlich, dak Marx die Lnvermeidlichkeit der UmwandIung der kapitalistischen Gesellschaft in die sozialistische einzig und allein aus dem ökonomischen Bewegungsgesetz der modernen Gesellschaft ableitet... Das ist hauptsachlich die materielle Grundlage für das unvermeidliche Kommen des Sozialismus." (Lenin: Karl Marx, LW, Bd. 21, S. 60)

,Wenn man von der historischen Notwendigkeit spricht, so meint mandarunter . . was unvermeidlich sich aus dem Gang der gesellschaftlichen Entwicklung ergibt." (N. Bucharin: Theorie des Historischen Materialismus - Geneinverstandliches Lehrbuch der marxistischen Soziologie, Hamburg 1922, S. 42) 
Theoretikern der II. und III. Internationale steht Lenin jedoch weit uber deren objektivistischem Marxismus. In seiner revolutionären Politik dominierte immer wieder das voluntaristische Moment der Praxis. obwohl es im Gegensatz zu seiner objektivistischen Theorie zu siehen schien. Besonders deutlich wurde dies in den Aprilthesen, als sich Lenin gegen die Parteimehrheit stellte. die in Rufsland nur eine klassische bürgerliche Revolution fur historisch moglich hielt.

\section{Der ..anschauende Waterialismus" des Proiekts Klassenanalyse}

Der Wissenschaftliche Sozialismus ist fü Bischoff ..nichts anderes als der ideelle Ausdruck dieses materiell-ökonomischen Prozesses" $(147)$. Heute muf konstatiert werden.

.dath w ir nach einer Periode orneuter Vartlachung und dogmatischer Verzerrung des Wissenschattlichen Sozialimus wiederum ror derselben Aufgabe der Wiederherstellung der revolutio-

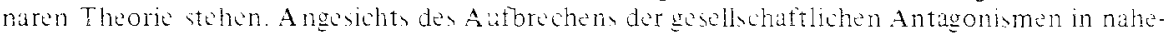
zu allen kapitalintiveken Liandern iat die Wiedergewinnung der w irkliehen Einsicht in die hisoriwhon Bedingungen der soziakn Emanzipation der arbeitenden Klasse die unabdingbare Vorausstzung. um gestutzt auf sine adaquate honzeption revolutionarer Taktik jede politische und okonomische Bewegung in Richtung auf die vollstandige Emanzipation der Arbeiterklasse beschleunigen zu konnen. Insofern die Entuicklung siner Winenschaft mit der wirklichen Bewegung der Geselhohat zusammenhangt, al, ihr blow theoreticher Reflex. mute sich die diatektiwhe tentwicklung der Arbeiterben egung in hrem ideellen Ausdruck. dem Wissenschaftlichen Sozidismus "iderspiegs'n" $" 148)$.

Danach vollzieht der Wissenschaftliche Sozialismus abbildhaft einen gemeinsamen Zyklus der Prosperität und Krise mit dem Kapital.

Jedem praktischen Neuantang nach ciner Nederlage entepricht atuch sin theoretischer: der hoheren Bewustheit dieses neuen Aufschwungs in der proletarischen Bersegung . . entspricht theoretisch dic Erklärung für den in dieser munnehr abgenchlosenen Phase erfolgten Prozets der Verflachung der revolutionaren Theorie" 11491.

Für das Projekt Klassenanalyse gibt es also eine direkte Identität von wirklicher Bewegung und dem sie ausdrückenden wissenschaftlichen Begriff bzw. einem objektiv wahren theoretischen System.

..Die Theorie kunn . . nur so kritisch und revolutionär sein wie es der sozioökononische Prozels selbst ist ... Allein wenn nit Hilfe objektiver Analyse der kapitalistischen Gesellschaftsfor-

.. Henn die Marxisten die Kommunistische Partei organisieren und in den Kampf führen. so ist dies ebenfalls ein Ausdruck der historischen Notwendigkeit. die sich eben durch den Willen und die Handlungen der Menschen ausdrückt." (Ebd.. S. 47)

Zum Problem des. .Zusammenbruchs" der kapitalistischen Gesellschaft bzw. der Alternative von Sozialismus und Barbarei vgl. den Abschnitt .. Gesellschaftliche Praxis und K'lassenkampt". S. $105 \mathrm{f}$

147) Bischoff, a. a. O., S. 105

148) Projakt Klassenanalyse: Leninismus, a. a. O., S. 18

149) Ebd.. S. 22 
mationen in einem gegebenen nationalen Rahmen und auf bestinmter Entricklungsstufe nachgewiesen ist. dat und in welchen Schritten sich diese notwendig in eine hohere Gesellschaltsfornation. den Sozialismus auflosen u ird. kann der Zersetzungsprozeds beschleunigt werden "(150).

Der wissenschaftlichen Analyse kommt so die Aufgabe zu, den ..verborgenen Sinn des sich vor unseren Augen abspielenden Klassenkampies (zu) bestimmen". Durch theoretische Kritik wird die ..Einsicht in die wirkliche Bewegung" gefördert (151). An diesem Punkt. nach der Erstellung eines allgemeinen Modells von zwei allgemeinen Taktiken. das durch die Wirklichkeit nur noch verifiziert wird(152), muß Theorie in instrumentell anwendbare Methode umschlagen.

.Da dieve Schrittiolge (von den allgemeinen zu den empirischen Bestimmungen) vom dem Resultat der Marxschen allgemeinen Lntersuchung der kapitalistischen Produktion her vorbestimmt jet und nur a uf dieser Grundlage verfolgt werden kann. so findet bej dem Übergang von der allgemeinen zur empirjichen Lntersuchung der burgerlichen Gescllschat quasi ein Umschlag von Theorie in Methode statt" 1153 ).

Aufgrund der Verfügung über diese Methode hat ein Teil der Arbeiterklasse mehr Einsicht in den Ablauf des gesellschaftlichen Produktionsprozesses.

..Die bewustesten Teje der Arbejterklasse. die aufgrund jhrer Einsicht in die wirkliche Bewegung des materjell-okonomischen Prozesses bewulst dita Auflosung der bürogerlichen Gesellschat beschleunigen. sind die Kommunisten" (154).

150) Bischoff. a. a. O.. S. 127. Diese Identität von Begriff und Faktizität kann Bischoff nur behaupten. inden er sich als Erkenntnissubjekt aus dem gesellschaftlichen Prozefs ausschliebt. Er macht eine Trennung von Forscher und Forschungsgegenstand. Er glaubt, uber einen ..objektiven" Vabstab wissenschaftlicher Analyse zu verfügen. Damit nähert er sich jedoch einem positivistischen Wissenschaftsbegriff. Der gescllschaftliche Erkenntnisprozefs soll sich auherhalb des Erkenntnissubjekts vollziehen und ist damit unabhängig von seiner praktischen Tätigkeit. Wethodisch besteht hier erneut eine Verwandtschaft zu Hilferding, der den Marxismus als wertfreje Wissenschaft begriffen wissen wollte. Die Einsicht in die Notwendigkeit des Sozialismus schlob danit nicht das Engagement dafür ein. Vgl. Hilferding, a. a. O. ..So bleibt der Marxismus, der logisch wissenschaftliche, objektive, von Werturteilen freje Wissenschaft ist. in seiner historischen Stellung notwendigerweise das Besitztum der Wortführer jener Klasse, deren Sieg er als Resultat seiner Untersuchung erhalt." Ebd., S. 21. Bei Hilferding besteht eine Dichotomie von wertfreiem Wissenschaftsbegriff und moralischer Parteilichkeit bzw, einen Glaubensbekenntnis.

151) Zur Taktik ...,a.a. O.. S. 8 und 11

152) ..Es kann sich also bei allen Lntersuchungen, die den drei Bänden des "Kapitals" nachfolgen müssen. nur um weitere Entfaltung bereits gegebener Bestimmungen und um die Angabe empirisch zufälliger Abweichungen handeln." Klassenbewulstsein und Partei, a. a. O.. S. 85

153) Ebd.. S. 27. Diese Auffassung, dajn eine lückenlose Kette vom allgemeinen Begriff bis hin zu taktischen Aufgaben hergestellt werden kann, bei der die korrekte Ableitung (dje Theorie) Kriterium der Taktik (der politischen Praxis) ist, zieht sich durch die gesamte Leninismuskritik. Das Verständnis des ..Kapitals" entscheidet über die ,richtige" Politik; hinzukommen methodisch unzulässige Verallgemeinerungen historischer Aussagen Marx' und Engels'. Die Schriften, die zur Konstruktion der allgemeinen theoretischen Modello herangezogen werden, sind von Marx als konkrete Zeitanalyse geschrieben worden. Ihre Verallgemeinerung ist eine irillkürliche Konstruktion des Projekts Klassenanalyse.

154) Ebd.. S. 92. Das Projekt Klassenanalyse verficht hier eine Theorie, derzufolge gesellschaftliche Praxis wcitgehend auf rationalem Verhalten aufbaut. Rationale theoretische 
Innerhalb dieses geschlossenen Systems von ökonomischem Prozef, Analyse. Einsicht. Taktik und Partei fehlt noch die explizite Selbsteinschätzung. der Platz. den das Projekt Klassenanalyse innerhaib dieses Systems auszufüllen ge denkt. Hier erinnert man sich der eigenen Herkunft aus den Studentenrevolten der 60er Jahre. Die Verscharfung der gesellschaftlichen Antagonismen habe sich in vermittelten gesellschaftlichen Bereichen ausgedrückt.

\footnotetext{
..Disser Widerspruch zwischen ontwickelten Potenzen gesellschaftlicher Arbeit und dem anachronistisch gewordenen Ausbildungusstem erhiclt in der Schüler- und Studentenbewegung reine Berregungstorm. Im Verlaut der Entsicklung dieses Widerspruchs haben vich die von Beginn an heterogenen Momente dieser Bewegung politisch und theoretisch in verschiedene Richtungen entwickelt. In dem Mals wie die Aneignung der proketarischen Anschaumngrte ise durch das Studium der neuen' Wissenschat Fortschritio machte. die wisconschaftliche A rbe it prazisiert wurde und auch zu ersten Resultaten führte, in dem Males schieden sich auch theoretisch die muchr proletarischen und die bürgerlichen A uftassungen. Die Projektgruppe Kklassenanalysi und dic von ihr vertretene politish-theoretische Auffassung hat sich im Prozel dieser politischen Auscinandersetzung der ketzten Jahre herausebildet" 155 .

..Sic sieht thre Aufgabe darin. Während der Phase der Qualifikation an der Hochschule. zur Rekonstruktion des Wissenschaftichen Sozialismus und seiner Anwendung auf gegenwärige gescllschat tliche Virhaltniso' cinen begrenzten Beitrag zu leisten*1156).
}

Das Dilemma. das unter revolutionären Intellektuellen immer wieder auftaucht, der Ruckfall in die Arbeitsteilung von akademischen Theoretikern und praktisch Kämpfenden. wird vom Projekt Klassenanalyse nicht mehr als hinderlich. als konkret immer wieder aufzuhebender Zustand angesehen. sondern in sein Gegenteil positiv verkehrt und hypostasiert. Indem dieser Mangel einer linken Bewegung - nämlich die Beschränkung von Intellektuellen auf Erarbeitung und Verbreitung von Theorie - als deren einzig mögliche Form auferhalb ieder Diskussion steht. taucht die Fragwürdigkeit einer solchen Organisationsform von theoretischer Arbeit, ihre mögliche Verselbständigung zur anschauenden bürgerlichen Sozialwissenschaft gar nicht mehr auf. Theore tische Arbeit, deren Fragestellungen durch prak. tisch-politische Tätigke it korrigiert, erweitert und aufgehoben werden. müssen auch in neuen Formen organisiert werden. ein Ansatz hierfür war in Berlin die Kritische Universität 1967/68. Ein solches Ziel stellt sich das Projekt Klassenanalyse nicht mehr. Die Selbsteinstufung als Theoretiker, als ..literarischer Repräsentant" einer ..proletarischen Partei" steht a priori fest und läßs einen notwendig prozefshaften Charakter voll Organisation gegenüber ihrer Verdinglichung nicht mehr zu.

Beim Verhältnis zur Studentenbewegung fällt auf. dafs vom Projekt Klassenanalyse eine differenziertere Einschätzung bisher fehlt. Die in allgemeinen Statements gehaltenen Erklärungsversuche sind oberflächlich oder falsch. Es ist z. B. historisch falsch, die Studentenbewegung unmittelbar aus dem Widerspruch von Produktivkräften und Ausbildungsbedingungen zu erklären. Dies war nur eines der

Aufklarung und ein intellektueller Lemprozelo haben sozialistisches Klassenberuistsein zum Resultat. Dazu P. Brückner: .In der Idee. Agitation sei das Mittel der Wahl. auf diesen (subjektiven) .,Faktor" einzuwirken, kehrt... der Rationalismus der bürgertichen Aufklärung in die Linke zurïck." Krịtik an der Linken, Köln 1973. S. 59

155) Zur Taktik .... a. a. O., S. 11

156) Vgl. ebd. 
Politisierungsmomente. Vielmehr kennzeichnete ihr Bewußtsein eine Verbindung von weltgeschichtlicher Totalität und individueller Erfahrung. Antiimperialismuskampagnen. Kapitalismus- und Stalinismuskritik. Debatten über die Formen sozialistischer Gesellschaften zählten ebenso dazu wie die kollektive Verarbeitung der Konflikte. die aus der autoritären Sozialisation resultierten. der Protest gegen den Faschismus der Elterngeneration, die Veränderung der Bedürfnisse, Kommunediskussion und erfahrung und die Hochschulrevolten. Nicht der technokratische Protest gegen schlechte Ausbildungsverhältnisse stand hier in Mittelpunkt. sondern der Angriff richtete sich gegen die affirmative gesellschaftliche Funktion der Hochschulen. gegen das positivistische und historistische Selbstverständnis der in ihr betriebenen Wissenschaften. Das emanzipatorische Ziel der Revolutionierung der Gesellschaft bestimmte die Radikalitat der Studentenbewegung. nicht das kleinliche Interesse an technisch besseren Ausbildungsbedingungen. Die sparsame Erwähnung der studentischen Protestbew egung. die nicht ausgeführten und damit diffamierenden Behauptungen - so im Vorwort zum Lenin-Buch Charakterisierungen wie "Garm des studentischen Sendungsbewufsiseins" oder ..kleinbürgerliche Konvertiten" zeigen vielmehr, dafi das Projekt Klassenanalyse den eigenen Bruch zur studentischen Protestbewegung historisch nicht vermitteln kann. Die the ore tische Selbstlegitimation erfolgt über die Enthistorisierung der eigenen Vergangenheit. Dadurch, daß sich das Projekt Klassenanalyse bewufst auf Theoriearbeit beschränkt, fällt es hinter die in Ansätzen emanzipatorische Praxis der Studentenrevolte auf eine anschauende, akademische. in der Gelehrtenrepublik verbleibende Sozialwissenschaft zurick.

\section{Klassenbewrustsein}

Zwischen 1919 und 1922 schrieb Georg Lukács eine Reihe von Aufsätzen, die 1923 zusammen unter dem Titel ..Geschichte und Klassenbewukisein" erschienen. Lukács versuchte erstmals, die theore tisch ungeklärte Frage von Klassenbewußtsein und revolutionärem Subjekt zu bestinmen. Dies loste eine hef tige Kontroverse über den dialektischen Marxismus aus, in deren Verlauf Lukács Selbstkritik übte. Die Frage nach dem Klassenbewufstsein machte sich jedoch auch später immer wieder an Lukács“ Thesen fest. Anhand seiner Bestimmung von Klassenbewußtsein wollen wir das Verhältnis von Bewufstsein und Partei prüfen. A us dem Ergebnis wollen wir Rückschlusse ziehen für die Beurteilung dieses Verhältnisses in der theoretischen Konzeption der Projek tgruppe Klassenanalyse, um mit einer gegensätzlichen Position - die allerdings nicht die unsrige ist -. der Wilhelm Reichs, diesen Abschnitt abzuschliefen.

Für Lukács ist in ,der Lehre und der Methode von Marx die richtige Methode der Erkenn tnis von Gesellschaft und Geschichte endlich gefunden worden ... Diese Methode ist in ihrem innersten Wesen historisch. Es versteht sich deshalb von selbst. dafs sie ununterbrochen auf sich selbst angewendet werden muß" (157). Erkenntnis

157) G. Lukács: Geschichte und Klassenbewufstsein, Berlin 1923. „Es ist der Verdienst von Lukács, gegenüber den szientistischen Verengungen der Marxschen Theoric während der 2. Internationale hervorgehoben zu haben. dafs die Marxsche Methode wesentlich histo- 
der Gegenwart ist danach vornehmstes Ziel der Marxschen Mcthode. Die Frage nach Klassenbewußstse in verzweigt sich in zwei zusammengehörige Teilfragen: "Was ist unter Klassenbewußtsein (theoretisch) zu verstehen? " und ,Was ist die Funktion des so ve rstandenen Klassenbewufitseins (praktisch) im Klassenkampf selbst?" "( 158 ).

Die in der Geschichte tätigen Einzelwillen erbringen oft ein ganz anderes als das gewollte Resultat. Es besteht eine Unabhängigkeit der wirklichen bewegenden Kräfte der Geschichte vom psychologischen Bewußstein der Menschen, denn die eigene gesellschaftliche Bewegung besitzt für sie die Form einer Bewegung von Sachen, unter deren Kontrolle sie stehen. Es scheint als ob dem Bewufitsein jede Wirkung im Geschichtsprozeß genommen wäre. Zwar vollbringen die Menschen ihre geschichtlichen Taten selbst, jedoch mit falschem Bewußtsein.

„Die dialektische Methode gestattet uns jedoch auch hier nicht, bei einem einfachen Feststellen der ,Falschheit" dieses Bewulstseins. . stehen zu bleiben. Sie forderi vielmehr, dats dieses, falsche Bewubtsein" als Moment jener geschichtlichen Totalitat, der es angehöt, als Stufe jenes geschichtlichen Prozesses, in dem es wirksam ist, konkret untersucht werden" (159).

Die marxistische Analyse ermöglicht es, die Gedanken zu erkennen, die Menschen in einer

„,bestimmten Lebenslage haben würden, wenn sie diese Lage, die sich aus thr heraus ergebenden Interessen sowohl in bezag a uf das unmittelbare Handeln wie auf den . . Aufbau der ganzen Gesellschaft vollkommen zu erfassen fähig wären; dic Gedanken usw; also, die ihrer objektiven Lage angemessen sind ... Die rationcll angemessenc Reaktion nun, dic auf dicse Weise ciner bestimmten typischen Lage im Produktionsprozeth zugerechnet wird, ist das Klassenbewulistscin. Dieses Bewuftscin ist also weder die Summe noch der Durchsehnitt dessen, was die cinzelnen Individuen, die die Klasse bilden, denken, empfinden usw. Und doch wird das geschichtlich bedeutsame Handein der Klasse als Totalität letzthin von diesem Bewulstsein und nicht vom Denken usw. des Einzelnen bestimmt und ist nur aus diesem Bewulstsein erkennbar" (160).

Dieser Widerspruch zwischen zugeordnetem bzw. idealtypischem Bewußtsein, zwischen unmittelbaren Interessen und Endziel, zwischen Empirie und objektiver Möglichkeit muß in der praktischen Politik überwunden werden. Dies übernimmt die ,organisatorische Form" des Klassenbewußstseins, die Kommunistische

risch ist, was bedeutet, dats sie fortwährend auch auf sich selbst angewand werden mufs; dats die von ihr untersuchten Gegenstände der Vergangenheit zugleich die geschichtliche Selbstreflexion dessen, der die Vergangenheit befragt, mit einschlieken mufs. Das Hauptziel der Methode, wie sie mit Lukács rekonstruiert wurde, ist, die Gegenwart zu begreifen, und zwar als zu gestaltende Geschichte. dadurch wurde der Marxismus abgelöst von rein archivarischen, akademisch bleibenden Interpretationen und bezogen auf wirkliche Tagcskämpfe." Alfred Schmidt, in: Cerutti u. a.: Geschichte und Klassenbewuistsein heute, Diskussion und Dokumentation, Amsterdam 1971, Schwarze Reihe Nr. 12 - Dic wichtigsten Kritiken an Lukács sind in diesem Band zusammengestellt. Neuere Kritiken in: K. Horn: Psychoanalyse - Anpassungslehre oder kritische Theorie des Subjekts, in: Marxismus, Psychoanalyse, Sexpol, Bd. 2, Frankfurt 1972, S. 126 ff. und Kluge/Negt: Öffentlichkeit und Erfahrung. Zur Organisationsanalyse von bürgerlicher und proletarischer Öffentlichkeit, Frankfurt 1972, S. 410 ff.

158) Lukács, a. a. O., S. $57 \mathrm{f}$.

159) Ebd., S. 61

160) Ebd., S. 62 
Partei (161). Damit existiert bei Lukács das revolutionäre Subjekt nur als überindividuclle Klasse oder als Partei.

.. lukian kimn mur dadurch, dats or das K'asensubjekt von den empirischen Individuen abtrennt.

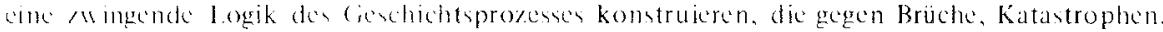

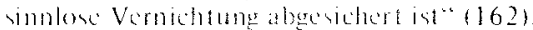

Das falsche Bewulstsein der Masse wird von Lukás fixiert und den in der Partei organisiertin Klassenbewuktsein gegenübergestellt, anstatt die Mechanismen des falschen Bewulstseins bei den konkreten Proletariern zu benennen. Durch diese Fixierung, die theoretisehe Konsiruktion der Unaufhebbarkeit der Differenz von empirischem Bewulstsein und zugeordnetem Klassenbewulstsein werden die konkreten Klassenindividuen aus der Betrachtung ausgeschlossen. Gegenstand der theoretischen Betrachtung bleibt als revolutionäres Subjekt nur noch die organisierte Form des Klassenbewultseins: die proletarische Partei, die damit hypostasiert und als Organisationsform prinzipiell nicht mehr in Frage gestellt wird. Fehler in der praktischen Politik sind dann nicht mehr auf die Organisationsform rückführbar, sondem auf Renegatentum. Verrat, bestochene Arbeiteraristokratie, auf ein ungluckliches Versagen einzeher (163).

Bevor wir weiter versuchen, die Frage nach dem Klassenbewulstse in zu diffe. remreren, vergleichen wir kurz. die Konzeptionen von Klassenbewußstsein be I. ikics und im theoretischen System des Projek ts Klassenanalyse. Obwohl losgelost wn dem wirklichen Proletariat, bleibt bei Lukacs ein subjektives, praxisbetontes Moment, das sich in der Partei darstellt. Lukács organisatorische Form des Klassenbewulstseins resultiert aus einem Widerspruch, in dem das Bewußtsein davon eingeschlossen ist, dak in der A rbeiterklasse sich nicht unvermeidlich notwendig revolutionares Bewußtsein entwickelt. Dieses Problembewußtsein fehlt bein Projekt Klassenanalyse. Bei ihm besteht eine ungetrübte Kongruenz von ökonomischem Prozeh. der Entwicklung yon Klassenbewußstsein und Partei. Liegt in der Theorie Lukács noch die Anerkennung eines subjektiven Monjents, so sind beim Projekt Klassenanalyse Klasse und Partei nur noch Ausführende, bestenfalls Beschleuniger der Notwen-

161) libd.. S. 88

162) Negt, in: Geschichte und Klassenbewutstsein heute, a. a. O., S. 23; vgl. Lukács. a. a. O., S. 329: ..Die organisatorische Loslosung der kommunistischen Partei von der breiten Masse der Klasse selbst beruht auf der bew utstsein madsig verschiedenen Gliederung der Klasse, ist aber zugleich dazu da, um den Prozeds der Ausgleichung dieser Schichtungen auf dem crreichbaren höchsten Niveau - zu betördern. Dic organisatorische Selbständigkeit der kommunistischen Partei ist notwendig. damit das Proletariat win cigenes K'lassenbewutstsein, als geschichtliche Gestalt unmittelbar crblicken könne: damit in jedem Ereignis des alltiglichen Lebens jene Stellungnahme, die das Interesse der Gesamtklasse erfordert, klar und für jeden Arbeiter verständlich in Erscheinung trete: danit für die ganze Klasse das cigene Dascin als Klasse ins Bew ulstse in gehoben werde."

163) Hicrhin gehört auch Lenins oberflächliche Erklarung der Arbejteraristokratie. Das Scheitern der Sozialdemokratie gegenüber ihren sozialistischen Zielen, ihre Unterstützung des imperialistischen Krieges resultierte für Lenin aus dem Renegatentum einiger Führer. Die Parteiform, die nicht etwa die Bedurfnisse und Interessen der konkreten Proletarier organisierte, sondern cin parlamentarischer Wahlverein - auf Mitgliederbasis autserhalb der wirklichen Lebensverhältnisse der Proletarier - war, wurde von ihm nicht in Frage gestellt. Konsequenterweise wurden in die III. Internationale nur bessere, numlich ..kommunistische" sozialdemokratische Parteien aufgenommen. 


\section{digkeit (164):}

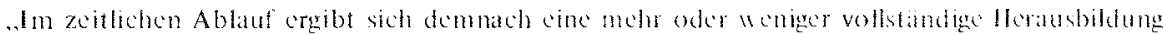

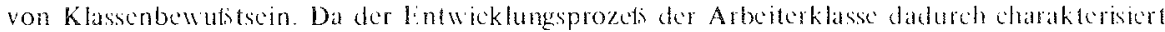
ist, dats bestimme Teile der Klasse sich schon zur linsteht in ihre Lage emporgenteitel haben, wenn andere noch die Hersehaft des kapilals als naturnolwendig himehnen, folgt munatuch, dath gerade die bewutitesten Feile des Proletariats in den Klassemorganisationen veremt sind Die Avantgarde der Klasse mut sich daruber hinas cine lorn geben, in der sie zu cinheitlechem Handeln fahig ist die proketarische Parted. Dicse Organisationstorm ist also Resultaf der lint ujekiung des Klatssenbewutidseins" (165)

Klassenbewuthein ist hier mehr ein emotional-proletariatsverbundes, die wirkliche Entwicklung harmonisierendes Postulat als für die Analyse handhabbare Kategoric. Harmonisierend deshalb, weil die Möglichkeit einer regressiven Entwicklung von Klassenbewuktsein unter der Mehrzahl des Proletariats nicht gesehen wird und hinter einer passiven Erwartungshaltung zurïcktritt. Die Forderung nach der Partei ist nicht mit dieser Erwartungshaltung vermittelt wozu eine Partei, wenn Klassenbewuktsein auch so entsteht? und bleibt so moralisierendes Bekemmmis.

Die harmonisierende Behauptung des Projek is Klassenanalyse einerseits, Klassenbewuktsein werde sich schon herausbilden, und Lukács Hyposiasierung einer übergeschichtlichen Partei andererseits zeigen beide cine gleiche Tendenz: dic Ignorierung des konkreten Erfahrungszusammenhanges der Proletarier. Alexander Kluge und Oskar Negt versuchen den Widerspruch, der im Begriff des Klassenbewutstseins enthalten ist, aufzuschlüseln. Klassenbewußstsein ist mehr Programm als cine Realkategorie.

,Klasse und Bewubtsein sind Realkategorien, die zu ej völlig versehiedenen, cinander konträren geschichtlichen Denkzusammenhängen entstammen. Die narxistische Tradition zicht sic zu einem Wort zusammen, um cin Programm anzudeuten. $\mathrm{l}$ s geh! in dicsem Programm um dic Vermittlung zu ischen der Entstehung des proktarischen Lebensusummenhangs, cinschlietilich sciner subjektiven, bew utsten' Seite, cinerseits und der praktischen Authebung dieses protetari sehen Lebenszusammenhangs andererseits. Die in diesem Begriff enthaltene Dialektik besteht darin, dats or auf Totalität gerichtet ist, gleichwohl aber den gesumten empirischen lirfahrungszusammenhang der Proletarier erfassen muts, wenn er nicht zu ciner bloten Sekk tionskaftgoric werden soll. Unsere Kritik an der Verwendung dieses Begrifís beinhaltet dic liorderung, ihn materich auszufüllen. In der marxistischen Orthodoxie wird Klassenbewutstsein als Resultat fixiert. In dieser form behindert der Begriff die Lösung konkreter Vermittlung zwischen gesellschaftlicher Totalitat, Klassenlage, verandernder Praxis und geschichtlich entstandener LebensWeise des Proletariers" (166).

Revolutionäres Bewuỉtsein entsteht nicht nach einem simplen Basis-Überbau-Schema. nach dem der unmittelbare Produktionsprozek das Bewußstsein bestimmt und so mit der ökonomischen Krise die revolutionäre Entwicklung einsetzen mufs. Zwar gilt für die Analyse von Bewußstsein, dak das Sein das Bewukistsein bestimmt, dak die „Produktionsweise des materiellen Lebens... den sozialen, politischen und geistigen Lebensprozefs überhaupt (bedingt)" (167). Aber die Produktionsweise des ma-

164) Vgl. den Abschnitt „Dic Zusammenbruchstheorie des PKA“, S.90

165) Projekt Klassenanalyse: Klasienbewufistsein und Partei, a. a. O., S. 25 f.

166) Kluge/Negt, Öffentlichkeit und Erfahrung, a. a. O., S. 412

167) Marx, Vorwort zur Kritik der politischen Ökonomic, MEW 13, S. 8 f. 
teriellen Lebens, das ist nicht der unmittelbare Produktionsprozeth in der Fabrik, sondern der Produktionsprozek vor gesellschaftlichen Lebensverhältnissen. Die Produktion des Bewutstseins

. geschioht geselkchatlich uber die formen gegenstandlicher Wirklichkeit, der Geschichte, der Soziatisation, der Iricbokonomic, des pyechischen Aufbaus der Persen, der lerziehung. der unmittolbaren frfahrungen im Arbeitsprozes und der Rück-und Wechschirkung aller dicser Lbenen. Wenn nan überhaupt den Begriff des Bew distscins hicr verwenden will, dann nübte er ats Resultat dieser Komponenten, die gerade aluch Unbew utstes und Vorbewutates enthalten. getalst werden" $(168)$

Indem die .materiellen Bedingungen" von Bewulk tse in weiter gefalß twerden als ein empiristisch verengter Begriff von Produktionsprozel konnen sich praktisch-organisatorische Perspektiven ergeben, die sich nicht in ein Schema von ökonomischem oder politischem Kampf, gewerkschaftlicher oder politischer Organisation zwängen lassen.

Bis zu diesam Punkt haben wir die immanent theoretische Schlüssigkeit einer Ableitung von Klassenbewuktsein und Partei untersucht. Konfrontieren wir die Theorie des Projekts Klassenanalyse über das Entstehen von Klassenbewuftsein mir der Geschichte der Klassenkämpfe, wird die Haltlosigkeit der Erklärungsversuche noch deutlicher. Nach seiner evolutionistischen Zusammenbruchstheorie (169) häte in der Weltwirtschaftskrise von 1929/30 nicht nur die (um mit Lukács zu reden) ,objektive Möglichkeit" bestanden, den revolutionären Umschwung einzuleiten, sondern die proletarischen Massen hätten auch revolutionäres Bewußtsein zeigen müsen. Stattessen begann der Machtergreifungsprozef der Nationalsozialisten, die auch in der Arbeiterschaft eine Massenbasis fanden. "Groke Teile des früheren Rotfrontkämpferbundes gingen zur SA"(170). Wilhelm Reich zeigte in seiner

168) Kluge/Negt, a. at. O., S. 411. Zweifellos ist dieser Bezngsrahmen des Bewutstseins in der bügerlichen Gesellschaft dureh das Kapitalverhaltnis bestinmt. Aber die konkrete Analyse darf sich nicht darauf beschränken, jede soziale Erscheinungsform unmittelbar damit zu orkliaren. Wonn Reich z. B. das faschistische Bew ufstsein zahlreicher Proletarier aus der Struktur und Sozialisation der Kleinfamilic erklart, dann hat das unmittelbar noch nicht viel nuit dem Widerspruch von Lohnarbeit und Kapital zu tun. Dałs in der Manufakturperiode altere lamilicistrukturen durch die Kleinfamilie als eine ökonomische Form verdrängt w urde, dati Askeseideale in die herrschende Moral - z. T. in neue Religionsableger in verschiedene Arten des Protestantismus - eingingen, ist zurückzuführen auf die sich durchsetzende kapitalistische Produktionsweise. Die Familiensozialisation gewinnt damit aber cine cigene Gesehichte, die zwar ständigen Beeinflussungen durch den Produktionsprozets unterliegt, aber niemals vom aktuellen Stand der Kapitalakkumulation unmittelbar und aktuell abgeleitet werden darf.

169) ,In dem Matie, wie die okonomische Umwälzung rascher und einschneidender vorangeht, in dem Mata müsen sich Matregeln mit Notwendigkeit aufdrängen zur Lósung der plötzlich ins Grolse und Unertriggliche gewachsenen Übelstande..." Zur Taktik. a. a. O.. S. 9. Michael Vester charakterisiert solche Katastrophenanalogien: .Die eschatologische Vorstellung ciner Revolution, die als reinigender Feucrsturm alles erneuern und den Menschen die Lösung alkr Probleme sehenken kann, kann besser als Projektion innerer Verzweiflung denn als Produkt von Gesellschaftsanalyse verstanden werden." Michael Vester. Solidarisierung als historischer Lernprozets, in: D. Kerbs (Hrsg.), Die hedonistische Linke, Neuvied 1971, S. 174.

170) W. Reich: Was ist Klassenbewubtsein? Raubdruck, S. 48 
„Massenpsychologie des Faschismus" Ursachen auf, die in verschiedenen Formen der Sexualunterdrükung, vor allem in der Fanilie, kulminierten.

..Die Sexualverdrangung . . schafft in der Struktur des bürgerlichen Menschen cine sckundare Kraft, ein künstiches Interesse, das dic herrschende Orcinung auch aktiv unterstükl. Ist namlich die Sexualiat durch den Prozeth der Sexualverdrangung aus den naturgenats gegefoenen Bahnen der Befriedigung ausgeschlossen, so beschreitet sie Wege der Irratzbetriedizung ... So \%. B. steigert sich die naturliche Aggression zum brutalen Sadismus... die exticlle Wirkung der Lnitorn ... die erotisch aufreizende, weil rhythmisch vollendete Wirkung des Parademarsche, der exhibitionistische (harakter des militarischen Auttetens"(171).

Reich betont, dak die europäische Freiheitsbewegung an dem Grundirrtum zu Grunde ging, daß sich autoritäre Gesinnung mit der "Bourgeoisie" und freiheitliche Gesinnung mit dem, Proletariat" deckten.

,Der vulgäre Marxismus, dessen wesentlichstes Kennzeichen ist, die diakektinch materialistieche Methode praktisch durch Nichtanwendung 7.4 negieren, mutne daher zur Authasung getangen, dats eine wirtuchaftliche Krise solchen Ausmatses wie 19291933 norwendigerweise ze cince idcologischen Linksentwicklung der betroffenen Massen führen musse. Wänrend sogur noch nach der Nicdertage im Januar 1933 von cinem ,revolutioniren Aufschu ung in Deutschland gesproshen wurde, zeigte die Wirklichkeit, dath die wirtschattliche Krise, die der fruartung nach cine Linksentwicklung der Ideologie häte mit sich bringen mussen, zu ciner extremen Rechts entwicklung in der Ideologie der proletarisierten Schichten und derjenjgen, die in ficferen lend als bisher versanken, getuhrt hatte. Ls crgab sich eine Schere zwischen der lntwicklung in der okonomischen Basis, die nach links drängte, und der l. ntwicklung der Ideologic breifor Schichten, die nach rechts crfolgte" (172).

Klassenbewurstsein oder revolutionäres Bewurstsein, das war für Reich die Schlukfolgerung, liek sich nur in Anknupfung an die Bedurfnisse der Klassenindividuen entwickeln (173).

171) W. Reich: Massenpsychologie des laschismus, Raubdruck, S. 53. Fin makabres Beispiel des autoritären Charakters für seine Identifikation mit Macht, dic potentiell für konterrevolutionäre Interessen umfunktionierbar ist schildert Kurl Retzlaw" ,Kurz vor sejnem Fnde -.. der ,Rote Frontkämpferbund" wurde im Mai 1929 von der sozialdemokratischen Regierung Preufsens verboten und aufgelöst beging eine Ortsgruppe eine schamlose Nicdertrachtigkeit. In der Sowjetunion hatte ein Schauprozels gegen Ingenieure stattgefunden, denen Sabotage vorgeworfen wurde. Mehrere der Angeklugten wurden zum Tode verurtejlt. Dic Ortsgruppe Zoppot-Danzig des RF B telegrafierte an Stalin: Wir bitten das Urteil chrenhalber vollstrecken zu dürfen, RI B, Zoppot. 'Das ZK der Kommunistischen Partei billigte das Telegramm und lick es im Parteiorgan, Dic Rote Fahnce als Beweis revolutionärer Gesinnung veröffentlichen. Da den Leuten das Zeug zu wirklichen Revolutionären fehlte, wollten sie wenigstens Henker sein." Spartakus Aufstieg und Niedergang, Erinnerungen eines Parteiarbeiters, 2. Aufl., Frankfurt 1971, S. 302

172) W. Reich: Massenpsychologie, a. a. O., S. 19 Reich wurde nach der veröflentlichung der ,Masscnpsy chologie“ aus der KPD wegen „,konterrevolutionärer Anschauung" ausgeschlossen. - Soweit das Projekt Klassenanalyso überhaupt auf dic historische Entwicklung der Arbeiterklasse eingeht, beginnt sie ,nach der Niederlage des Faschismus... " Leninismus, a. a. O., S. 17 und 22. An der Frage des Klassenbewusstseins hört die "Analyse" des Projekts Klassenanalyse dort auf, wo sie in Widerspruch zu den eigenen a-priori-Theoremen geraten würde.

173) W. Reich: Was ist Klassenbewulstsein?, a.a. O., S. 58 fr. Die Konzeption rationa!-verbaler Aufklärung, die das Projekt Klassenanalyse vertritt, ist das genauc Gegenteil davon. 
..Sic folic Kominterntuhrung) sagt immer richtig, daßs Massenarbe it geleistet werden muli, aber vie wehet weh selbst gegen dic kenkreten lnhalle der notwendigen Massemarbeit: und dies umsomedr, ic endternter dicse Inhalte vom lfochpolitischen, je naber sie dem Personlichen stehen. Sie setzt cinen absoluten Giegensity, von Personliden und Politischem, statt die dialek-

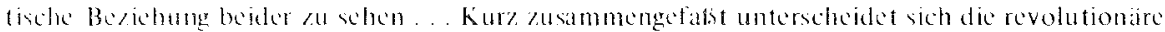
ven jeder Ar1 burgerlichen Politik dadurch, dats jene die Politik in den Dienst der Bedurfnisbefricdigung der Masce stellt, diese jedoch ihre ganze Politik aul der strukturellen, geschichtlich bedingen Ansprudolosigkeit der Masson aufbatt"(174).

Man muk nicht mit der empiristischen Verengung von Reichs Theorie übereinstimmen (175), aber seine Forderung, mit der politischen Massenarbeit bei den sozialen und psychiscinon Bedurfinissen am/usetzen, ist zuzustimmen. Nur so kann der Schritt an ciner Stellvertreterorganisation für Klassenbewuts tsein vermieden werden; indem namlich dic Passivitat der Massen nicht mehr nur konstatiert, sondern auf ihre Ursachen zuruckgegangen wird. Die Analyse des verdinglichten Bewußstseins bliebe nicht mehr wic beim Projekt Klassenanalyse in oberflachlichen Erklärungen wie "Tradition" und ,Vorurteil" stecken, sondern würde vertieft in bezug auf Triebstruktur, Sorialisation, Lrrichung, Lebensgewohnheiten usw. Diese Erkenntnisse stcllen cinc neac Grundlage für die Organisationsdebatte dar, die damit aus dem falschen Schema von okonomischen Kampf in der Gewerkschaft und politischem in der Partei heraustüht, und den ganzen Erfahrungsbereich der Klassenindrviduen bericksichtigt, wie ihn Michad Vester kurz umschreibt:

Der arbeitenden Klasse muls, ,doch, nur der verborgene Sinn ihrer tagtigglichen Kämpfe crklint werelen". Klassenbenutstsein und Partei, a. a. O., S. 61

Damit unterstellt das Projekt Klassenamalyse, dals der Lermprozeds der Proketarier gemads Gesetzen der ratbonalen Erkenntnis ertolgt. ,Daraut futst dann dic Annahme cines linearen oder zasistutigen Theorik-Praxis-Verhaltnisses. Danach konnen die Mensehen, gleichsam wie im Sehulunterricht, zuerst gew isse Wahtheiten atul mehr oder minder intelketueflem Wege erlernen und diese dann ein für alle Mal richtig anwenden. Die psychoanaly tiwhon und die sozialpsychologischen Wissenschat ten haben bokannt gemacht dab dicser Prozedis Wegen dé Dazw ischentretens von Mechamismen der Verdringung. der Projektion. Des Drucks sozialer Gruppon und dinglicher Verhaltnisse usw. nicht gradling verlaufen kann." M. Vester, Solidurisiertung, a. a. O., S. 1 t6

174) W. Reich: Was isl Klassenbewultstsein", a. a. O., S. 60

175) . . Es mag heute notwendig sein, den Reichschen Ansatz ciner methodologischen Kritik zu unterzichen, aber es bleibt sein groties Verdienst. als erster die komplexen Bedurtintsstrukturen des Proktariats aufgedeckt und ihre lolgen für den politischen Klassenkampt zur Diskussion gestellt zu haben. Denn wer von den Marxisten. dic sich mit ihrer Orthodoxie nicht genug tun konnten, hat schon gesehem, datis Sexullhemmungen Angst erzengen, Angat anch vor revolutionaren Veränderungen? Dats die bügerliche familienstrukfur im Proletariat in bestimm ter Weise fortexistierte und alutoritäre Einstellungen arzengtc, die in der Regel der Anpassung an die bestehonden Verhaltnisse zugute kamen? Walurend Lukies im Grunde darin nur das Problem sieht, dafis die Proletarier ihre Klassenlage noch nicht adtigyuat erfitht haben, weist Reich nach, dats das tragende Element ibres Handelns keincireg lediglich cine unklare, undurchsehaute Antizipation des Klassenbewutstsins ist, sondern data in der Struktur ihres Bewulstseins wie ihrer psychischen Fnergien die Moglichkeit ainer reaktionaren Lmfunktionierung der revolutionimen lnteressen und Bedürnisse sehon mit anthalten ist." Negt, in: (ieschichte und Klassonbewutitsion heute. a. a. O.. S. 45 


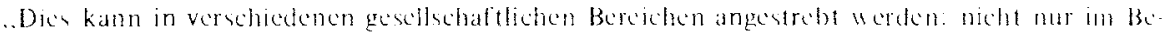
trieb, sondern atuch in der lreizcit, im Konsum, in der Nachbarschalt, im Sixualverhaltin. In den Moral und Rechtsvorstellungen. Die lintstefung des, netwen Menschen ist freilich esn languieriger, die epochate Datder von Revolutionen motbedingender Prozeth. Der traditionalle

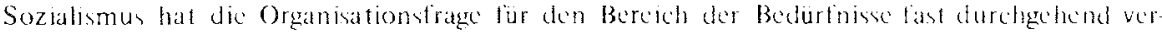
drangt" (176).

Diesen Aspekt vernachlässigl auch das Projekt Klassenanalyse. Die individuelle Seite des gesellschaftlichen Emanzipationsprozesses tritt hinter die objektiven Gesctze als deren bloker Appendix zurük. Hier zeigt sich erneut der Objektcharakter, den das Projekt Klassenanalyse dem Individuun ausschlieklich zugesteht. Emamzipation erhäl so einerseits den Charakter eines Unvermeidlichen, dem man sich zu fugen hat. Andererseits erhäl Emanzipation bzw. Praxis den Status eines rationalistisch-autklarerischen, sich den Verhätnissen anpassenden Verhaltensschemas. Hlierbei wird irrationales Affektverhalten ausgespart und damit jenes Dilemma von intellektucllem revolutionären Bekenntnis und der enotionellen Unfahigkeit zur verwirklichenden Praxis umgangen, das Dieter Duhm beschreibt:

,Dic verstandesmatsige leinsicht in die Irationalitat der bügerlichen Verhaltensou ange und die intellektuelle Kritik an ihnen sind zwar notwendige Voraussetzung fur die liberführang der bürgerlichen Identitat in eine revolutionare, sie allerion konnen aber lange nicht genugen, uson hatten wir. . hunderttausende von Revolutionaren. (ierade in dem hitufigen Auseinanderklaffen von Imotion und Intellekt zeigt sich unser flentifïationsdilemma, unsere Zu ischemstellung as ischen revolutionarer flentitat, die $w$ ir intellektuelf vertreten, und burgerlicker ldentitat, dic in umseren limotionen zum Ausdrack kummt. . Solange die l.inke das I manzipationeproblem

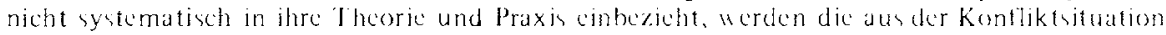
resulticrenden Angste vorwiegend in Sinte unserer bürgerlich-reaktonaren ( basakterstraktur verurbeitet" 1177$)$.

Im Gegensatz zum kontemplativ-aufklärerischen Konzept des Projekts Klassenanalyse, in dem der administrative, objektive Aspekt des sozialrevolutionaren Prozesses einseitig betont wird (178), war bei Marx durchgängig von seinen frühesten Werken bis zu seinem späteren politisch-ojkonomischen Schriften eine starke individualitätsbetonte Seite, der Befriedigung der Bedurfnisse und Befreiung von jeder Unterdrückung, enthalten.

„Die Kritik der Religion endef mit der Lehre, dals der Mensch das hoctuste Wesen tür den Menschen sei, also mit dem kategorischen Imperativ, alke Verhaltnisse umzuwerfen, in denen der Menuch ein erniedrigtes, cin geknechtetes, cin verlassenes, ein veruchtliches Wesen ist" $(179)$.

176) Vester, a. a. ()., S. 181

177) D. Duhm: Angut im Kapitalismus, Hagen 1973, S. $155 \mathrm{f}$.

178) Man spricht meist von "ökonomischer" oder ,politischer form der Fmanzipation". Dies sind zwar Marxsche Begriffe, aber im Kontext der Schriften des Projekts objektivisticel vereinseitigt.

179) Einleitung zur Kritik der Hegelschen Rechtsphilosophic, MLW 1, S. 385; siche auch: Bricfe aus den deutsch-franzosischen Jahrbüchern, MEW 1, S. 346: vgl. auch den Abschnitt über "Kommunismus" in den ökonomisch-phifosophischen Manuskripten, llamburg 1966, S. $75 \mathrm{ff}$. 
Alfred Schmidt verweist darauf, dat3 das individualistische Moment in Marx' Vorstellung einer mündigen Gesellschaft nie verschwindet.

.Bezcichnenderweise wohnt den spärlichen Äutherungen des reifen Marx, die sich auf einen menschenwïrdigeren Zustand bexichen, cin anarehistisches Element inne. Der Terminus ..Gesellschaft" kommt so gut wio gar nicht vor, ganz zu schwcigen vom Staat, moist ist vom freicn gesellsehaftlichen Lndividuum", vom, Verein freier Menschen', von den assozierten Produzenten", von , Reich der l'reilacit" die Rede" 1809$)$

Marx unterschied das Reich der Freiheit von seinen ,materiellen Bedingungen" (181). Zwar ist die materielle Produktion, ihre rationelle Organisierung die Basis für das Reich der Freiheit. Aber diese Freiheit, ,die menschliche Kraftentwicklung, die sich als Selbstzweck gilt", ist keine mechanistische, zwangsläufige Folge dieser planmäßigen Organisierung des Produktionsprozesses. Diese Freiheit liegt nicht zeitlich, sondern, ,der Natur der Sache nach jenseits der Sphäre der eigentlichen materiellen Produktion"(182).

,In fact aber, wenn dic bornierte bürgerliche form abgestreift wird, was ist der Reichtum anders, als die im universellen Austausch erzeugte Lniversalitat der Bedurfnisse, Fähigkeiten, Gemüsse, Produktivkrafte efe, der Individuen? Die volle Entwicklung der menschlichen Herrsehaft uiber die Naturkratte, die der sogenannten Natur sowohl wie seiner eigenen Natur?" (183)

Dieses revolutionäre, enranzipatorische Ziel setzt eine pe manente Revolutionierung der Revolutionäre voraus, ihrer Bedürfnisse, Kommunikations- und Verkehrsformen, ebenso wie dic Revolutionierung der Ökonomie, der Produktivkraftsteigerung, der Enthierarchisierung und kollektiven Gestaltung des Produktionsprozesses. Die vollständige Entfaltung der menschlichen Individualität, die Befriedigung der Bedurfnisse setzt zwar die rationelle Organisierung der Produktion. die Verkürzung des Arbeitstages voraus. Soll die Entwicklung aber nicht eine technokratische Richtung nehmen, die das psychisch verkrüppelte Individuum nur noch als Anhängsel des okonomischen Prozesses und der Maschinerie kennt, dann muls mit der Entfaltung der Produktivität der menschlichen Arbeit die Befreiung von psychischen Zwängen und Ängsten korrespondieren, die Selbstveränderung der Individuen in solidarischen Lebensformen.

„Die materialististhe Letre von der Veranderung der Imstände und der Erziehung vergilist. dals die Umstände von den Menschen verandert und der lizieher selbst erzogen werden mutis" (184).

Dieses Problem ist in der revolutionären Arbeiterbewegung nicht neu, obwohl es of t aus dem Blickfeld verschwand. Bei uns hat die Studentenbewegung mit der Verbalisierung des Problems und praktischen Lösungsversuchen solidarischerer Lebenstor-

180) Ujoer Geschichte und Geschichtsschrsibung in der materialistischen Dialektik, in: Iolgen cincr Theoric Essays über ..Das Kapital" von Karl Mars, Frankfurt 1967. S. 114 t'.

181) Vgl. Marx: Brict an Caficro vom 29. 7. 1879, MEW 34, S. 384

182) Vgl. Das Kapital Bd. III, MEW 25, S. 828

183) Marx: Grundrisse zur Kritik der politischen Ökononie, Berlin 1953. S. 387

184) Marx, Thesen über Feuerbach, a. a. O.. S. 5 t. 
men den Begriff von Revolution erneuert, der im traditionellen Marxismus auf eine ökonomistische Beschränkung verengt war. Der Sowjetmarxismus mit seiner Überbetonung der technologischen Entwicklung als bereits sozialistischer Transformation bleibt dabei hinter seiner eigenen Geschichte zurück. Wilhelm Reich schilderte in seinem Buch „Die sexuelle Revolution“ (185), welch wichtige Rolle in den ersten zehn Jahren nach der Oktoberrevolution die praktische Suche nach neuen Lebensformen spielte, sowohl auf seiten der revolutionären Gewalten in Form von fortschrittlichen Dekreten, wie auf Seiten der Individuen in verschiedensten Experimen. ten.

Die ersten Ehedekrete 1917 z. B. gaben der Frau rechtlich volle materielle und sexuelle Selbstbestimmung, die auch frei Name, Wohnsitz und Staatsbürgerschaft bestimmen konnte. Die Schwangerschaftsunterbrechung wurde legalisiert. Jugendkommunen versuchten kollektive Lebensformen alternativ zur traditionellen Familie zu schaffen. Die Kleinkindererziehung sollte nicht auf den Familienrahmen beschränkt bleiben: in einigen Kinderheimen dienten Erkenntnisse der Psychoanalyse als Grundlage für eine nichtautoritäre Erziehung. Die meisten Versuche scheiterten, z. T. wurden diese Gesetze später durch andere ersetzt, aus denen eine puritanische, kleinbürgerliche Moral sprach, finanzielle Mittel für fortschrittliche Erziehungsinstitutionen wurden nicht mehr zur Verfügung gestellt. Die Ursachen für das Umschlagen von sozialrevolutionären Momenten in den ge sellschaftlichen Verkehrsformen in konservative können wir hier nicht darstellen, uns kam es darauf an. aufzuzeigen, daß die Veränderung von Bedürfnissen und Lebensformen keine Erfindung psychologistischer Sekten der Studentenbewegung sind, sondern aus sozialrevolutionären Prozessen in der Geschichte der Arbeiterbewegung nicht wegzudenken sind.

Für Wilhelm Reich schloß deshalb eine Kulturrevolution u. a. die Ablösung der patriarchalisch-autoritären Familie durch natürliche Bindungen ein. Für Stalin, den Exponenten der sowjetischen Richtung des Sozialismus war Kulturrevolution nur noch technologische Qualifikation. Die möglichen Folgen der Entwicklung einer Gesellschaft, deren Wandel sich auf eine durchorganisierte Wirtschaft beschränkt, sah Reich voraus: „Eine glänzend technisierte Wirtschaft... die von Neurasthenikern und lebenden Maschinen betrieben wird, aber kein Sozialismus" (186).

\section{Gesellschaftliche Praxis und Klassenkampf}

Bei der Bestimmung des revolutionären Subjekts in der kapitalistischen Gesellschaft macht es sich das Projekt Klassenanalyse einfach. Aufgrund der Klasseninteressen kann die revolutionäre Umwälzung nur vom Proletariat ausgehen. Das „Proletariat“ bzw. die "Arbeiterklasse" besteht aus „Erwerbstätigen“, die vom Verkauf ihrer Arbeitskraft leben (187). Zwar gibt es innerhalb dieser Arbeiterklasse Fraktionen

185) Reich: Dic sexuelle Revolution. Frankfurt 1971

186) Ebd.. S. 210

187) Vgl. Zur Taktik ..., a. a. O., S. 7 f. und Bischoff, a. a. O., S. $135 \mathrm{f}$. 
und unterschiedliches Bewultsein, aber in dem Mafe. wie die gesellschaftlichen Antagonismen sich zuspitzen. ..verlieren diese trennenden Schranken an Bedeutung". In dem Mafse. wie sich die ökonomische Krise verschärt. soll die revolutionäre Aktion ermöglicht werden. die den Auflösungsprozefi der kapitalistischen Gesellschaft beschleunigt. Die Arbeiterklasse ist Exekutor eines unvermeidlich ablaufenden Prozesses. In dieser kurz noch einmal charakterisierten theoretischen Position ist en für die marxistische Theorie zentrales Problem vollig aufier acht gelassen: Das Subjekt-Objekt.Verhälnis und die Bedeutung der Praxis.

Beim Projekt Klassenanalyse bestimnt der Produktionsprozed, das Bewulntsein der handelnden Individuen. Diese konnen Einsicht in den Ablaut dieses Prozesses gewinnen, sich ihm anpassen und ihn beschleunigen. Produktionsprozefi und Handeln. Subjekt und Objekt stehen sich so nicht vermittelt. sondern einseitig determiniert gegenüber. Die Vermittlung wird gegenuber einer ...materialistischen" Abhängigkeit des Subjekts aufgegeben (188). Praxis reduziert sich aut eine eingeschränkte Variable der ... Votwendigkeit" des Produktionsprozesses. Objektive Gesetzmärigkeiten bilden so den Hauptgegenstand des Materialismus des Projekts Klassenanalyse. Im Mittelpunkt des Marxschen Materialismus steht dagegen die gesellschaftliche Praxis. Dies war das Ergebnis der Kritik an Feuerbachs anschauendem Materialismus.

..Der Begrift der Praxin. wite die Feuerbachthesen von 1845 ihn erreichen, int der gerade theore. fisch w whtigste Warxsche Begriff. Auf ihn ist immer wieder zuruckzukommen, will man sich Klarheit darüber verschaffen. Was bei Mars Materialsmus heist und mit welchem Recht diver dialek tisch genannt zu werden verdient. Im Gegensatz zu allen sowjetmarsistischen Darlegungen ist der authentiche Marxismus kein naturalisierter Hegelianismus. der sich darin erechopt cin on tologisches Subitrat. den Geist. durch ein anderes. die Materie. einfach zu ersetzen" (189).

Danach steht der Mensch den materiellen Verhältnissen nicht gegenüber und wird nicht einseitig von ihnen beherrscht. In seiner praktischen Tätigkeit im Arbeitsprozeb ist er Bestandteil. Voraussetzung und Resultat dieser Verhältnisse.

..Der Hauptmangel alles bivherigen Materialismus . . ist, dal der Gogenstand, die Wirklichkeit, Sinnlichkeit nur unter der Form des Objekts oder der. Anschaung gefalit wird: nicht aber als sinnlik'h menschliche Tätigkeit. Praxis. nicht subjektiv... Feuerbach will sinnliche von den Gedankenobjekten wirklich unterschiedene Objekte. aber er fatst die menschliche Tatigkeit selbst nicht als gegenstandliche Tatigkeit ... Er begreif daher nicht die Bedeutung der, revolutionären". der praktisch-kritischen Taitigkejt" (190).

Der gesellschaftliche Rahmen für die praktisch kritische Tätigkeit ist durch den Gegensatz von Lohnarbeit und Kapital vorgegeben. Aber es wäre vereinfacht und falsch, daraus den Schluß zu ziehen, daß für Marx , die Lohnarbeiter" oder , die Arbeiterklasse" die Authebung dieser Gesellschaftsform vollzieht. Wir wollen deshalb kurz auf den Marxschen Klassenbegriff im "Kapital" eingehen und uberprüen, inwieweit er eine Realkategorie darstellt, $d$. h. seine Definition unmittelbar auf die

188) Entfallt

189) A. Schmidt: Der Begrifte der Natur in der Lehre von Marx, Neuaugabe. Frankfurt 1971. S. 203

190) Marx: Thesen über Feuerbach, MEW 3, S. 5 
Wirklichkeit ,anwendbar" ist.

Der kapitalistische Produktionsprozers, soweit er im ..Kapital" dargestellt ist. verläuft unter vereinfachten Voraussetzungen. Die drei Bände des ..Kapital” bilden das Kapital im allgemeinen. Allgemeine Warenproduktion. kapitalistischer Produktions-, Zirkulations- und Gesamtprozefs werden unter methodisehen Voraussetzungen analysiert, die die Produktion ungestört ablaufen lassen.

.In der Theorie wird vorausgesetzt. dat dic Gesetze der kapitalistischen Produktion welse sich rein entwickeln" (191).

Diese Abstraktion von der empirischen Realität findet auch seine Anwendung auf den Klassenbegriff. Personen sind nur so welt dargestellt. wie sie die Tendenzen re in verkörpern. „Es handelt sich um die Personen nur, soweit sie die Personifikation ökonomischer Kategorien sind " (192). Ein unmittelbares Ubertragen dieses Klassenbegriffs auf die Wirklichkeit mul zu einer statistisch-soziologischen. den realen Erfahrungszuammenhang der konkreten Proletarier einschränkenden Verengung führen, gegen die sich Marx entschieden aussprach (193). Vielmehr verwies er auf den Klassenkampf als wesentliches Moment fur den Auflösungsprozef. der burgerli. chen Gesellschaft (194). Der aus der philosophischen Feuerbach-Kritik gewonnene Begriff der praktisch-kritischen Tätigkeit taucht als Abschluf der Kritik der politischen Ökonomie im Klassenkampfbegriff auf konkreterer Ebene wieder auf. Klas*

191) Das Kapital Bd. III. HEW 25. S. 184. Dic im Band I vorhandenen historischen Ausführungen sind keine vollständigen Lntersuchungen von klassenkämpten. sondern die Entwicklung der Gesetze illustrierende Darstellungen. . Historische Ausweitungen". Brief an Engels vom 10. 2. 1866, MEW 31. S. 174:..Historische Skizze". WEW 23, S. 315 : ..Hauptillustration der theoretisehen Entwicklung ". ebd.. S. 12

192) lobd. S. 16. -... Die Personen existieren hier nur füreinander als Repräsentanten von Warc und daher als Warenbesitzer. Wir werden überhaupt in Fortgang der Entwicklung finden, dals die okonomischen Charaktermasken der Personen nur die Personitikationen der okonomischen Vurháltnisse sind." Ebd.. S. 100. Dals die Klassengliederung in England nicht rein hervortritt. ..ist ... für unsere Betrachtung gleichgültig". MEW 25. S. 892.

193) ..Es ist charakteristisch für dic Absicht des statistischen Betrugs. . Wenn die englische Fabrikgesetzgebung die zuletzt im Text erwännten Arbeiter" - Ingenieure. Mechaniker, Schreiner usw. - atusdrücklich als Nicht-Fabrikarbeiter von ihrem Wirkungskreis ausschlictst, andererseits die vom Parlament veroffentlichten. Returns' ebenso ausdrücklich nicht nur Ingenjeure. Mechaniker usw.. sondern auch Fabrikdirigenten. Kommis, Ausläufer, Lagerautsohen, Verpacker usw., kurz alle Leute, mit Ausschluts des Fabrikeigentümers selbst, in dic Kategoric der Fabrikarbeiter cinschlielsen." MEW 23. S. 443 (Anm.)

Im Gegensatz zu Marx hält das Projekt Klassenanalyse einen statistisch exakten Klassenbegriff für destilliwbar: .So könnte mit dem Material, das Marx im .Kapital", in seinen zahlreichen Zeitungsartikeln wie in vicken Bricten veröffentlicht bzw. kommentiert hat. cinc vollstiandige, bis ins kleinste Detail gehende Analyse des engiischen Kapitalismus in der Mitte des 19. Jh's. cingeschlossen die genaueste Bestimmung der Fraktionen der englischen Arbeiterklasse und der entsprechenden Bewufstseinsformen, unternommen " verden." Zur Taktik, a. a. O., S. 46: vgl. auch ebd., S. 56. Das wesentliche Moment für dic Konstitution von revolutionärem Bewutstsein, Praxis, fehlt.

194) Für Marx löste sich der kapitalistische Produktionsprozed nicht abstrakt aus sich selbst alut, sondern der ,Klassenkampf als Schlub. worin sich die Bewegung und Auflösung der ganzen Schcitio autlöst". Mit diescm Satz schlok Marx dic Erläuterung seines Systems der Kritik der politischen Ökonomie. Brief an Engels vom 30. 4. 1868 , MFW 32, S. 75 
senkämpfe sind jedoch nicht in abstrakten Kategorien, sondern nur geschichtlich darstellbar.

Hier liegt der Hauptfehler des Projekts Klassenanalyse, daßs es die historische Betrachtungsweise nicht kennt. In konkreten lntersuchungen sieht es nichts weiter als ..Entfaltung bereits gegebener Bestimmungen und ... Angabe empirisch zufälliger Abweichungen" (195). Das ..Kapital" wird damit zu einem kategorialen Schema, in das empirische Daten nur noch einzutragen sind. Theorie schlägt um in Methode. Die Kritik der politıschen Ökonomie wird unabhängig vom Gegenstand instrumentell verwendbar. Geschichtliche Analyse können danach nur bestätigen, was ohnehin schon klar ist. Diese Theorie bleibt gegenuber konkreten Klassenkämpfen unkritisch und dogmatisch, weil sie selektiv vorgeht und nur die geschichtlichen Ereignisse heranzieht. die die allgemeinen Aussagen bestatigen.

... Mifst man die Marxschen Begriffe nicht an der Entwicklung des Kapitalismus und zieht man daraus nicht die entsprechenden Konsequenzen für die politische Praxis, so erctarrt die Marxsche Theorie zum mechanisch wiederholten .Grundvokabular', zu einer versteinerten Rhetorik. die kaum noch Bezug zur Realität hat... Die Verdinglichung der Marxschen Theorie, welche die Praxis des Kapitalismus nicht eingeholt hat. kann schwerlich eine Praxis anleiten. dic daraut abhebt, den Kapitalismus aufzuheben. Die Reduktion der Marxschen Theorie auf feste Strukturen" scheidet die Theorie von der Wirklichkeit und verkiht ihr einen abstrakten, distanzierten. .wissenschaftlichen" Charakter, der ihre dogmatische Ritualisierung erleichtert" (196).

Geschichtliche Analyse von Klassenkämpfen bedeutet deshalb kritische Untersuchung der revolutionären Bewegungen, vor allem die Kritik ihrer Praxis. Fehler in ihren Strategien, in den Organisationsformen mussen herausgearbeitet werden. Das bedeutet, daß man den gesamten materiellen gesellschaftlichen Prozeß analysiert. soweit er auf die Praxis des emanzipatorischen Subjekts in seiner jeweils konkreten historischen Gestalt einwirkt. Das heißt kein additives Aneinanderreihen empirischer Daten, sondern Auswahlkriterium, Ausgangspunkt, das Interesse an der Untersuchung bildet das konkrete Subjekt in den Klassenkämpfen. Je nachdem ob und wieweit die Praxis des proletarischen Klassenkampfes die gesellschaftliche Emanzipation vorantreibt, bestimmt ihre revolutionäre oder integrative Funktion. Kritik beinhaltet die Suche nach möglichen Alternativen. Die historische Untersuchung enthält so ein spekulatives Moment, das jedoch nicht willkürlich ist, sondern sich an der historischen oder aktuellen Totalität orientiert, der A neignung des gesellschaftlichen Prozesses durch die Praxis. Die historische Kritik hat herauszufinden, wo die

195) Klassenbewufstsein und Partei, a. a. O., S. 85

196) Marcuse: Konterrevolution und Revolte, Frankfurt 1973, S. 44. Marx selbst war sich der notwendigen Beschränktheit abstrakter Darstellung durchaus bewufit: .An ihre (der Philosophie) Stelle kann höchstens eine Zusammenfassung der allgemeinsten Re'sultate treten, die sich aus der Betrachtung der historischen Entwicklung der Menschen abstrahieren lassen. Diese Abstraktionen haben für sich, getrennt von der wirklichen Geschichte, durchaus keinen. Wert. "Deutsche Ideologie. MEW 3. S. 27

Die Geschichtslosigkeit des Projekts Klassenanalyse zeigt sich auch daran, dais, wenn es schon Geschichte cinbezieht, es diese pragmatisch handhabt. So z. B. in der rigiden Verallgemeinerung konkreter Marx/Engelsscher Analysen, um zwei allgemeine Taktiken und die Notwendigkeit der Partei überhaupt im kategorialen Apparat unterbringen zu können. 
konkreten alternativen Möglichkeiten revolutionärer Politik in bestimmten Zeiträumen lagen. Das Erkenntnisinteresse der marxistischen Analyse ist das der gesellschaftlichen Emanzipation, sowohl der rationellen Organisation der Produktion wie auch der vollen Entfaliung der menschlichen Individualität. Das schliefst die empiristische Verkürzung der Kategorien der Kritik der politischen Ökonomie aus. Klassenkämpfe als Gegenstand historischer Lntersuchung schliefer auch die Vorstellung eines linearen Fortschritts aus. Löst sich der gesellschaftliche Prozefs in Praxis, in Klassenkampfe auf. dann bleibt fur eine evolutionistische Theorie kein Platz. mag sie sich noch so "marxistisch" artikulieren. Klassenkämpfe bewegen sich immer zwischen den Extremen von Konterrevolution und Befreiung der Gesellschaft. der Ausgang ist offen. Diese ständig aktuelle Alternative von Sozialismus und Barbarei meinte auch Rosa Luxemburg, wenn sie sagte: ..auf Schritt und Tritt gibt es zwei Notwendigkeiten, die zueinander in Widerstreit geraten" (197).

Wenn damit der Begriff eines .,revolutionären Subjekts"im Klassenkampf überhaupt eine Funktion haben soll, dann schliefst er eine soziologische Verengung oder eine apriori-Konstruktion au (198).

..In dem Begriff des Proletarischen schwingt bej Marx ein Bedeutungsgehalt mit. der nicht in den soziologischen und politisch-okonomischen Bestimmungen der Arbeiterklasse aufgeht. obwohl diese ihr materielles Fundanent sind. Im Proletariat fabt sich die praktische Vegation der bestehenden Welt zusammen, die nur noch auf den Begriff gebracht werden nuts. un Teil der politischen Emanzipationsgeschichte der Arbeiterklasse sein zu können" (1991.

197) ..Eine marxistische Analyse kann sich nicht damit trosten. dato der Kapitalismus sich auf lange Sicht nicht wird halten konnen. .Langfristig " wird das System in der Tat zusammenbrechen. aber die Marxsche Theoric kann nicht vorhersagen. durch welche Gesellschaftsform (sofern überhaupt) es ersetzt werden wird. In Rahnen der objektiven Bedingungen hängen die Alternativen (Faschismus oder Sozialismus) von der Intelligenz und dem Willen. dem Bewuhtsein und der Sensibilitat der Menschen ab. Die Gesellschaftsform hängt von ihrer immer noch existierenden Freiheit ab. Die Vorstellung einer gegenüber der sozialistischen Alternative sich hinziehenden Periode der Barbarei - einer aut den technischen und wissenschaftlichen Errungenschaften der Zivilisation beruhenden Barbarei - steht im Mittelpunkt der Marxschen Theorie. Gegenwärig liegen Initiative und Macht bei der Konterrevolution. die durchaus in einer solchen barbarischen Zivilisation gipfeln könnte." Marcuse, Konterrevolution, a. a. O.. S. $38 \mathrm{f}$.

198) Diese a-priori-Konstruktionen waren in Marxismus der II. und III. Internationale ötters mit Vorstellungen eines Waffenganges gegen den Klassenfeind verbunden, der in der Entscheidungsschlacht besiegt wird. ..Die Kritik der politischen Ökonomie ist geschrieben und das Proletariat steht ... das ist a priori ... Gewehr bei Fuf" ", so charakterisieren A. Schnidt und H.-J. Krahl cine solche Auffassung, in: Geschichte und Klassenbew ufstsein heute, a. a. O., S. 44

Für Stalin war die Arbeiterklasse die ...Armee der Partei". Auch das Projekt Klassenanalyse neigt stellenweise zu martialischen Analogien: .Diese Reihenfolge in der Lntersuchung der verschiedenen Klassen der französischen Gesellschaft ist nicht zufällig ... wir (wollen) hier darauf hinweisen, dafs sich in dieser bestimmten Reihentolge rein formell die reale Schlachtaufstellung der einzelnen Klassen widerspiegett.. Gelingt es dem Proletariat, die Kluft zwischen sich und den Parzellenbauern sowie Kleinbürgern durch eine richtige Bündnispolitik zu überbrücken. dann kann die Bourgeoisie in die Zange genommen werden." Zur Taktik ... a. a.,O.. S. 45

199) Kluge/Negt: Öffentlichkeit und Erfahrung. a. a. O.. S. 11. Hierzu zählen revolutionäre Intelligenzbewegungen ebenso wie revolutionäre. kollektivistische Bestrebungen von Bauern. obwohl beide keine Proletarier im Sinne von ..Lohnarbeiter" sind. 
Das revolutionare Subjekt ist nicht von vornherein vorgegeben, sondern Ergebnis eines widersprüchlichen Prozesses der Herausbildung von revolutionärem Bewußtsein. dak sich in praktischen Kämpfen bildet. Dieser Konstitutionsprozefs ist keine abbildhaite Widerspiegelung des Produktionsprozesses, sondern ein historischer Lernprozer. resultierend aus dem gesamten Erfahrungszusammenhang der Klassenindividuen (200). Die bisher in Europa weitestgehende sozialistisch-revolutionäre Entwicklung - die spanische Revolution in den ersten Monaten des Bürgerkrieges 193637 - belegt dies anschaulich (201). Was der auf wenige Monate zusammenge. drängte Aufschwung der spanischen Revolution und sein konterrevolutionärer Umschlag zeigen. ist. daf bei der Analyse ein statistischer Proletariatsbegriff so gut wie gar nichts auszusagen vermag. Revolutionäres oder konterrevolutionäres Bewußtse in zog sich quer durch die Arbeiterorganisationen. war aber auch hier nicht statistisch festzumachen. sondern schlug in der Entwicklung um. Die proletarischen Gewerkschaften LGT und CXT unterstutzten den revolutionären Aufschwung, um dann auf ein Programm des legalen parlamentarischen Staates umzuschwenken. Die Kommunisten waren kontinuierlich die Partei der Legalität und der Ordnung und unterdrückten in blutigen Verfolgungen Anarchisten und die unabhängige ,.Arbeiterpartei der marxistischen Eingung" (POLM) (202). Unter den Bauern fanden teilweise bewaffnete Auseinandersetzungen über Kollektivierung oder kleinbürgerlichen Privatbesitz statt. Kommunistische Arbeiter vertraten andere Ziele als die anarchisti-

2001 In den letzten Jahren wurden verschedene Versuche unternommen. einer verdinglichten Proletariatidefinition eine begriffliche Bestimmung des revolutionären Subjekts gegenüberzustellen. Michael Mauke gelangte dabei zum Begriff des ..Lagers" (M. Mauke: Die Klassentheorte von Marx und Engels. Frankfurt 1970): Kluge Negt entwickeln die Kategorie der ..proletarisehen Öffentlichkeit" rÖftentlichkeit und Erfahrung. a. a. O.): Michual Vester spricht von der emanzipatorischen Klasse" (Solidarisicrung als Lernprozeb, a. a. O.1

Der Lager-Begriff erhalt bei kluge Negt eine andere Bedeutung als bei Mauke. Sie bezeichnen als ..Lager" Organisationsformen und Strategien. die die Erfahrungen einer potentiellen proketarischen Öffentlichkeit einschränken. sich organisatorisch abkapseln, isolieren und sjeh der bürerlichen Konterrevolution nicht gewachsen zeigen. Kluge/Negt tühren beispielhaft die sektiererhafte Sozialfaschismuspolitik und die organisatorische Isolicrung der osterreichisehen Sozialdemokratic vor dem Zweiten Weltkricg an.

In SoPo 11 erfuhr Maukes Buch eine Rezension durch das Projekt Klassenanalyse. Darin steht allerdings wenger das von Mauke autgeworfene Problem im Mittelpunkt als eine scholastische Zitatentreue gegenüber Marx. die gegen Mauke ins Feld getührt wird. Eine Diskussion findet deshalb nicht statt. In Gegenteil. diese wird unsolidarisch. wenn cin Grundrisse-Zitat gegen llauke ins Feld getührt. ein anderes auf der gleichen Seite. das diesem Recht gibt, unterschlagen wird - S. 593 -: wenn Mauke angegriffen wird, er habe den Klassenbegriff durch den des Lagers ersetzt, ohne anzugeben, dads sich Mauke a uf das Kommunistische Vanifest beruft: Wenn das Projekt Klasscnanalyse den Lagerbegriff ablehnt und Bischoff ihn in SoPo 14:15 auf S. 125 selbst verwendet.

201) Wir stützen uns hier auf das Buch von P. Broué und E. Témime: Revolution und Krieg in Spanien. Frankfurt 1968.

202) Vel. Broué. Témime, a. a. O. Dabei war das Bewudstsein der Kommunisten im Rahmen der Volksfrontpolitik weniger Resultat der spanischen ökonomischen Verhältnisse als der materiellen Abhängigkeit von der LdSSR und der unkritischen Identifizierung mit ihrer Politik. Es konnte und durfte nicht sein, dats die Sowjctunion cine reaktionärc und antisozjalistische Politik betrieb. 
schen. Innerhalb der Massenorganisationen kam es wiederum zu Oppositionsbewegungen. Oder die Massen opponierten gegen die Zentralregierung. ohne dafs die Arbeiterorganisationen sich an ihre Spitze gestelit hätten.

Ein abstrakter Begriff eines ..revolutionären Proletariats" ist en soziologi. scher Idealtyp und hält der konkreten Analyse nicht stand. Der Konstitutionsprozefo zur Klasse fur sich ist nur als historischer Lemprozefo zu begreifen.

..Die Arbeiterklase int nicht als sin homogenes Gebilde vorsellbar. sondern als ein historischer Prozcli, in dem sich sehr ferschiedene Gruppen von Abhingigen au, eigenen kämplen lemend koalieren, ohne aber dabei alle ihre Besonderhoiten vollig einebnen zu konnen“' 203 ).

\section{Lenin - Revolutionarer Theoretiker oder praktischer Revolutionar?}

Das Projekt Klassenanalyse geht davon aus. dafe der wissenschaftliche Sozialismus blofs theoretischer Reflex, ideeller Ausdruck der Entwicklung der Arbeiterbewe. gung ist. Ebenso wie der Prozefr der proletarisehen Bewegung durchläuft der wissenschaftliche Sozialismus Höhen und Tiefen (204). In dem Mafe. wie der wissen. schaftliche Sozialismus bei den literarischen Repräsentanten der Arbeiterklasse - für solche hält sich das Projekt Klassenanalyse - und bei deren fortgeschritten. sten Teilen die Einsicht in den naturnotwendigen $G$ ang der kapitalistischen Produktionsweise vertieft, in dem Mafse kann umgekehrt dieser Prozefs beschleunigt werden. Die Theorie soll so revolutionar werden.

..Dik Theoric ist nur kritiseh und revolutionar. sotern in ihr die stetig for unseren Augen vorgehende Zersetzung der herrschenden Geselhchaftsordnung auf den Begriff gebracht ist" 1205 .

Die allgemeinen Bestimmungen dieser Theorie sind nach dem Projekt Klassenanaly. se für die bürgerliche Gesellschaft ein für allemal geleistet worden. Da diese Bestimmungen den Hintergrund abgeben für die Einsicht in den ablaufenden gesellschaftlichen Prozef. ist jede Politik abhängig vom ..richtigen" Verständnis der Marx Engelsschen Theorie bzw. ihrer angeblichen zwei allgemeinen Taktiken. Politische und historische Kritik wird auf das Verstehen von Marx und Engels einge schränkt (206). Die Untersuchung der historischen Verhältnisse wird damit überflüssig.

Durch die Konstruktion des Primats der Theorie sieht das Projekt Klassenanalyse die Ursachen für politische Fehler ausschlieflich im unzureichenden Verständ. nis eines theoretischen Modells: der allgemeinen Taktik für entwickelte oder unent-

203) .1. Vester. a.a. O.. S. 182

204) Entfält

205) I. Bischoff: Matericle und geistige Produktion - Solm-Rethels. Siegeszug durch die nicht-revisionistische Linke. SoPo 12. S. 7

206) In diesem Simnymeint das Projekt Kiassenanalyse auch Rosa Luxemburg nachträglich bolchren zu müsen: ..Dats. Marx und Engels dic Taktik für Länder mit unentwickeltem Kapitalverhaltnis weit ausführlicher entwickelt haben als die für hochentwickelte kapitalistische Lander und dab damit die Auseinandersetzung der Bolschewiki auf der Grundlage der sozialistischen Wissenschaft gefürt werden kann, entgeht ihr." Leninismus. a. a. O.. S. 37 
wickelte Länder. Primäre Aufgabe ist für Lenin demnach der Kampf gegen die Verflachung der marxistischen Theorie, alles weitere praktische wird nebensächlich oder zwangsläufig Folge des jeweiligen Theorieverständnisses (207). Bevor wir diese These exemplarisch überprüfen, wollen wir noch einmal kurz auf die mechanistische Abbildauffassung vom wissenschaftlichen Sozialismus und Theorie eingehen.

Ihr liegt die Vorstellung einer Identität von Wirklichkeit und Begriff, von gesellschaftlichem Prozers und seinem theoretischen Reflex zugrunde. Dieser Reflex ist an subjektive Trager gebunden, von daher ist immer die Möglichkeit des Verlustes oder die Verflachung wissenschaftlicher Einsicht gegeben. „Objektiv“ existiere jedoch eine die Wirklichkeit ausdrückende, revolutionäre Theorie (208).Diese Auffassung läßst außer acht, daß es einen Begriff von Wirklichkeit nur durch praktische Erfahrung vermittelt geben kann.

.Wir kennen die Wirklichkeit nur im Verhaltnis zum Menschen. Lnd da der Mensch geschichtliches Werden ist, sind auch Erkenntnis und Realitat ein Werden, ist auch Objektivitat ein Herden"(209)

Eine solche „Objektivität” muß sich jedoch in der Praxis erweisen. Die Einheit von Theorie und Praxis besteht niemals unmittelbar.

..Weil immer schon durch geschichtliche Arbeit filtriert, stellen die unabhängig vom Bewulstsein existierenden Dinge gerade in dieser Lnabhangigkeit etwas Gewordenes dar, ein ins Für-Uns übersetztes An-sich. Damit entfällt auch die primitive Vorstellung von der Erkenntnis als Abbild, bei der Bewlibtsein und Gegenstand entgegengesetzt werden und die für letzteren konstitutive Rolle der Praxis a ufer Betracht bleibt. Die gegenständliche Welt ist kein blob abzubildendes An-sich. sondern in hohem Maße ein gesellschaftliches Produkt... Stets geht also das Bewußtsein als tätiger Geist in die von ihm reproduzierte Wirklichkeit ein. Vor ihr, die wic eine steinerne Wand um die Menschen herumsteht, nicht zu kapitulieren, ist die Aufgabe der Erkenntnis. Indem sie die in den ausgemachten Fakten erloschenen menschlich-geschichtlichen Prozesse wieder verlebendigt, erweist sie die Wirklichkeit als von Menschen hervorgebracht und folglich veränderbar: Praxis als wichtigster Erkenntnisbegriff schlägt um in die politische Aktion" $(210)$

Eine solche Bestimmung von Wissenschaft, von Theorie schließt jedoch aus, daß es eine revolutionäre Theorie a priori gibt. Theorie als solche ist immer nur potentiell

207) ,Lenins Programm ist daher der Kampf gegen die Verflachung des Marxismus durch die Ĺbernahme der damals verbreiteten neukantianischen Philosophic und die idealistische Verzerrung des von Marx und Engels formulierten Zusammenhangs der Untersuchung der grundlegenden Gesetze der kapitalistischen Produktionsweise und der Anwendung ihrer Resultate auf eine gegebene Entwicklungsstufe der bürgerlichen Gesellschaft mit der Ausarbeitung einer revolutionären Taktik zur Beschleunigung des naturwüchsigen A uflösungsprozesses der bürgerlichen Gesellschaft. "Leninismus, a. a. O., S. 33

208) .So kann zwar gesagt werden, dafs das mit der Formulierung des Wissenschaftlichen Sozialismus erreichte epochalc Bewustsein objektiv existiert und per Studium angeeignet werden kann. aber auf Grund der charakteristischen Verlaufsform der industriellen Entwicklung kann weder die Konstitution des Proletariats zur Klasse für sich ein kontinuierlicher Prozefs sein, noch kann eine zeitweilige Verflachung des wissenschaftlichen Soziajismus ausgeschlossen werden." Klassenbewußtsein und Partei, a. a. O., S. 128

209) A. Gramsci: Philosophie der Praxis, Frankfurt 1967, S. 228

210) A. Schmidt: Der Begriff der Natur ..., a. a. O., S. 205 f. 
revolutionär (211). Faktisch ist sie es nur in Verbindung mit der politischen Aktion. Soweit das Projekt Klassenanalyse meint, daß die Theorie be reits revolutionär ist, in der die Zersetzung der herrschenden Gesellschaft auf den Begriff gebracht isi, verfällt es Marx' Kritik am anschauenden Materialismus:

„Dic Frage, ob dem menschlichen Denken gegenständliche Wahrheit zukomme ist keine Frage der Theoric, sondern eine praktische lrage. In der Praxis muts der Mensch dic Wahrheit. i. e. Wirklichkeit und Macht, Diesseitigkeit seines Denkens beweisen. Der Streit über die Wirklichkeit oder Nichtwirklichkeit des Denkens das von der Praxis isoliert ist ist eine rein scholastische Frage" (212).

Beansprucht das Projekt Klassenanalyse in seiner Kritik historisch zu sein, indem es politische Praxis kritisiert - und dies macht das Projekt Klassenanalyse in dem Leninisrnusbuch -- dann muß es Bedingungen dieser Praxis, des Klassenkampfs reflektieren. An einem kurzen Beispiel aus dem Zeitraum 1917/18 soll noch einmal vorgeführt werden, daß eine Kritik der Theorie Lenins unvollständig bleibt ohne Berücksichtigung der historischen Situation.

Auffallend ist die Unbefangenheit, mit der das Projekt Klassenanalyse die historischen Ereignisse nach der Februarrevolution ignoriert. Eine Schilderung der Klassenkämpfe stützt sich ausschließlich auf die Interpretation Leninscher Texte, bestenfalls scheinen die Genossen aus dem Projekt Klassenanalyse noch die Anmerkungen aus den Lenin-Werken herangezogen zu haben. Nicht an einer einzigen Stelle werden jedoch Quellen oder Darstellungstexte der revolutionären Entwicklung in Rußland berücksichtigt. Dieses Verfahren muß jedoch als historische Kritik unzureichend bleiben. Lenin schrieb keine sozialwissenschaftlichen Abhandlungen über die russische Revolution, er war kein Historiker, der die Entwicklung beschreiben wollte, sondern seine Schriften waren Bestandteil der politischen Auseinardersetzungen. Lenins Ausführungen sind keine Darstellung der russischen Revolution, sondern parteiische Pamphlete. Die Aufgabe der historischen Kritik kann nicht darin bestehen, diese Aussagen ungeprift als wahr zu übernehmen. Eine historische Kritik muß vielmehr beurteilen, ob Lenins Einschätzungen zur aktuellen Situation richtig waren und ob seine Politik alle Möglichkeiten subversiver Aktion einschloß, ob sie den revolutionären Prozeß vorantrieb oder ihn behinderte. Ein solches Urteil muß aber die Gesamtheit der gesellschaftlichen Verhältnisse 1917 ein beziehen.

Eine materialistische Kritik der Leninschen Politik verweist auf die historische Analyse der Revolution. Beschränkt diese sich auf die Repetition Lenins, murs sie entweder unkritisch und apologetisch bleiben, oder aber ein idealtypisches Modell wird zum Maßstab der Kritik. In einem solchen Modell können historische Entwicklungen, die nicht hineinpassen, als unwesentliche Randerscheinungen außer acht 211) Über die oft beschränkte praktische Wirkung theoretischer Traktate, wenn sie nicht an konkrete Erfahrungen anknüpfen konnten, waren sich konterrevolutionäre Kräfte immer bewußt. Der Intelligenz gegenüber wurden hier immer Zugeständnisse gemacht. So waren die Zensurbestimmungen in den Karlsbader Beschlissen ausdrücklich beschränkt auf Schriften unterhalb der Grenze von 20 Druckbögen. Dickere Schriften wurden nur von wenigen akademisch Gebildeten gelesen, blieben damit isoliert, unbekannt und brauchten so nicht zensiert zu werden. Der I. Band des, Kapitals‘ passierte 1872 die zaristische Zensur mit der Begründung, dałs nur wenige es lesen und verstehen würden.

212) Marx: Thesen über Feuerbach, a. a. O. 
gelassen werden. Die Kritik bleibt dann in einem außsergeschichtlichen Raum. Absoluter Mafsstab ist das Modell. Theoretische Aussagen und Klassenkämpfe sind nur noch Illustrationen des a priori feststehenden Geschichtsverlaufes. Eine solche Kritik beschränkt sich auf den Rotstift, der gut und schlecht benotet, je nachdem ob das theoretische Modell verstanden wurde oder nicht. Vom Projekt Klassenanalyse wird diesc Revolutionsschablone den Leninschen Aussagen übergestiilpt (213).

Entscheidend für die positive oder negative Begutachtung ist das jeweilige "Verstehen" der Marx/Engelsschen Theorie. Weil Lenin 1916 in der Schweiz noch einmal Marx und Engels gelesen hat, deshalb und hauptsächlich deshalb kann er eine revolutionäre Taktik verfolgen. Mit der Verschärfung der Klassenkämpfe entwickelt sich die Doppelherrschaft, nach dem bewaffneten Aufstand wird der Staatsapparat zerschlagen und die politische Form der sozialen Emanzipation errichtet, danach können die ersten sozialistischen Maßnahmen begonnen werden. So klar und administrativ vereinfacht stellt sich das Projekt Klassenanalyse die revolutionäre Entwicklung vor. Und die Untersuchung gilt nur noch dem Zweck, ob Lenin diese theoretische Einsicht auch richtig anwendet:

.Aufgrund cines neven, intensiven Studiums der Marxschen Schriften über die Pariser Kommune int Lenin nun in der Lage, seine bisherige Position zu korrigieren. Fr kommt zu der Einsicht, f.s. :uch in Landern mit noch schwach entwickeltem Kapitalverhältnis unter bestimmten Bedifgungen die lirrichtung der politischen form der sozialen Emanzipation möglich ist. Dicse Padingungen sicht er in Rutsland nach der Februarrevolution für gegeben an. Durch die Errichthing der Doppellereschaft, durch die Existenz der Sojets sind Voraussetzungen geschaffen worden, die es dem russischen Proletariat ermoglichen, sich an die Spitze der revolutionären Bewegung zu setzen und, insofirn es gelingt, die Mehrheit der Bauern auf seine Seite zu zichen, in Rutiand eine Regierung gegen die Bourgeoisic zu errichten, d. h. die politische Form der sozialen Fiminzipation zu etablieren" $(2141$.

.Nachdem das Proletariat die Macht übernommen hat, gilt es nun, unverzüglich. dicjenigen Mathnahmen zu treffen, für die das Volk gekämptt lat" (215).

Mit der Reduzierung der Leninschen Politik auf die Verifizicrung eines sozialtechnischen Lntwicklungsmodells bleiben cinige für die Lrklärung der bolschewistischen Politik notwendigen historischen Entwicklungen außerhalb der Betrachtung: die von den Bolschewiki erwartete westeuropäische Revolution und der Klassenkampf der Betriebskomitees (216).

213) Das idealtypische Modell einer revolutionären Taktik für Länder mit unentwickeltem Kapitalverhältnis bildet den Selektionsmechanismus, nach dem Lenin-Texte ausgewahlt und kritisiert werden.

214) Projekt Klassenanalyse: Leninismus, a. a. O., S. 467 f.: vgl auch S. $507 \mathrm{f}$.

215) Ebd., S. 511. Dic Etablierung der ,politischen Form" der sozialen Einanzipation scheint dem Projekt genug Gewähr zu bieten, dab der Weg zum Sozialismus unaufhaltsam ist. Anders ist es nicht zu erklären, da1s die einzige Kritik, die an der Politik der Sowjetunion geubt wird, sich in dic verschämte und unklare Formulierung ,dogmatische Verzerrungen" kleidet. Vgl. Leninismus, a. d. O., S. 17, 23, 29. Die Möglichkeit ciner regressiven Lntwicklung scheint das Projekt Klassenanalyse in seinem mechanistischen Denken nicht zu kennen.

216) Wir beschranken uns hier in der Kritik des Projekts Klassenanalyse auf die Bedeutung der westeuropaischen Revolution als Bestandteil der bolschewistischen Politik und die Entwicklung der Arbeiterkontrolle, weil sie bereits den schematischen Erklärungsrahmen des Projekts Klassenanalyse widerlegen. 
In seiner Imperialismusanalyse kommt Lenin zu dem Ergebnis, dath aus allem, ,was über das ökonomische Wesen des Imperialismus gesagt wurde (hervorgeht), daß er charakterisiert werden muß als Übergangskapitalismus oder, richtiger, als sterbender Kapitalismus" (217). Der imperialistische Weltkreg ist nach Lenin aus einer Epoche hervorgegangen, in der die Produktivkräfte des Weltkapitalismus über die engen Schranken der nationalstaatlichen Gliederungen hinauswachsen und die objektiven Bedingungen für die Verwirklichung des Sozialismus völlig herange re if $t$ sind (218). Der Krieg schafft die Moglichkeit einer revolutionaren Situation in den beteiligten Ländern.

„Auf dem Boden des durch den Kricg hervorgerufenen Ruins in der ganzen Welt erwiichst somit die weltweite revolutionäre Krise, dic, welch lange und schwere Wandlungen sic auch durchnachen mag, nicht anders enden kann als mit der proletarisehen Revolution und deren Sieg"(219).

Zwischen der sozialistischen Revolution in Europa und der russischen Revolution besteht für Lenin ein untrennbarer aktueller Zusammenhang.

„Der imperialistische Krieg hat die revolutionäre Krise in Rubland, cine Krise auf dem Boden der burgerlich-demokratischen Revolution, mit der wachsenden Krise der proletarischen, der sozialistischen Revolution im Westen verbunden. Diese Verbindung ist derart unmittelbar, dats keinerlei Einzellösung der revolutionären Aufgaben in diesem oder jenem Land möglich ist: Die bürgerlich-demokratische Revolution in Rubland ist heute schion nicht mehr nur der Prolog, sondern ein untrennbarer Bestandteil der sozialistischen Revolution in Westen" (220).

In seinem Abschiedsbrief an die Schweizer Arbeiter betont Lenin diesen Zusammenhang noch einmal:

„Dem russischen Proletariat ist die grofse Ehre zuteil geworden, die Reihe von Revolutionen, dic der imperialistische Kricg mit objektiver Unvermeidlichkeit erzeugt, zu beginnen " $22 \mathrm{l}$ ).

Diese theoretische Einschätzung und praktische Erwartung ging nicht nur in die Politik Lenins ein, sondern war in den folgenden Jahren Allgemeingut innerhalb der bolschewistischen Partei. Lenin wollte nicht ein sozialistisches Entwicklungsmodell in einem unentwickelten Land praktizieren, sondern für ihn war die russische Revolution Auftakt zur Revolution in Westeuropa, Teil einer internationalen sozialistischen Umwälzung. Die westeuropäische Revolution, die man später täglich erwartete, bildete ein wesentliches Motiv für die Oktoberrevolution. Auf dem geheimen Parteitag Ende Juli 1917 wurde zwar um das Wesen der bevorstehenden russischen Revolution gestritten, aber als selbstverständlich vorausgesetzt wurde das Bündnis zwischen dem westeuropäischen Proletariat und der russischen Revolution (222). Die Politik der bolschewistischen Partei wurde von dieser Einstellung bis in den Bürgerkrieg hinein bestimmt. Als das deutsche Proletariat den Annexionsfrieden

217) Lenin: Der-Imperialismus als höchstes Stadium des Kapitalismus, Lw, Bd. 22, S. 307

218) Lenin: Die Konferenz der Auslandssck tionen der SDAPR, LW, Bd. 21, S. 148

219) Lenin: Der Imperialismus, a. a. O., S. 196

220) Lenin: Die Niederlage R uf3lands und die revolutionäre Krise, LW, Bd. 21, S. 385

221) Lenin: Abschiedsbrief an die Schweizer Arbeiter, LW, Bd. 23, S. 384

222) Vgl. I. Deutscher: Stalin, Stuttgart 1962, S. 172 
von Brest-Litowsk nicht verhinderte, betrachtete man in der bolschewistischen Partei die Chancen der westeuropäischen Revolution zwar differenzierter, aber sie blieb ein test einkalkulierter ökonomischer und politischer Faktor in der Transformation Sowje trußlands (223).

Daß3 diese Erwartung der westeuropäischen Revolution sich auch bei höchsten Parteifunktionären zu realitätsferner Borniertheit steigern konnte, zeigt Victor Serge. Im Januar 1919 erreichte der Exilrusse Petrograd, um sich in den Dienst der bolschewistischen Revolution zu stellen.

"Junge I rauen mit roten Stirnbinden und junge Agitatoren mit Brillen fatsten für uns die Lage zusammen: Hungersnot, lleckfieber, Konterrevolution überall. Aber die Weltrevolution wird uns retten.' Sie wuthes es besser als wir. Unsere Zweifel machten sic für Augenblicke argwöhnisch. Sie fragten uns lediglich, ob Europa bald in lammen stehen werde. Worauf wartet das französische Proletariat, um die Macht zu crgreifon?" "(224)

\section{Kurz darauf traf Serge mit Sinowjew zusammen.}

„Dic Unterhaltung crstreckte sich vor allen auf den Geisteszustand der Massen in den Ländern des Westens. Ich sagte, dats ungeheure Ereignisse heranreiften, aber allmählich, inmitten von Unfähigkeit und Unwissenheit, und dats, besonders in Frankreich in absehbarer Zeit keine revolutionäre Erhebung zu erwarten sei. Sinowjeu lachelte mit einer Miene wohlwollender Uberlegentreit: Man sicht, Sic sind kein Marxist. Der Gang der Geschichte ist unaufhalt$\operatorname{san}^{\prime} "(225)$.

Ebensowenig wie die Revolution in Westeuropa als Bestandteil bolschewistischer Strategie, findet die Arbeiterkontrolle Platz im Revolutionsschematismus des Projekts Klassenanalyse. Die Formen des Klassenkampfes der Arbeiter werden, wenn uberhaupt, nur in der Form der Sowjets der Arbeiter- und Soldatenräte berucksichtigt (226). Der Klassenkampf zwischen Kapital und Arbeit fand jedoch auf seiten

223) Ausdrücklich bestätigte Lenin auf dem 7. Parteitag im März 1918 noch einmal, dáf cr 1917 mit der westeuropäischen Revolution gerechnet hatte: .Wenn wir ... das ganze Werk allein in unsere Hände genommen haben, so haben wir das in der Überzeugung getan, dath die Revolution in allen Landern heranreift, dats die internationale sozialistische Revolution, welche Schwerigkeiten wir auch durehzumachen haben, zu guter letzt ... kommen wird - denn sie ist unterwegs: dabs sie reif werden wird - denn sie reift heran und wird völlig ausreifen." Lenin Werke, Bd. 27, S. 81. Lenin sieht sich jetzt gezwungen, dic Parteimitglieder mit den Schwierigkeiten za konfrontieren, denen ein Sowjetrudsland gegenübersteht, das nicht sofort vom revolutionären Westeuropa unterstützt wird. „Ebensowenig wie man irgendwie bestreiten kann, dałs alle Schwierigkeiten unserer Revolution erst dann überwunden sein werden, wenn die sozialistische Weltrevolution, die jetzt überall heranreift, vollständig ausgere ift stein wird, ebenso völlig absurd ist auch die Behauptung, daßs wir jede gegebene konkrete momentane Schwier igkeit unserer Revolution bemänteln müssen mit den Worten: Ich setze auf dic internationale sozialistische Bewegung, ich dart nach Herzenslust Dummheiten machen." Ebd., S. $81 \mathrm{f}$. V. Serge: Beruf: Revolutionär. Erinncrungen. Frankfurt 1967, S. 84 f.

226) Über das Bewufktsein der Arbeiter gibt die Politik des Petrograder Sowjets aber nur bedingt Aufschlüsse. Die langwährende Duldung der provisorischen Regierung und dic dann folgende Kooperation hatten cine ihrer gewichtigsten Ursachen in der Tatsache, dak im Sowjet die Soldaten aufgrund eines sie begünstigenden Wahlmodus dominierten. Die Soldaten stammten zum größten Teil aus der Bauernschaft und standen hinter den 
der Arbeiter in den Betriebskomitees seine organisierte Form. In ihnen vollzog sich die radikalste Entwicklung (227). In den Betriebskomitees hatten die Bolschewiki seit dem Frühjahr 1917 ihre festen Stützpunkte. Zunächst hatten die Betriebskonitees Mithestimmung und Intfernung mikliebiger Ingenieure und Betriebsleiter zum Ziel. Als die Unternehmer die Produktion sabotierten, ihre Fabriken schlossen, Kapital ins Ausland transferierten, gingen die Komitees dazu über, die Produktion in eigene Regie zu übernehmen (228). Aus den anfänglichen Notmáśnahmen entwickelte sich eine Welle von Enteignungen durch die Arbeiter. Im Begriff der „Arbeiterkontrolle" drückte sich das Programm dieser spontanen Bewegung aus. Darunter ,verstand man eine Kontrolle der Arbeiterorganisationen auf allen Gebieten des Wirtschaftslebens, die Organisation der Produktion, die Verteilung der Roh- und Brennstoffe, die Finanzierung und Verteilung der Erzeugnisse" (229). Organisationszentrum wurde der Petrograder Zentralrat der Betriebskomitees. Die Bolschewiki unterstützten bedingungslos die Bewegung der Arbeiterkontrolle, ohne zunächst zu bedenken, daß die Enteignungen im Widerspruch zu den geplanten, nachrevolutionären Wirtschaftsmaßßnahmen standen, die ja nur die Nationalisierung der Banken, einiger Syndikate und des Transportwesens, im übrigen aber eine vorläufige Zusammenarbeit mit den Kapitalisten vorsah. Vorbild war die staatskapitalistische Wirtschaft einiger kriegführender kapitalistischer Staaten.

In der Interpretation des Projekts Klassenanalyse hat es den Anschein, als ob die Arbeiterkontrolle eine der ersten revolutionären "Maßsnahmen der Sowjetmacht ist, nachdem das Proletariat die politische Macht übernommen hat (230). Diese Interpretation geht jedoch an den wirklichen Intentionen vorbei. Das Dekret über Arbeiterkontrolle war ein Versuch, die Enteignungswelle unter Kontrolle zu bringen, es versuchte, eine spontane Bewegung der Arbeiter zu bremsen (231).

Die im Dekret faktisch verordnete Doppelherrschaft von Arbeitern und Unternehmern in den noch nicht nationalisierten Betrieben waren die Unternehmer nicht bereit zu akzeptieren. Ihre Verbände riefen zum Widerstand gegen dieses Dekret auf. Die daraus resultierenden Konflikte ließsen die Zahl der Enteignungen weiter ansteigen. Auch die Beschränkung des Konfiskationsrechts auf den im De-

Sozialrevolutionären. Unter den Arbeitern im Sowjet hatten die Delegierten aus kleineren Betrieben ein relatives Übergewicht über diejenigen aus Grokbetrieben. Vgl. dazu O. Anweiler: Dic Rätebewegung in Rufsland 1905 -1921, Leiden 1958, S. 131 ff.

227) Daneben wuchsen die bis 1917 illegalen Gewerkschaften stark an, standen jedoch bis 1918 in der Bedeutung hinter den Betriebskomitees zurück.

228) „Planmásig wurden dic revolutionären Fabriken und Betriebe geschlossen, um die Arbejter clurch Hunger mürbe zu machen... Die Unternchmer schliction dic Betricbe, dic Arbeiter öffnen sie wieder, und wenn der Unternehmer Widerstand entgegensetzt, so wird er von der Roten Arbeitergarde fortgejagt; erklärt cin Fabrikant, dals er keine Rohstoffe oder kein Geld mehr habe, so prüft cine von den Arbeitern gewahlte Kontrollkommission seine Bücher, kontrollieren die Kasse, geht in scine Bank und stell fest, inwieforn die Schlicfsung des Betriebes unvermeidlich set." Lozowsky: Dic Gewerkschaf tsbewegung in Rufsland, Leipzig 1920, S. 6 f.

229) Die Tätigkeit des Allussischen Metallarbeiterverbandes in den Jahren 1917.1920, in: Kleine Bibliothek der Russischen Korrespondenz, Nr. 17, Berlin 1920, S. 20

230) Vgl. Leninismus, a. a.O., S. 511 und 514

231) Vgl. R. Lorenz: Wirtschaftspolitische Alternativen der Sowjetmacht im Eiühaln und Sommer 1918, in: Neue Kritik, Nr. 45, S. $11 \mathrm{f}$. 
zember 1917 gegründeten Obersten Volkswirtschaftsrat hielt die Nationalisierungen nicht auf.

Zunächst vermied die Partei eine Stellungnahme gegen diese ihrem Wirtschaftsprogramm widersprechende Entwicklung. Ein Umschwung setzte erst ein im Friihjahr 1918, als Lenin in seinen Schriften ,Die nächsten Aufgaben der Sowjetmacht" und "Über linke Kinderei und Kleinbürgerlichkeit" die Einstellung der unmittelbaren Expropriationen, hohe Bezahlungen der bürgerlichen Spezialisten, materielle Anreize, Taylorsystem, Einmannleitung im Betrieb und andere einschneidende Marnahmen forderte.

Auch hier harmonisiert das Projekt Klassenanalyse die russische Entwicklung. Es erweckt den Anschein, als ob Lenin nichts anderes tut, als die revolutionäre Taktik fur unentwickelte Länder wie sie von Marx und Engels vorgeschrieben wurde, durchzuführen. Aber Lenin schrieb die „Nächsten Aufgaben der Sowjetmacht" nicht als Konkretion eines allgemeinen Rezepts, sondern reagierte auf die neue aktuclle politische und okonomische Situation. Nur kurze Zeit zurück lag der Annexionstrieden von Brest-Litowsk. Die ohnehin ,.schwer angeschlagene Wirtschaft" geriet dadurch völlig aus dem Gleichgewicht.

.,Mit der l:krams und (etwas spiter) dem Donecbecken verlor Rubland seme wieltigsten Rohstofflasen, d. h. uber zwei Drittel der Kohk- und Lisenforderung ein Verlust, der durch keinerlei Unsiedlung von Betricben . . Wie sie sehr rasch eingeleitet wurden, ausgeglichen werden kounte last $50 \%$ aller Industrieanlagen und damit die Häfte der Arbeiterschaft kamen unter fremde Besatzung. Der Ausfall der Kornkammer Rudilands und $90 \%$ der gesamten Zuckerindustrie untergrub die Lebensmittelversorgung der groben Städe. Schliefblich mubte der ntm völig vom Westen abgeschnittenc Sowjetstalt lat Vertrag finanzielle Verpflichtungen in Höhe vicker Milliarden aut sich nehmen“ (232).

Der Umschwung in der bolschewistischen Industricpolitik gegen die Bewegung der Betriebskomitces, ausgelost durch die wirtschaftlichen Folgen des Friedens von Best-Litowsk, ist auf konkrete historische Ursachen zurückzuführen, nicht auf die "Anwendung" einer instrumentellen Theorie. Das Hauptproblem der russischen Transformationsgesellschaft war der Gegensatz von Stadt und Land. Der Aufbau einer leistungsfïhigen Industrie konnte nur über einen staatssozialistischen industriellen Sektor erfolgen (233). Allerdings wurden aus dieser Erkenntn is ebenso wie in der politischen Organisation einseitige Konsequenzen gezogen. die zur Liquidierung der Betriebskomitees führte, die in den nächsten Jahren in der Zwangsgewerkschaftsorganisation aufgingen. Die antidemokratische, zentralistische Organisationsform setzte sich in allen gesellschaftlichen Bereichen durch. Auf jeden Fall waren für Lenin die Probleme der russischen Revolution nie theoretische, auf die Realisie-

232) R. Lorenz, a. a. O., S. 13

233) Dic Akkumulation in der Industric konnte nur aut Kosten der Ballem arfolgen, d. h. über ainc gesteucte Prispolitik bei industricllen Erzeugnissen mubte cin Teil des bäuerlichen Mehrprodukts abgeschopft werden. Dieses Konzept trug Trotzki bereits 1924 die falsche Kritik cin, er ziek aut cine Lnterdrückungspolitik gegenüber den Bauern. Dic Bucharinsche Konzeption mit ilten Zugeständnissen an die Bauern setzte sich durch (..Bereichert Euch..." 1926 wies dann Preobraschenski nach, dats Abschöptung cines Teils des Meluprodukts der Bauern, im Tausch mit dem staatssozialistischen industriellen Sektor vereinbar war mit ökonomischem Wachstum des Einzelbauern. 
rung von Modellen beschränkte Fragen: ,Wir gingen in unserer Revolution praktisch, nicht theoretisch vor" (234).

Eine durchaus sinnvolle Kritik der Theorie Lenins hat nur einen begrenzten Aussagewert für die Kritik seiner Politik. Soweit die Leninismuskritik des Projekıs Klassenanalyse eine historische Kritik zu sein beansprucht, indem sie praktisch-politische ,Fehler" mit einem Maksstab bewertet, der sich darauf reduziert, Lenin habe Marx nicht verstanden und deshalb Fehler machen müssen, ist sie scholastisch und methodisch grundsätzlich falsch, weil sie die konkrete historische Totalitat aufier acht läßt (235).

Wir haben uns im letzten Abschnitt auf die Probleme der westeuropaischen Revolution und der Arbeiterkontrolle beschränkt, weil es ausreichte, aufzuxeigen, daß ein jdealtypischer Maßstab siner allgemeinen Taktik an den historischen Verhältnissen of vorbeigeht und diese in eine Schablone zwängt. Eine solche Kritik neigt zum Räsonnieren, weil sie nicht mehr die konkrelen Verhältnisse reflektiert, unter denen die kritisierten Personen handeln. Nur durch Aufzeigen historisch wirklich moglicher Altemativen wirl dic Kritik froththat fur akucllo lempromesse.

234) Lenin: Thesen und Referat über bürgerliche Demokratic und Diktatur des Proketariath, vorgetragen und bestätigt auf dem Internationalen Kommunistinchen Kongres. am 4. 3. 1919, zit. nach: Der 1, und 2. Kongreds der Kommunistischen Internationale, Berlin 1959, S. 67.

Der Versuch, in wenjgen Punkten den historischen Fintergrund zu konkretisieren, vor dem Lenin handelte, heifst nicht, dals wir die Leninsche Politik gegenuber den Betriebskomitees für richtig halten.

235) Wenn dennoch einige richtige linschatzungen vorliegen, dann deshalb, weil historiach richtige Einschiatzungen von Marx und Engets methodisch falsch verallgemeinert ,angewendet" werden dabei methodisch falsch konkretisiert und dabei auf ahnliche historische Bedingungen wie bei Marx und Ingels treffen. Ein Prozes doppelter Negation hinter dem Rücken des Projek ts Klissenanalyse.

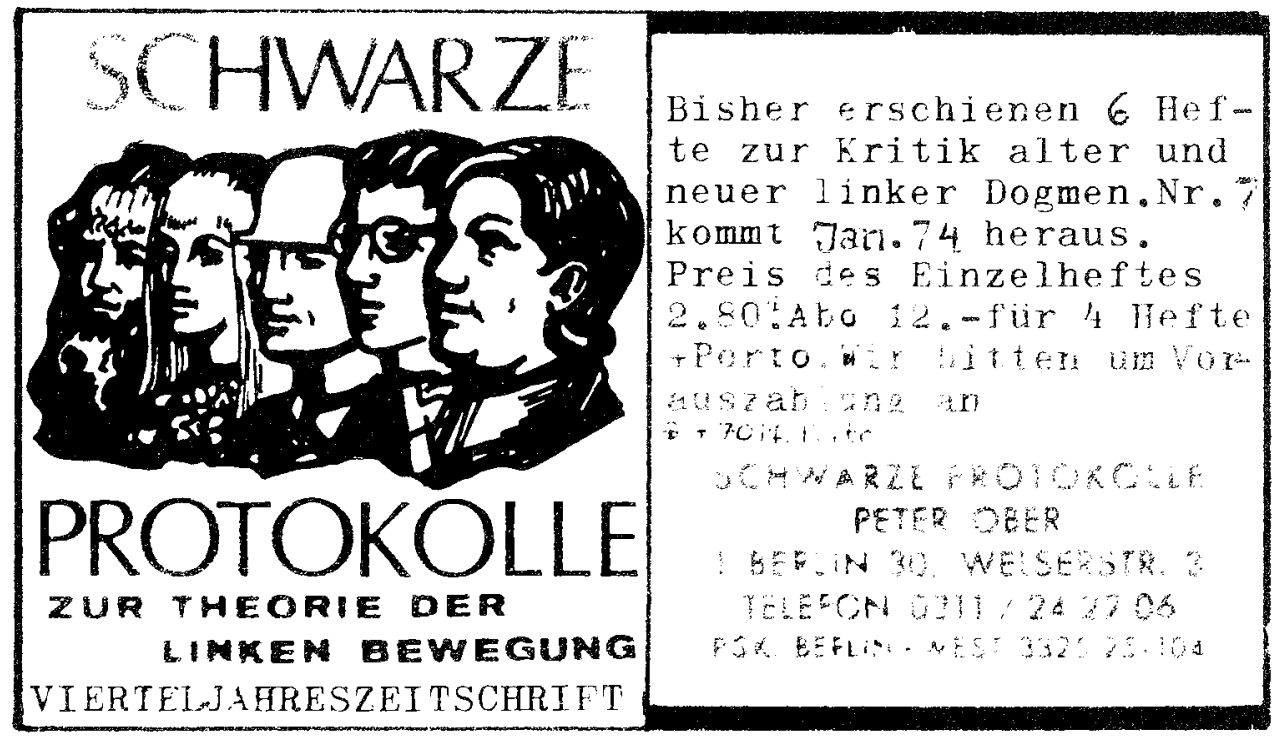

